ORNL/TM-2010/59

\title{
Wear Analysis of Wind Turbine Gearbox Bearings
}

\section{March 31, 2010}

P. J. Blau, L.R. Walker, H. Xu, R. Parten, J. Qu, and T. Geer Materials Science and Technology Division Oak Ridge National Laboratory 


\title{
DOCUMENT AVAILABILITY
}

Reports produced after January 1, 1996, are generally available free via the U.S. Department of Energy (DOE) Information Bridge.

Web site http://www.osti.gov/bridge

Reports produced before January 1, 1996, may be purchased by members of the public from the following source.

\author{
National Technical Information Service \\ 5285 Port Royal Road \\ Springfield, VA 22161 \\ Telephone 703-605-6000 (1-800-553-6847) \\ TDD 703-487-4639 \\ Fax 703-605-6900 \\ E-mail info@ntis.gov \\ Web site http://www.ntis.gov/support/ordernowabout.htm
}

Reports are available to DOE employees, DOE contractors, Energy Technology Data Exchange (ETDE) representatives, and International Nuclear Information System (INIS) representatives from the following source.

Office of Scientific and Technical Information

P.O. Box 62

Oak Ridge, TN 37831

Telephone 865-576-8401

Fax 865-576-5728

E-mail reports@osti.gov

Web site http://www.osti.gov/contact.html

This report was prepared as an account of work sponsored by an agency of the United States Government. Neither the United States Government nor any agency thereof, nor any of their employees, makes any warranty, express or implied, or assumes any legal liability or responsibility for the accuracy, completeness, or usefulness of any information, apparatus, product, or process disclosed, or represents that its use would not infringe privately owned rights. Reference herein to any specific commercial product, process, or service by trade name, trademark, manufacturer, or otherwise, does not necessarily constitute or imply its endorsement, recommendation, or favoring by the United States Government or any agency thereof. The views and opinions of authors expressed herein do not necessarily state or reflect those of the United States Government or any agency thereof. 


\title{
WEAR ANALYSIS OF WIND TURBINE GEARBOX BEARINGS
}

\author{
Final report
}

Prepared for

Wind and Hydropower Technologies Program

Office of Energy Efficiency and Renewable Energy

U.S. Department of Energy

by

P. J. Blau, L. R. Walker, H. Xu, R. Parten, J. Qu, and T. Geer

Materials Science and Technology Division

Oak Ridge National Laboratory

$3 / 31 / 2010$

Prepared by

OAK RIDGE NATIONAL LABORATORY

Oak Ridge, Tennessee 37831-6283

managed by

UT-BATTELLE, LLC

for the

U.S. DEPARTMENT OF ENERGY

under contract DE-AC05-00OR22725 



\section{Foreword}

Wind power offers a promising renewable energy option for the United States, but its implementation depends upon a combination of technological, political, and economic factors. Any one of these factors has the potential to delay meeting the goals of a national wind energy plan. The focus of this report is on just one part of wind technology: the reliability of the wind turbine gearbox bearings. Specifically, it was the objective of this study to systematically characterize several used wind turbine gearbox bearings with respect to the nature of their wear and surface damage. Both surface and subsurface examinations were conducted using a variety of measurements and metallurgical tools.

In course of this study, a systematic reporting format was developed. Hopefully, such a scheme could be adapted as the basis for a more comprehensive data collection program, one that enables the assembly of a comparative database of tribological failures in wind turbine gearbox bearing components in the United States. It is only through the compilation of such information that important trends in failure modes can revealed. Knowing the dominant failure modes can suggest priorities for research on new bearing materials, surface treatments, component design, and the formulation of lubricants to mitigate wear and reduce friction.

The authors wish to acknowledge the financial support of the U.S. Department of Energy, Energy Efficiency and Renewable Energy, Wind and Hydropower Technologies Program, for its support. We also acknowledge the support of Brennan Smith and Tom King of Oak Ridge National Laboratory for their support. Sandy Butterfield and Jim Johnson of the National Wind Technology Center of the National Renewable Energy Laboratory, Boulder, Colorado, graciously provided the bearings for examination.

On behalf of the analysis team,

Peter J. Blau

Materials Science and Technology Division

Oak Ridge National Laboratory

March 2010

Disclaimer: Mention of specific commercial products in this report is intended solely for completeness of documentation, and constitutes neither an endorsement, nor a caution, nor a contra-recommendation as regards their use. It is well-recognized in the engineering community that even the most well-designed, properly installed, appropriately lubricated, and well-maintained bearings have finite lifetimes. Unforeseen factors in the operating environment can prematurely end the life of an otherwise welloperating bearing. The selection of the particular bearings for this examination was based on their availability, and the kinds of surface damage and wear described here should not be construed to represent a worst-case, a best-case, or a typical-case scenario. Current observations are based on the condition of the bearings that we received after a period of storage and shipment across the country. In the field of failure analysis it is important to preserve parts in their as-used condition. The better the preservation of the component surfaces, lubricants, and areas surrounding the failure, the more straightforward will be the failure analysis. Samples for failure analysis should be carefully disassembled so as not to introduce scratches or chips or misleading artifacts. This work has attempted to ignore handling artifacts and focus on features that were felt to be produced during service. 


\section{CONTENTS}

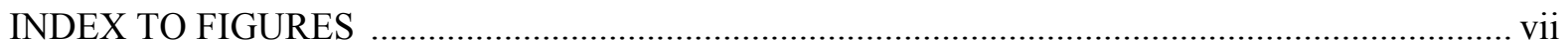

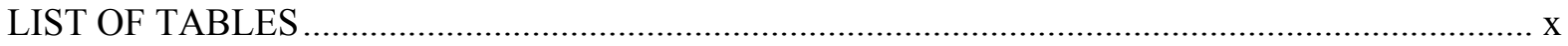

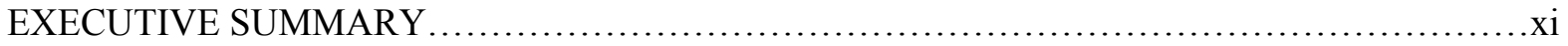

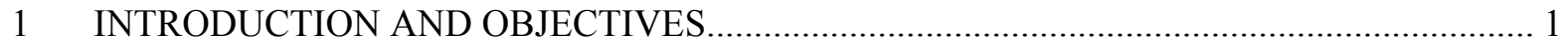

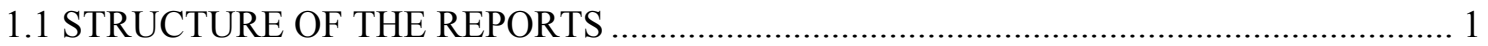

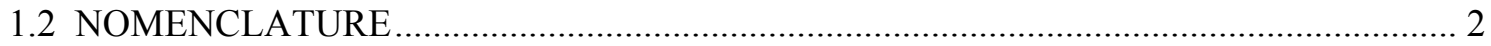

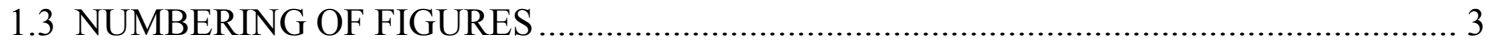

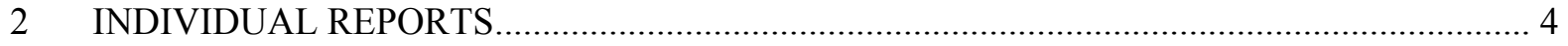

2.1 SPHERICAL ROLLER BEARING - ROLLING ELEMENT .......................................... 4

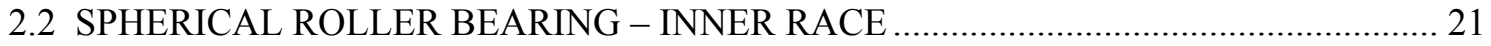

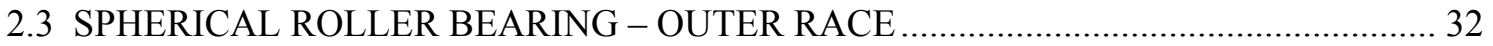

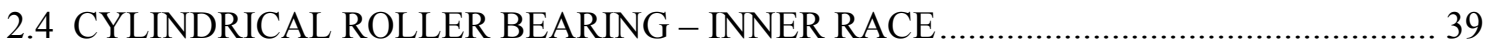

2.5 CYLINDRICAL ROLLER BEARING - ROLLING ELEMENT AND SEPARATOR..... 43

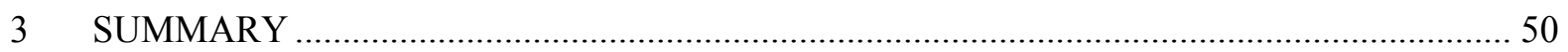




\section{INDEX TO FIGURES}

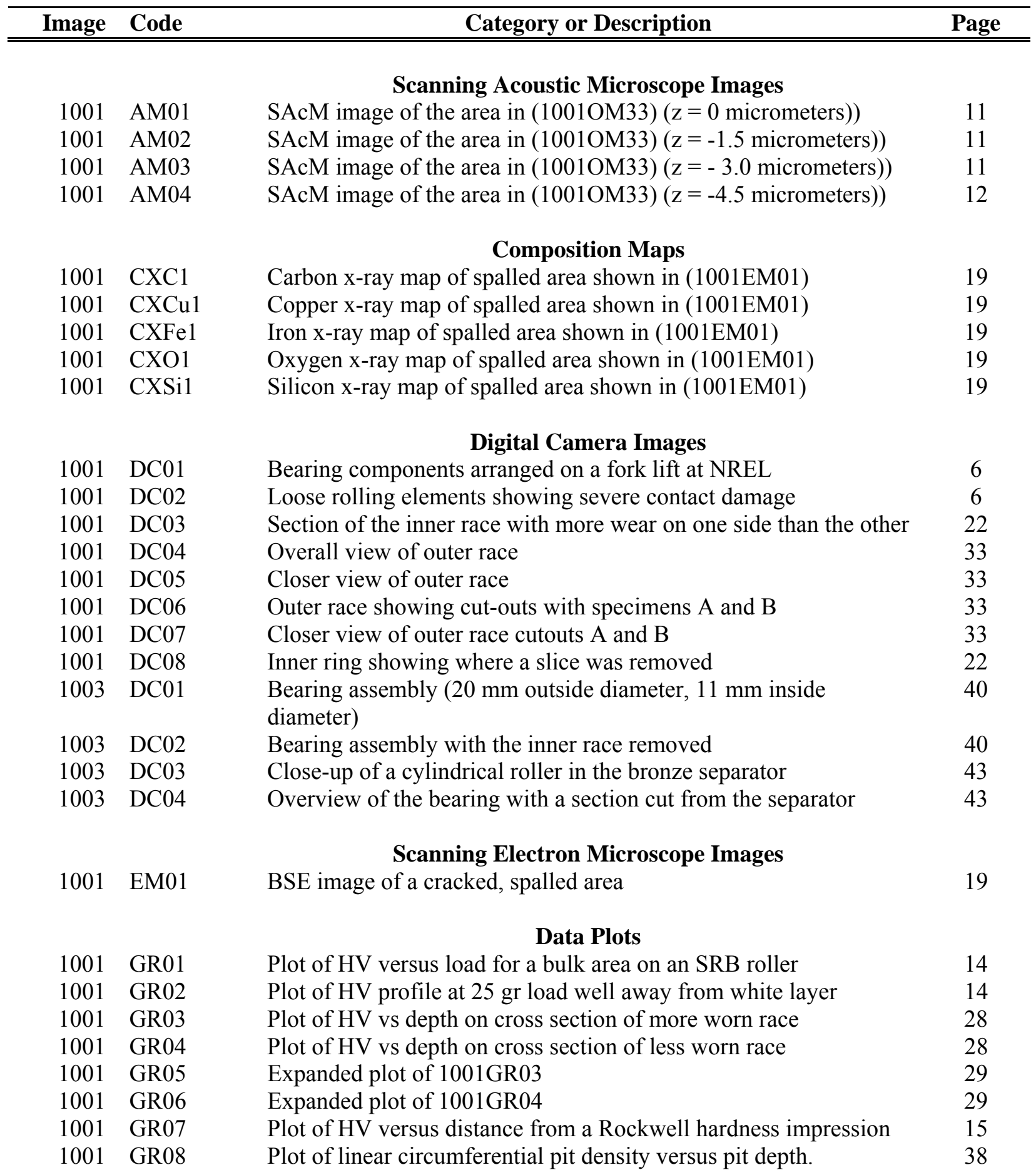

*Note: Acronyms are defined in Section 1.3. 


\begin{tabular}{|c|c|c|c|}
\hline Image & Code & Category or Description & Page \\
\hline & & Optical Microscope Images & \\
\hline 1001 & OM01 & MacI of flow lines on a smeared equatorial region & 6 \\
\hline 1001 & OM02 & MacI of a smeared dish depression on a roller & 6 \\
\hline 1001 & OM03 & MacI of clam shell fatigue indications on a roller & 7 \\
\hline 1001 & OM04 & MacI of a brownish deposit on a roller & 7 \\
\hline 1001 & OM05 & Unetched PXS of cracks on a roller & 8 \\
\hline 1001 & OM06 & Unetched PXS of cracks on the roller in (1001OM05) & 8 \\
\hline 1001 & OM07 & $\begin{array}{l}\text { Unetched PXS showing plastic deformation of the smeared surface } \\
\text { layer }\end{array}$ & 8 \\
\hline 1001 & OM08 & Vickers microindentations on shear-strained surface layers & 8 \\
\hline 1001 & OM09 & MacI of embedded debris particles and indentatations & 7 \\
\hline 1001 & OM10 & Higher mag MacI of the roller in (10010M09) & 7 \\
\hline 1001 & OM11 & $\begin{array}{l}\text { Etched PXS showing white-etching characteristics of the smeared } \\
\text { surface }\end{array}$ & 9 \\
\hline 1001 & OM12 & White-etching layer showing localized shear flow and microcracks & 9 \\
\hline 1001 & OM13 & Etched PXS showing white-etching features paralleling microcracks & 9 \\
\hline 1001 & OM14 & Detail of flow lines in white layer showing a surface crack & 9 \\
\hline 1001 & OM15 & Delamination indication on a plastically-deformed white layer & 10 \\
\hline 1001 & OM16 & Branched tip of a microcrack shown at the center left of (1001OM13) & 10 \\
\hline 1001 & OM17 & Etched Rockwell indentation near the center of a worn SRB element & 13 \\
\hline 1001 & OM18 & $\begin{array}{l}\text { MacI of the deep ridge on the inner race, about } 5-6 \mathrm{~mm} \text { from the outer } \\
\text { edge }\end{array}$ & 23 \\
\hline 1001 & OM19 & Tilted view of the same area as $10010 \mathrm{OM} 13$ & 23 \\
\hline 1001 & OM20 & MacI of the damage on the inner race that showed more wear & 23 \\
\hline 1001 & OM21 & Adhered, embedded fragments in the smoother-appearing inner race & 23 \\
\hline 1001 & OM22 & Vickers micro-indentations near the indentation shown in (1001OM17) & 13 \\
\hline 1001 & OM23 & PXS showing surface material removal and subsurface cracks & 24 \\
\hline 1001 & OM24 & PXS showing nucleation and lateral propagation of subsurface cracks & 24 \\
\hline 1001 & OM25 & Surface-breaking cracks below a shallow debris indentation & 25 \\
\hline 1001 & OM26 & $\begin{array}{l}\text { Lateral propagation of subsurface cracks from high Hertz contact } \\
\text { stresses }\end{array}$ & 25 \\
\hline 1001 & OM27 & Etched area corresponding to the feature on (1001OM24) & 25 \\
\hline 1001 & OM28 & White-etching layer on the side of the wear step and plateau region & 25 \\
\hline 1001 & OM29 & Higher magnification view of the flowed material shown in (1001M28) & 26 \\
\hline 1001 & OM30 & Adherent deposit on a flat zone outboard of the wear step & 26 \\
\hline 1001 & OM31 & Prominent groove in the center of the contact & 26 \\
\hline 1001 & OM32 & Enlarged area of the groove shown in (1001OM31) & 26 \\
\hline 1001 & OM33 & Unetched PXS of a spall on the circumference of a worn roller & 11 \\
\hline 1001 & OM34 & Macro of more worn area on slice A of the outer race & 34 \\
\hline 1001 & OM35 & Macro of less worn area on slice A of the outer race & 34 \\
\hline 1001 & OM36 & Macro of more worn area on slice B of the outer race & 34 \\
\hline 1001 & OM37 & Macro of the less worn are on slice B of the outer race & 34 \\
\hline 1001 & OM38 & Prominent groove on the centerline of the more worn race on Side B & 35 \\
\hline 1001 & OM39 & Enlarged area of the groove in (1001OM38) & 35 \\
\hline 1003 & OM01 & MacI of a cylindrical roller showing numerous debris indentations & 44 \\
\hline 1003 & OM02 & MacI of the bronze separator showing embedded wear particles & 44 \\
\hline 1003 & OM03 & Contact surface of the outer race showing shallow indentations & 40 \\
\hline 1003 & OM04 & Shallow pits and scratches nearby the area that shown in (1003OM03) & 40 \\
\hline
\end{tabular}




\section{LIST OF TABLES}

Table

Page

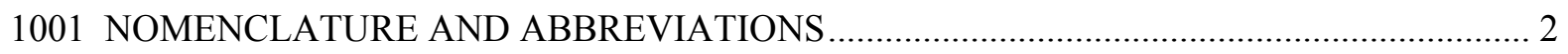

1001 b-1 COMPARISON OF VICKERS HARDNESS OF BEARING AND INNER RACE

MATERIALS FROM BEARING 1001

1001 b-2 VICKERS MICROINDENTATION HARDNESS OF BEARING AND INNER RACE

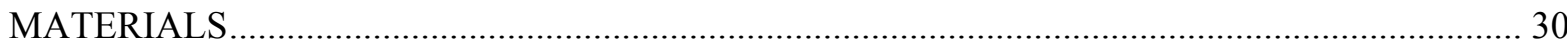

1001 b-3 PIT DENSITY AND DEPTH FOR INNER AND OUTER BEARING RACES ........ 31, 37

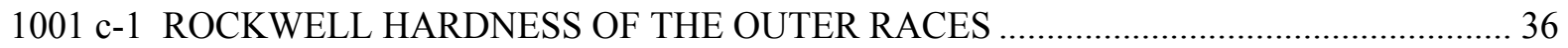

1003 b-1 SURFACE ROUGHNESS OF A CYLINDRICAL ROLLER ........................................... 45 


\section{EXECUTIVE SUMMARY}

Today's wind power turbines are complex, highly-engineered machines. When replicated by the hundreds or thousands, they have the potential to supply an increasing percentage of the nation's electrical energy, and to supplant less environmentally-friendly fossil fuel plants. The viability of wind power as a major energy source depends on a number of factors, including public acceptance, the cost and distribution of wind power, and the reliability of the turbine fleet. As wind turbines begin to populate the landscape and eventually spread to off-shore areas, it is essential that the rotors, towers, and internal moving parts perform satisfactorily for many years without extraordinary maintenance or downtime. The mechanical reliability of gearbox components has recently been singled out as an area of growing concern. The Department of Energy's National Wind Technology Center (NWTC), which is affiliated with the National Renewable Energy Laboratory, has established a Gearbox Reliability Consortium (GRC) to attack these problems. Through participation in several GRC meetings and a topical workshop on micro-pitting, tribology specialists in the Materials Science and Technology Division of Oak Ridge National Laboratory became aware of a need for a materials characterization component within the GRC to complement the activities already underway.

To supplement extensive computer analysis and the development of large-scale, highlyinstrumented testing facilities associated with the NWTC, DOE called upon ORNL to conduct a preliminary study of several worn gearbox bearings retrieved from a wind farm in northern Colorado. The present report resulted from that study. It illustrates the application of metallurgical tools and tribology expertise to characterize the variety of wear and surface damage indications observed in rolling element bearings that were retrieved from wind turbine gearboxes.

This report comprises only one aspect of a comprehensive study. It lacks key details about the each turbine's operating history. That kind of information is needed in order to connect the detailed surface observations presented here to the conditions of turbine operation that ultimately caused them. In developing a format to conduct the present analysis, however, provision was made to include such additional information should it become available. By consistent numbering of sections and figures, the format used here was also designed for easy integration into a reliability database.

Relative to the forms of damage observed in rolling element bearings, there was nothing particularly unusual or unique about the kinds of surface features observed on the current gearbox components; however, the relative occurrence and severity of these kinds of surface damage is unknown within the U.S. wind turbine fleet. Some have proposed alternative materials, coatings, or lubricants for wind gearbox wear and friction issues without having the benefit of diagnostic information like that presented here. Additional studies of this type would therefore better define the nature and extent of bearing damage in wind turbine gearboxes of various designs, and could add value to a national wind turbine gearbox reliability database. Supplementing field examinations with detailed metallurgical studies of selected components would also help to determine whether there is any need for new materials, surface treatments, or lubricants. It would also facilitate the selection or development of laboratory tests aimed at gauging the ability of materials and lubricants to withstand the primary modes of gearbox bearing failure. It does little good to employ screening tests that inadequately simulate actual operating conditions. 
Finally, it was recommended that standardized terminology and nomenclature be established to promote consistency when reporting wind turbine bearing failure modes and wear features. A wear terminology standard for the wind industry would facilitate reporting root causes of bearing gearbox wear and surface damage, and would enable designers and manufacturers to better communicate, understand, document, and compile data on the most prevalent durability issues in wind turbine fleets. It could be based on glossaries that are available through industry consensus and standards organizations such as ASTM. 


\section{INTRODUCTION AND OBJECTIVES}

The objective of this effort was to investigate and characterize the nature of surface damage and wear to wind turbine gearbox bearings returned from service in the field. Bearings were supplied for examination by S. Butterfield and J. Johnson of the National Wind Technology Center (NREL), Boulder, Colorado. Studies consisted of visual examination, optical and electron microscopy, dimensional measurements of wear-induced macro-scale and micro-scale features, measurements of macro- and micro-scale hardness, 3D imaging of surface damage, studies of elemental distributions on fracture surfaces, and examinations of polished cross-sections of surfaces under various etched and non-etched conditions.

In order to facilitate the characterization of the bearing components, a systematic framework for identifying specimens, figures, and other data was developed. Each component analysis was formatted in a separate numbered section to enable cross-referencing to related cases. A compilation of the analyses is contained in this report. It is hoped that this information will contribute to a better understanding of the root causes for premature wind turbine gearbox bearing failures, and will serve as a guide for future work of this kind.

\subsection{STRUCTURE OF THE REPORTS.}

Each report consists of twenty sub-sections. Some of these have additional subsections devoted to specific techniques. For example, section 15 is further subdivided into digital camera images, macroscope images, microscope images, etc. The following list describes the twenty major sections:

1) Record number - a tracking number referring to the specific bearing. A record number with a suffix, such as ' $a$ ' or ' $b$ ' refers to different components within the bearing.

2) Source of the part - from whom the bearing component was obtained

3) Date received - date of receipt at Oak Ridge National Laboratory

4) Turbine manufacturer - manufacturer of the wind turbine from which the bearing was obtained

5) Bearing manufacturer - self-explanatory

6) Part or catalog number of the bearing - self-explanatory

7) Bearing type - general type of bearing (see the nomenclature list in 1.2)

8) Gearbox type and bearing location within it - manufacturer of the gearbox and location of the bearing

9) Form of hardware and condition - whether a full or partially-assembled component when received

10) Specific component type - a roller, a bearing race, a separator, or other part of a bearing assembly

11) Construction material and condition - material (alloy) of which the given component is composed and its condition, such as heat-treated, coated, etc.

12) Lubricant and method of application - lubricant used for the bearing and how it was supplied (fully-flooded, mist lubrication, splash lubrication, pressurized lubrication, etc.)

13) Running history - conditions under which the turbine was operated prior to removal of the part for examination

14) Other description of the components to be examined - comments from the provider of the component as may regard field analysis or observations of the component condition

15) Photographs of components - images acquired by digital cameras, electron microscopes, optical microscopes, or scanning acoustic microscopes. (see the figure codes in Section 1.3 for additional details)

16) Property measurements - measurements of certain properties, such as hardness, made on the components 
17) Dimensional Measurements - data on component shape or surface roughness

18) Surface chemical analysis - any surface chemical analysis made of the components

19) Summary of analysis - summary of key findings of the investigation of the given part

20) Related analyses - ID numbers of other reports than relate to the given report, such as a report on the rolling element that matches the race being discussed, etc.

\subsection{NOMENCLATURE}

For expediency, certain nomenclature has been adapted for use in this consolidated report. An alphabetical list of abbreviations and their definitions follows in Table 1. Not all listed abbreviations were used in this report, but are provided as a resource should future studies like this be undertaken.

\section{Table 1. Nomenclature and Abbreviations}

\begin{tabular}{|l|l|}
\hline Abbreviation & \\
\hline \hline ACB & angular contact ball bearing \\
\hline AM & in a figure ID number, signifies a scanning acoustic microscope image \\
\hline BB & ball bearing \\
\hline BC & broken component (condition when received - fragments, missing parts, etc.) \\
\hline CRB & cylindrical roller bearing \\
\hline CX & in a figure ID number, signifies a elemental distribution image (EDXA) \\
\hline DC & in a figure ID number, signifies digital camera image \\
\hline DR & double-row (bearing) \\
\hline EDXA & energy dispersive x-ray analysis \\
\hline EM & in a figure ID number, signifies electron microscope image \\
\hline FB & fully assembled rolling element bearing (bearing condition when received) \\
\hline GR & in a figure ID number, signifies a graph \\
\hline HRC & Rockwell C-scale hardness number \\
\hline HV & Vickers microindentation hardness number (kg/mm²) \\
\hline IR & inner bearing race \\
\hline LC & loose components (bearing condition when received) \\
\hline LCPD & linear circumferential pit density - referring to a damaged bearing surface \\
\hline OM & in a figure ID number, signifies optical microscope image \\
\hline OR & outer bearing race \\
\hline PD & partially-disassembled (bearing condition when received) \\
\hline SEP & rolling element separator (describing a component) \\
\hline SK & in a figure ID number, signifies a schematic diagram, sketch, or scanned figure \\
\hline SP & in a figure ID number, signifies surface profile or shape data plot \\
\hline SR & single-row (bearing) \\
\hline SRB & spherical roller bearing \\
\hline TCB & tapered cylindrical rolling bearing \\
\hline VSI & vertical scanning interferometry - a surface topography mapping method \\
\hline X & corrosion or rough handling of the parts \\
\hline
\end{tabular}

In addition to the abbreviations listed in Table 1, several terms have been used frequently in this report. For example, the terms "white layer" and "white-etching layer" are commonly used to describe certain wear-related features in polished and chemically-etched cross-sections of ferrous alloys. They refers to 
bright, nearly-featureless structures that have been subjected to high, localized contact stresses. The microstructure of these layers makes them less susceptible to chemical etching, and therefore, they appear white or relatively featureless when viewed in a light-optical, reflecting-type microscope.

\subsection{NUMBERING OF FIGURES}

In order to facilitate the indexing and cross-referencing of figures in this report, the following coding method was devised for figures.

\section{Format: $\boldsymbol{X X X X A A Y Y}$}

$X X X X \quad$ Bearing component identifier. Each bearing assembly was assigned a separate four-digit number. Parts of that bearing, like rollers or races, are identified by suffixes "a", "b," etc.

$A A$

Type of figure:

$\mathrm{AM}=$ image taken with a scanning acoustic microscope*

$\mathrm{CX}=$ surface chemical analysis image (X-ray composition map)

The suffix is the element being mapped (for example, CXFe1 is the first image of the iron distribution on the area of the specimen.)

$\mathrm{DA}=$ data file, spreadsheet, table, etc.

DC $=$ digital camera image, including close-ups

$\mathrm{EM}=$ electron microscope image (scanning, transmission, back-scattered electron)

$\mathrm{GR}=$ plot or graph

$\mathrm{OM}=$ optical microscope image. These include a magnification scale bar.**

$\mathrm{SK}=$ hand sketch, schematic diagram, or scanned in diagram

$\mathrm{SP}=$ surface profile, roundness profile, or topographic image

YY sequence number (01 to 99$)$

Example: 10010M15 is the fifteenth optical microscope image associated with bearing assembly identified as 1001.

Footnotes:

* A scanning acoustic microscope uses high-frequency (for example $100 \mathrm{MHz}$ to $2 \mathrm{GHz}$ ), acoustic waves to probe the surface of a specimen that is coupled to the microscope objective with drop of fluid. By adjusting the frequency and focus, it is possible to image features at and below surfaces. For further information on applications to wear studies see: P. J. Blau and W. A. Simpson, Jr. (1995) "Applications of scanning acoustic microscopy in analyzing wear and single-point abrasion damage," Wear, Vol. 181-183, pp. 405-412. A good general text is: A. Briggs (1992) Acoustic Microscopy Clarendon Press, Oxford.

** The acronym MacI is used in certain OM-type figure captions to refer to surface images obtained from a lowpower macroscope (typically about 8-25X), and that the acronym PXS is used in figure captions to designate a polished cross-section. 


\section{INDIVIDUAL REPORTS}

This section contains five individual reports that describe the wear and surface damage on selected bearing components. Each report is formatted in the manner described in Sections 1.1, 1.2, and 1.3. The record numbers refer to the numbering of the component parts as they were received. Reports are based on examinations by a variety of methods. The selection of the methods used for each analysis depended on the nature of the surface damage. Not all methods were used on every part; however, for consistency, sections are numbered in the same way. For example, Section 15.1 is reserved for digital camera images, section 16.1 is reserved for macrohardness data, and so forth.

A note on the use of hand-drawn sketches and computer illustrated diagrams: In some cases, due to reflections or poor contrast of certain features, it was more useful to include hand renderings or schematic representations of the surfaces of worn parts rather than to use photographic images that were subject to glare and reflections or lack of adequate depth of focus. In some cases, the human eye can be more sensitive to certain details than the camera lens, and it sometimes made more sense to represent features with a detailed drawing than with a less than adequate photograph. Examples of this approach may be found in Section 2.1 [Figures (1001SK03), (1001SK04), and (1001SK05)], and in Section 2.2. [Figure (1001SK02)].

\subsection{SPHERICAL ROLLER BEARING - ROLLING ELEMENT}

\begin{tabular}{|l|l||l|l|}
\hline 1) Record number & $1001 \mathrm{a}$ & 2) Source/Contact name & NREL/Johnson \\
\hline $\begin{array}{l}\text { 3) Date rec'd } \\
\text { (yyyymmdd) }\end{array}$ & 20081230 & $\begin{array}{l}\text { 4) Turbine mfr (site } \\
\text { locale) }\end{array}$ & Micon 750 (Ponnequin farm, \#19) \\
\hline 5) Bearing mfr. & SKF & 6) Part cat. number or ID & $\begin{array}{l}\text { 22322 E (specs are available on- } \\
\text { line at: <www.skf.com }>\text { ) }\end{array}$ \\
\hline 7) Bearing type & DR/SRB & $\begin{array}{l}\text { 8) Gearbox type / brg } \\
\text { location }\end{array}$ & Brooks and Hansen / high-speed \\
\hline $\begin{array}{l}\text { 9) Specimen type } \\
\text { condition }\end{array}$ & $\begin{array}{l}\text { FBS / LC } \\
\text { and BP }\end{array}$ & $\begin{array}{l}\text { 10) Specific component } \\
\text { type }\end{array}$ & Worn spherical elements (rollers) \\
\hline
\end{tabular}

Notes: 1) Bearing types: $\mathrm{SR}=$ single row; $\mathrm{DR}=$ double row; $\mathrm{CRB}=$ cylindrical roller bearing; $\mathrm{TCB}=$ tapered cylindrical roller bearing, $\mathrm{SRB}=$ spherical roller bearing; $\mathrm{BB}=$ ball bearing; $\mathrm{ACB}=$ angular contact ball bearing

2) Specimen type: $\mathrm{FBS}=$ full bearing set; $\mathrm{RE}=$ rolling element, $\mathrm{OR}=$ outer race. $\mathrm{IR}=$ inner race, $\mathrm{SEP}=$ separator

3) Condition codes: $\mathrm{FB}=$ received as a fully-assembled bearing, $\mathrm{PD}=$ partially disassembled bearing, $\mathrm{LC}$ $=$ loose component (in tact), $\mathrm{BC}=$ broken piece(s) of a loose component, $\mathrm{X}=$ surface corroded, scratched, or otherwise marred when received

11) Construction Material and Condition: (Information not provided with the sample).

12) Lubricant and Method of Application: (Information not provided with the sample) 


\begin{tabular}{|l|l|}
\hline 13) Running history & (unknown) \\
\hline $\begin{array}{l}\text { 14) Other description } \\
\text { of the component(s) } \\
\text { to be examined }\end{array}$ & $\begin{array}{l}\text { Description from the source: "One side of bearing (not marked as up or down } \\
\text { wind) is so badly damaged that the rollers were no longer caged. The cage } \\
\text { was completely ground up except for a single } 2 \text { mm wide ring of steel. The } \\
\text { rollers from this side were being dragged or skidded in the races (they were } \\
\text { not rolling). The other side of the bearing is in better condition, mostly } \\
\text { denting from debris on the rollers and races. There is severe fretting } \\
\text { corrosion on the OD of the outer race." }\end{array}$ \\
\hline
\end{tabular}

\subsection{Sketches.}

Thirteen loose rollers from the more severely-worn complement were examined, and showed three general types of damage. Three of thirteen rollers showed the circumferentially-dished appearance, as illustrated by the pencil drawing shown in (1001SK03); seven rollers showed the belted-scalloped appearance, as depicted in Figure (1001SK04); and two rollers had long, narrow features extending in from the edges, as shown in Figure (1001SK05).

\begin{tabular}{|c|c|c|}
\hline & \\
\hline$(1001 \mathrm{SK} 03)$ & $(1001 \mathrm{SK} 04)$ & $(1001 \mathrm{SK} 05)$ \\
\hline
\end{tabular}

15) Photographs of components.

\section{1) Digital camera images.}

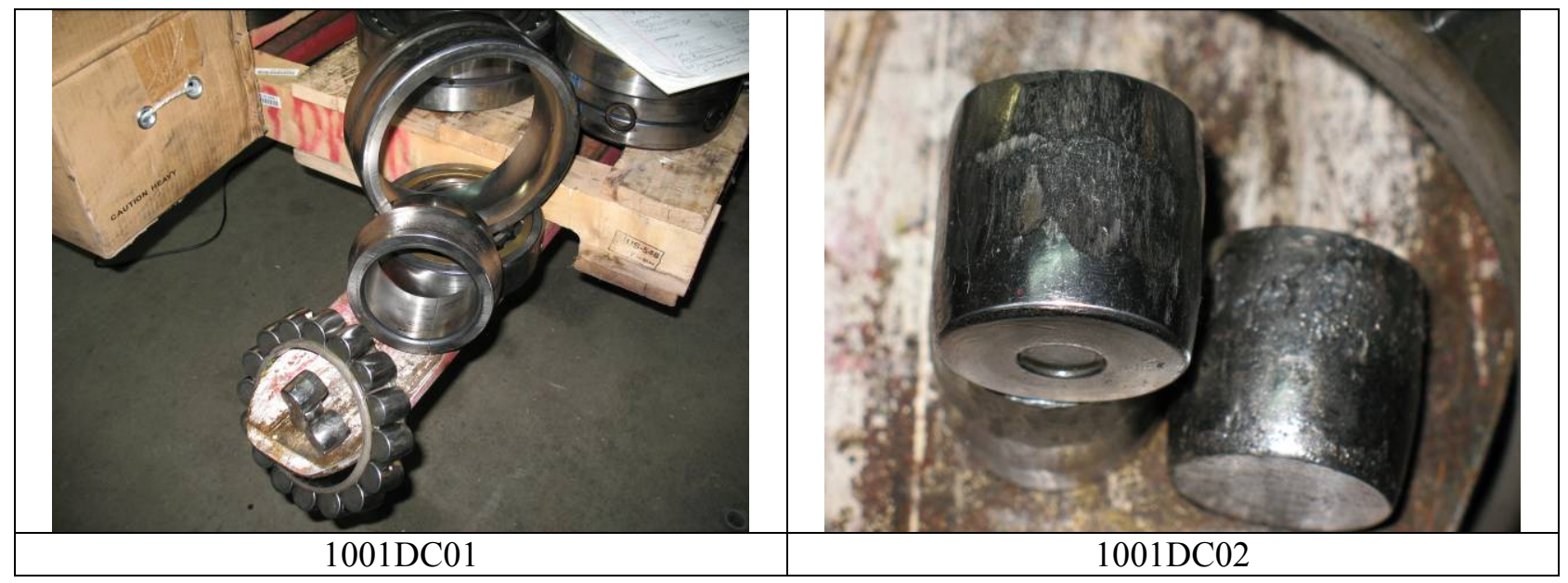


Photograph captions / notes:

(1001DC01) Bearing components arranged on a fork-lift at NREL prior to shipment to ORNL (image courtesy of NWTC, Boulder, CO)

(1001DC02) Loose rolling elements showing severe contact damage. Less-badly worn components comprise the full ring or rollers shown in 1001DC01. (image courtesy of NWTC, Boulder, CO)

\section{2) Macroimages of surfaces. (Light optical)}

Close-up images were obtained using a Nikon macro-zoom microscope. The first set of images was on the more severely- damaged, loose rollers, and the second set on a roller removed from the in-tact 16roller complement shown perched on the end of the forklift in Figure 1001DC01.

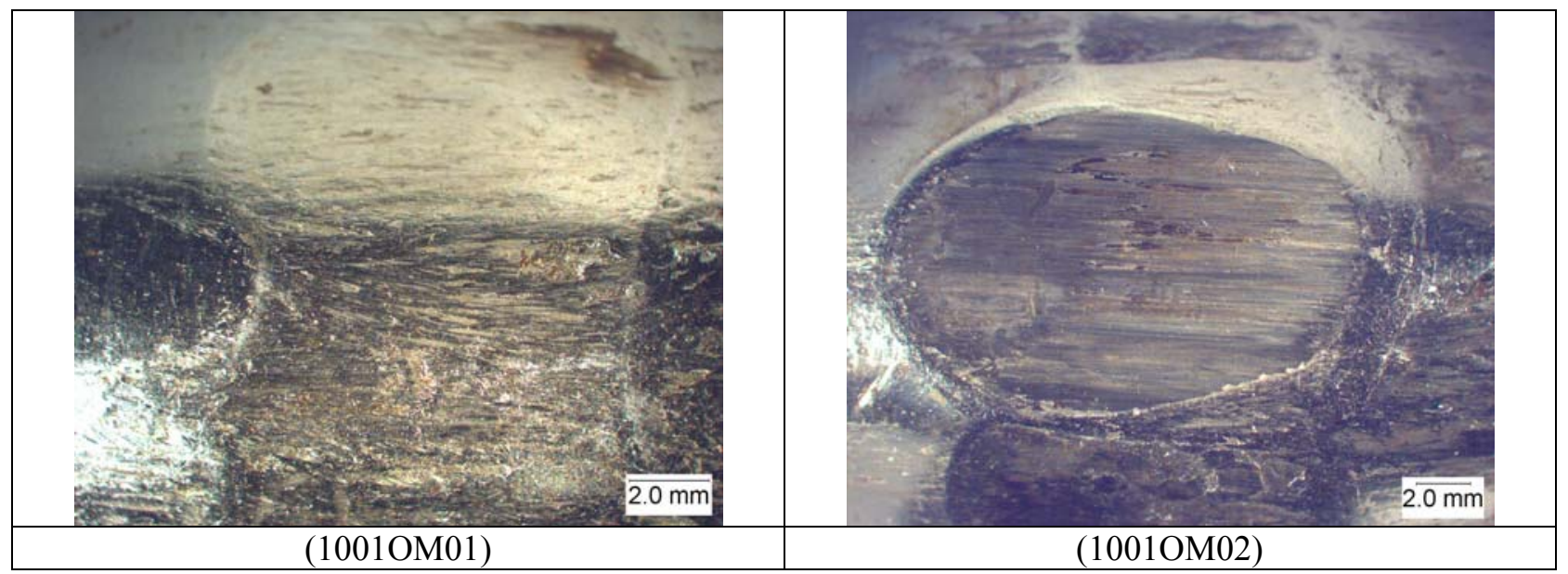

Photograph captions / notes:

(1001OM01) MacI of flow lines on the smeared equatorial region of a spherical rolling element.

(1001OM02) MacI of a smeared dish depression on the equatorial region of a spherical rolling element (SRE). Smears are approximately parallel to the longitudinal axis of the SRE. An extruded lip has formed at the left edge of the dished region.

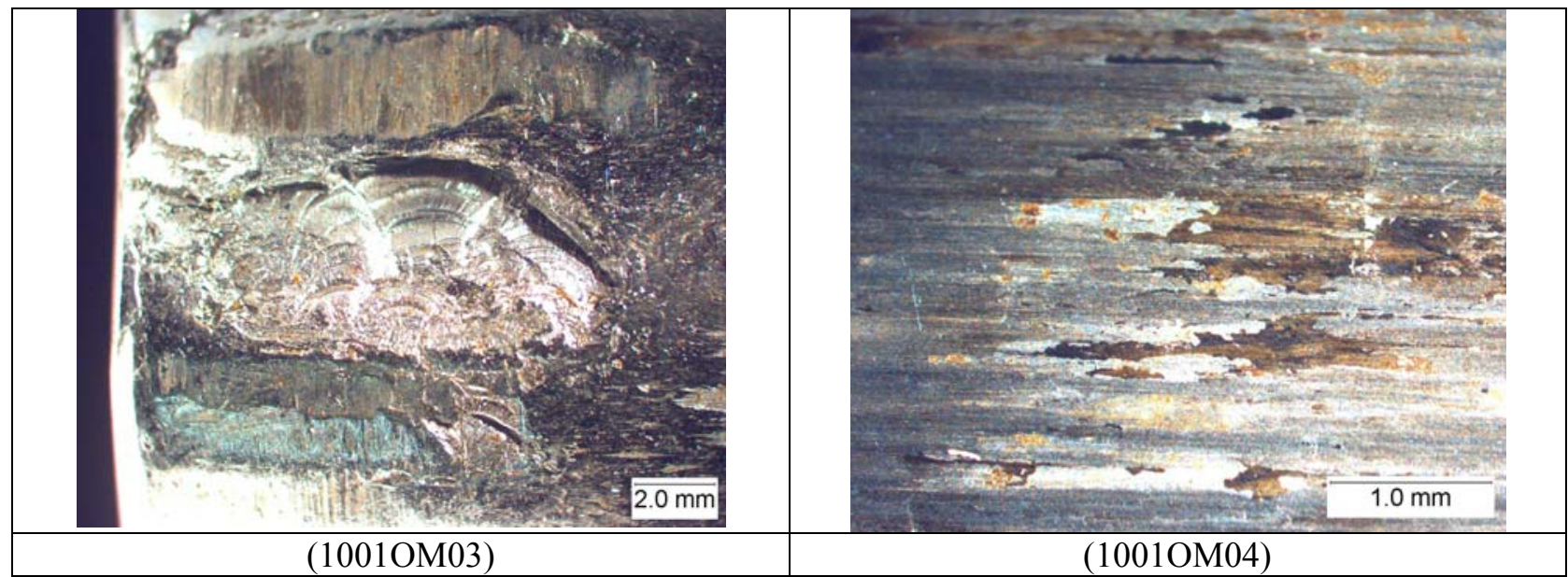

Photograph captions / notes:

(1001OM03) MacI of clam-shell fatigue indications inside a near-edge spall on a spherical rolling element. There seem to be at least two independent origins for the clam-shell markings. The 
spacing of the fatigue striae seems to increase with radial distance from the fracture origin, suggesting a rapid last-stage of growth, prior to the detachment of the overlying flap.

(1001OM04) MacI of a brownish deposit at the center of the smeared dish in 1001OM02. This film, which was not removed by light brushing or an air jet, may be a residue (boundary film) from the lubricant additive package. It does not have the normal appearance of general corrosion products, and was present only at sparse, streaked locations on the dished areas along the roller's equator.

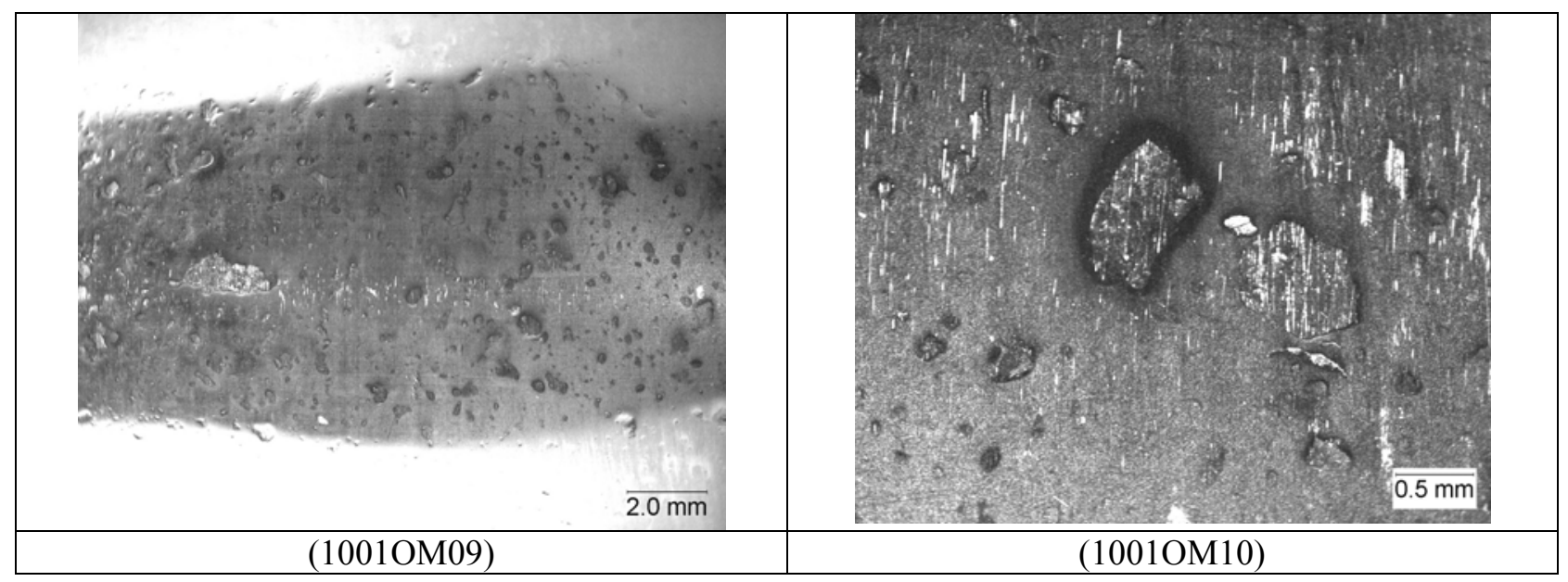

Photograph captions / notes:

(1001OM09) MacI of embedded debris particles and indentations on the surface of a rolling element removed from the 16 roller complement that was less damaged. The axis of the roller is approximately horizontal.

(1001OM10) Higher magnification MacI of the roller in 1001OM05 showing angular metallic fragments adhered to and embedded into the surface. The rotational axis of the roller is approximately horizontal with respect to the image orientation. 


\subsection{Polished cross-sections (Optical microscopy).}

Polished cross-sections of the heavily worn (loose) rolling element, without etching, revealed the fine network of subsurface micro-cracks associated with spalls and pits.

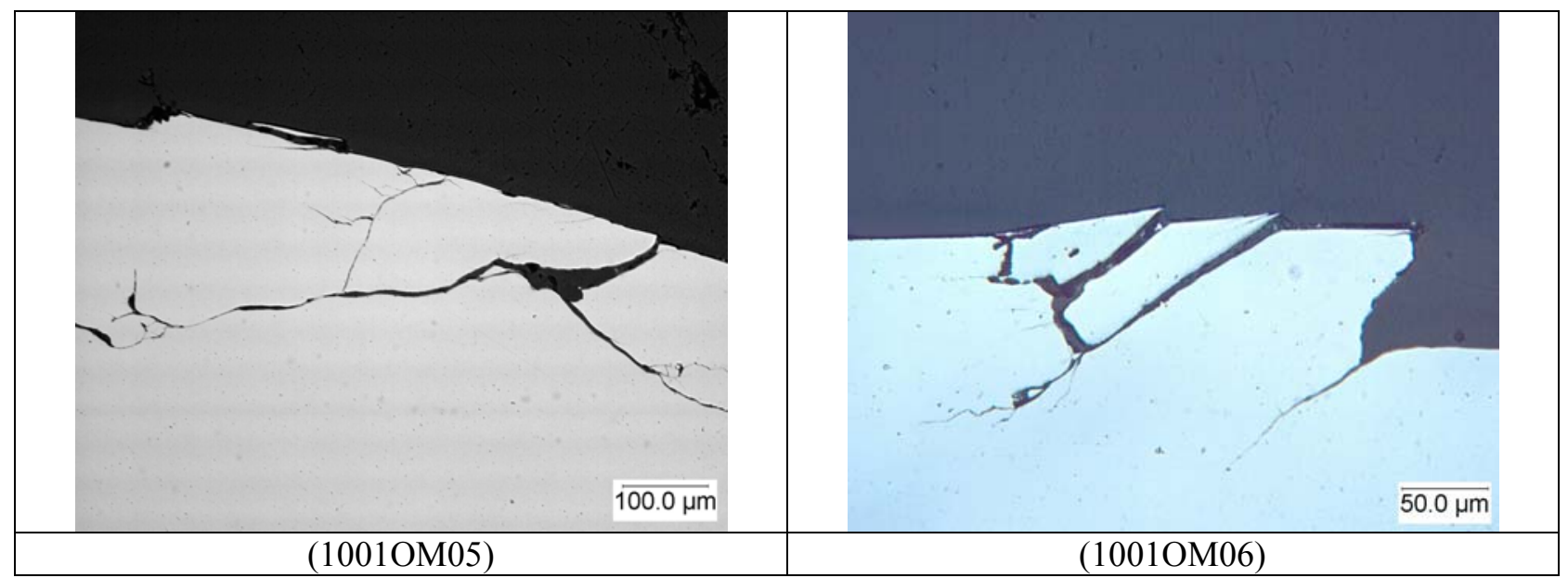

Photograph captions / notes:

(1001OM05) Unetched PXS of cracks on a roller, approximately $1 / 3$ the distance from one end. The plane of polish is perpendicular to the axis of rotation. It shows a series of branched subsurface micro-fractures. Fine networks of such micro-fractures join the major fissures with the surface. Depths of cracking as much as 200-300 $\mu \mathrm{m}$ are common. Apparently, cantilevered segments break off when micro-fractures coalesce and meet the free surface.

(1001OM06) Unetched PXS of cracks on the roller shown in 1001OM05. It shows a series of stacked micro-fractures. The direction of these inclined fractures seems to be consistent around the entire circumference of the roller, suggesting they were caused by shear tractions (from right to left.) Stress concentrations at the roots of the segments can help to propagate fatigue fine fractures as the upper lip of the segments repeatedly contact the opposing surface. It is likely that the higher features 'sprang up' after the bearing surface lost contact.

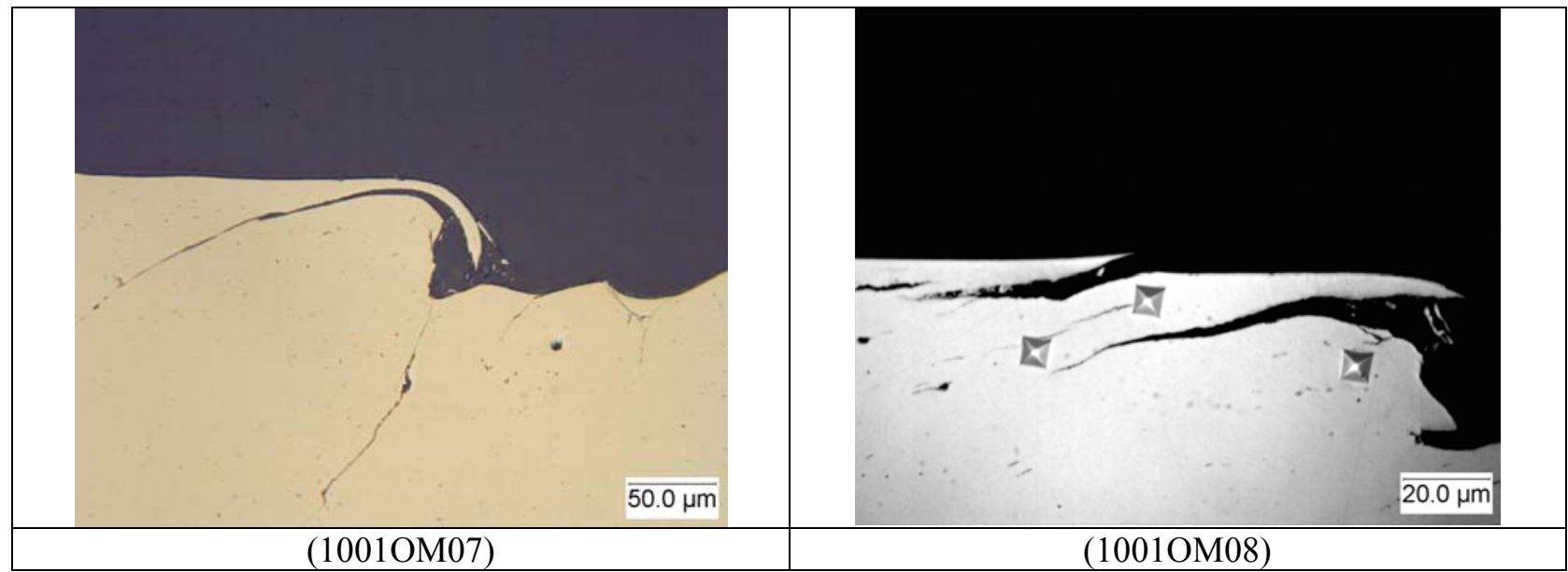

Photograph captions / notes:

(1001OM07) Unetched PXS showing plastic deformation of the smeared surface layer that extends over the edge of a second feature under intense surface tractions (not etched). Such deformation 
suggests the presence of a high hydrostatic stress field. Such a stress field would allow shear strains far in excess of those normally observed in a typical tensile test of the same alloy.

(1001OM08) Vickers microindentations (25 g-f load) on shear-strained surface layers on roller shown in Image 1001OM05. The Vickers hardness (HV) of these features was lower than the HV at the same load measured at the center of the cross-sectioned rolling element. The microfracture bridging the two left-most indentations was observed only after indenting, suggesting that it was caused by the HV procedure or was opened up by the pyramidal diamond indenter. Further HV measurements on white-etching regions, however, did show that such deformed regions were considerably harder than the bulk material below (see Section 14.2).

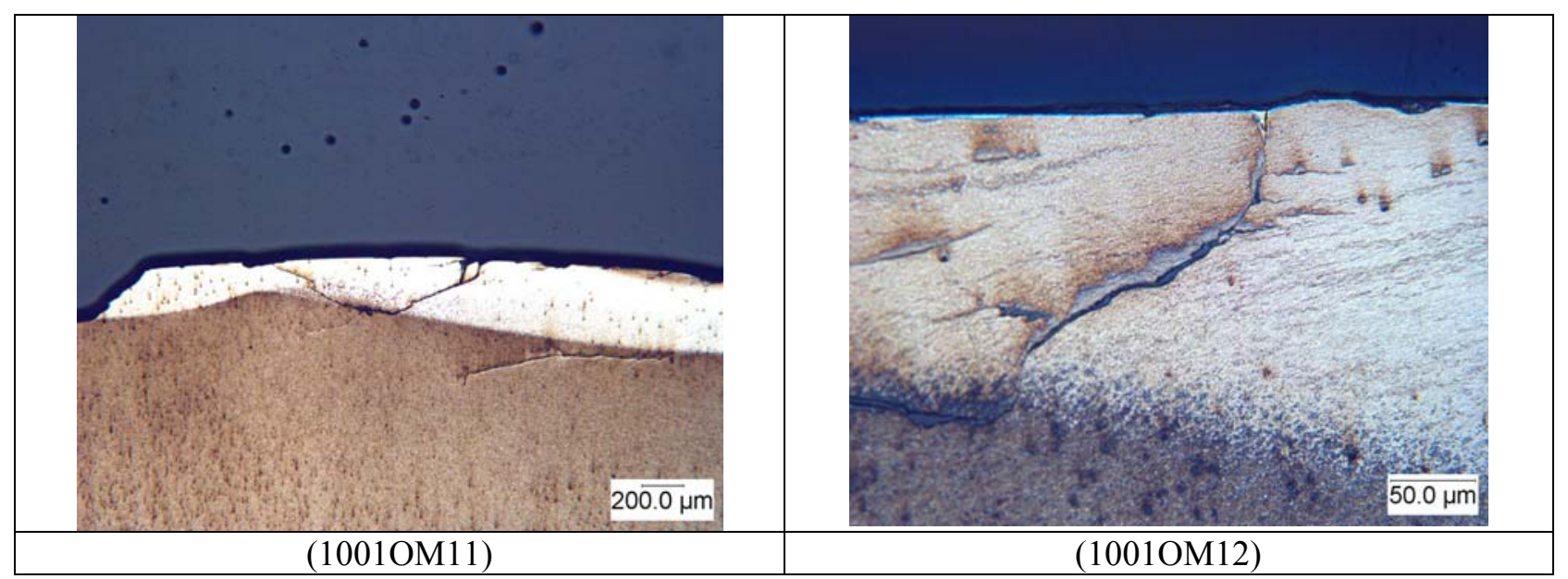

Photograph captions / notes:

(1001OM11) Etched PXS showing white-etching characteristics of the smeared surface (5\% nital etch). Cracks change direction when they reach the white-etched/substrate boundary, but some cracks seem to have originated below the highly-strained and propagated downward at an angle.

(1001OM12) White-etching layer showing localized shear flow and micro-cracks (5\% nital etch).

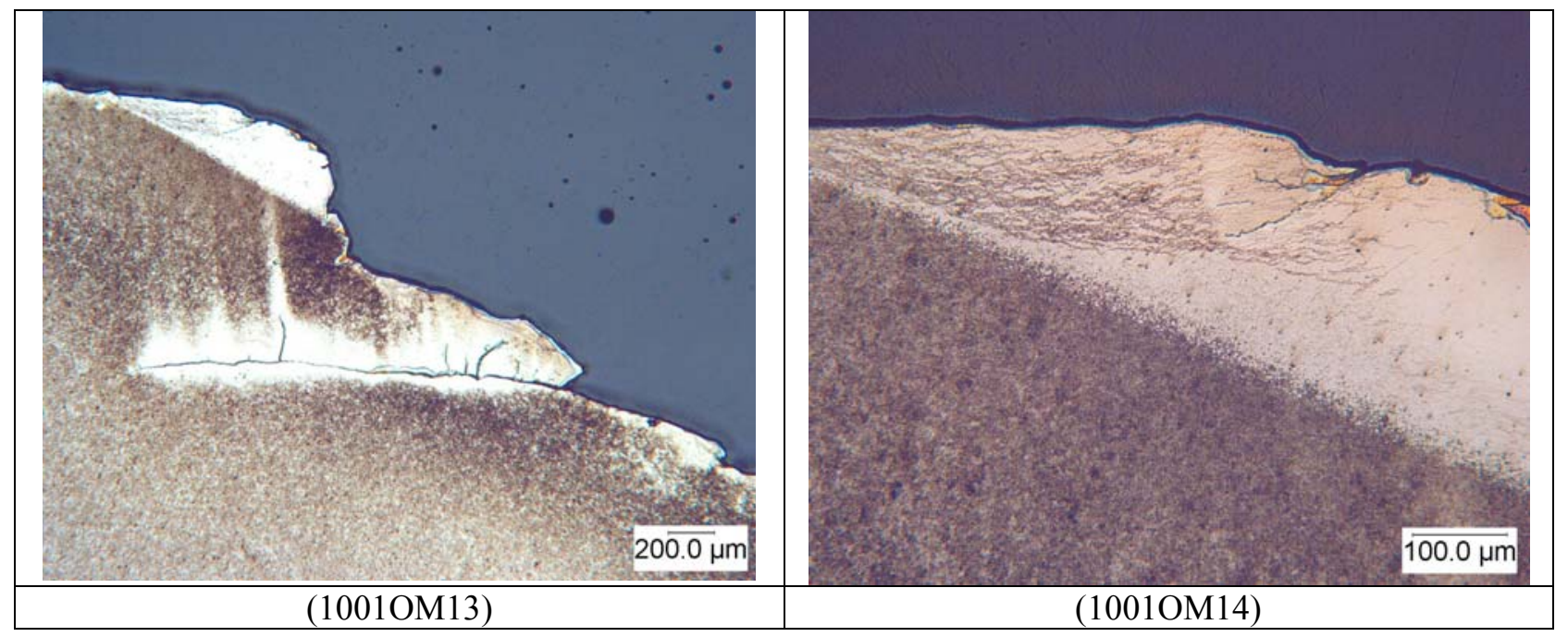

Photograph captions / notes:

(1001OM13) Etched PXS showing white-etching features paralleling micro-cracks. (Ralph's etch). . 
(1001OM14) Detail of flow lines in a white-etching layer showing a surface crack from a shallow pit turning into the direction of the flow (Ralph's etch).

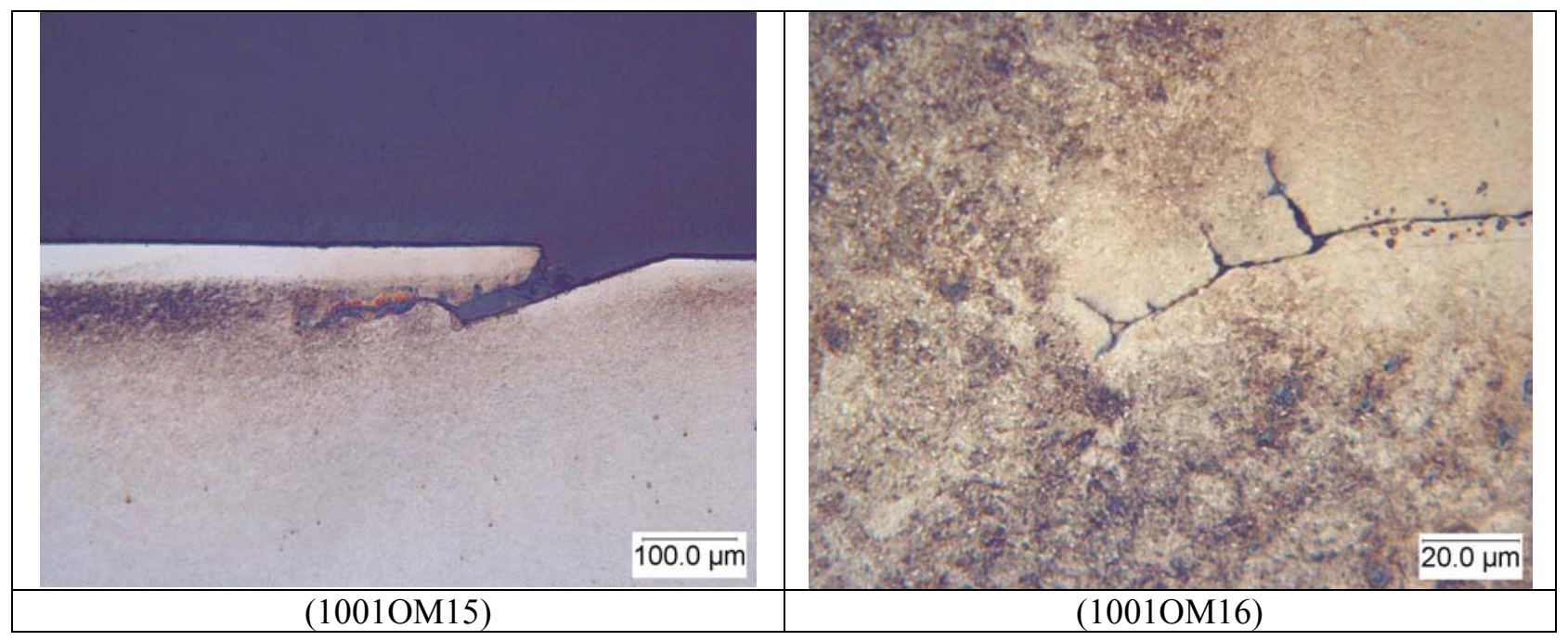

Photograph captions / notes:

(1001OM15) Delamination indication on a plastically-deformed white layer at the surface of the rolling element. The cantilevered portion can oscillate to cause the crack tip to advance below the layer. (Ralph's etch).

(1001OM16) Branched tip of a microcrack shown at the center left of (1001OM13). Multiple branching is evident, as is the roll of a fine particle, possibly a microstructural inclusion in promoting branching at the crack tip (Ralph's etch).

\section{4) Scanning acoustic microscopy (SAcM).}

A scanning acoustic microscope [KSI (Germany) initially sold as a Ernst Leitz Scanning Acoustic Microscope] was used to obtain images of the edges of a spall on a polished cross-section of a rolling element. The SAcM offers one an opportunity to probe the materials several micrometers below the surface non-destructively, revealing details of cracks, grains, strains, and other features that disrupt the speed of sound on a local basis. Figure (1001OM33) shows a light-optical image of the edge of a spall. The curved surface at the top left of the image is a portion of the original bearing surface that ends at the edge of the spalled area.

A SAcM image of the same area was obtained at a frequency of $1 \mathrm{GHz}$ [see Fig. (1001AM01)]. The plane of focus was at the surface $(\mathrm{z}=0 \mu \mathrm{m})$, and the acoustic image shows essentially the same features as those shown in the optical microscope image to the left. When the focus plane (defocus) is set below the surface, other features are revealed. For example, Figures (1001AM02 - 05) show progressively deeper planes in the surface. As the penetration increases, it become apparent that several of the microcracks are in fact longer than they appear in the light optical image. There are also indications of additional porosity and material damage in the area above center in the image, and in the region between the ends of the microcracks at the left of center. There is also a faint indication of an inclined crack at the lower left of Figure (1001AM05). This feature is invisible in the light optical image, suggesting that Hertzian contact damage may be much more severe in the spalled areas than is directly revealed in the light optical microscope. 


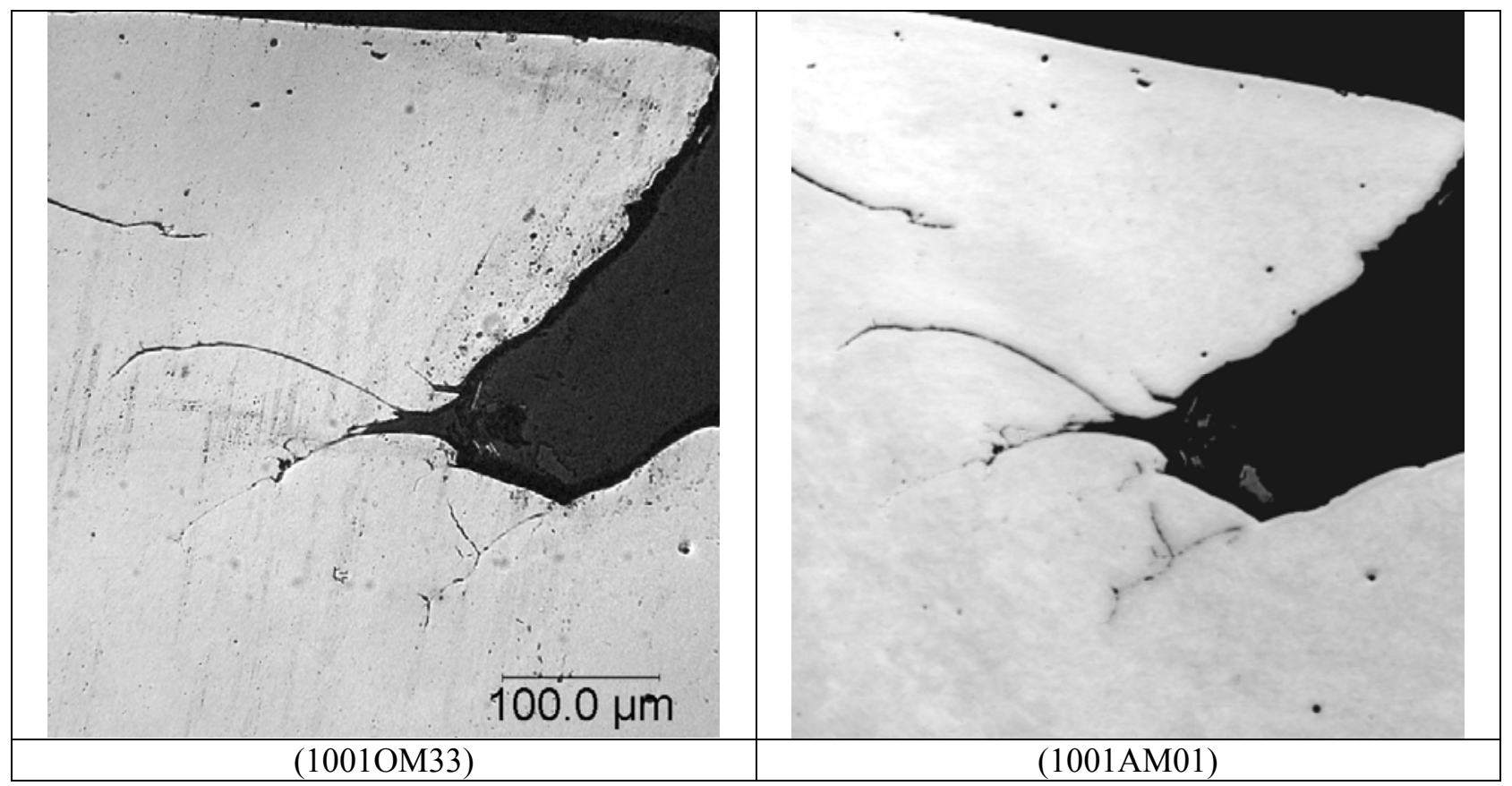

Photograph captions / notes:

(1001OM33) Unetched PXS of a spall on the circumference of a worn rolling element. This image was obtained after scanning with the SAcM and shows some evidence of staining and minor pitting due to its expose to water during the scanning process.

(1001AM01) Scanning acoustic microscope image of the edge of a spall taken at $1 \mathrm{GHz}$ frequency in 60 ${ }^{\circ} \mathrm{C}$ water $(\mathrm{z}=0 \mu \mathrm{m})$. The magnification is the same as that for Fig. (1001OM33) at the left

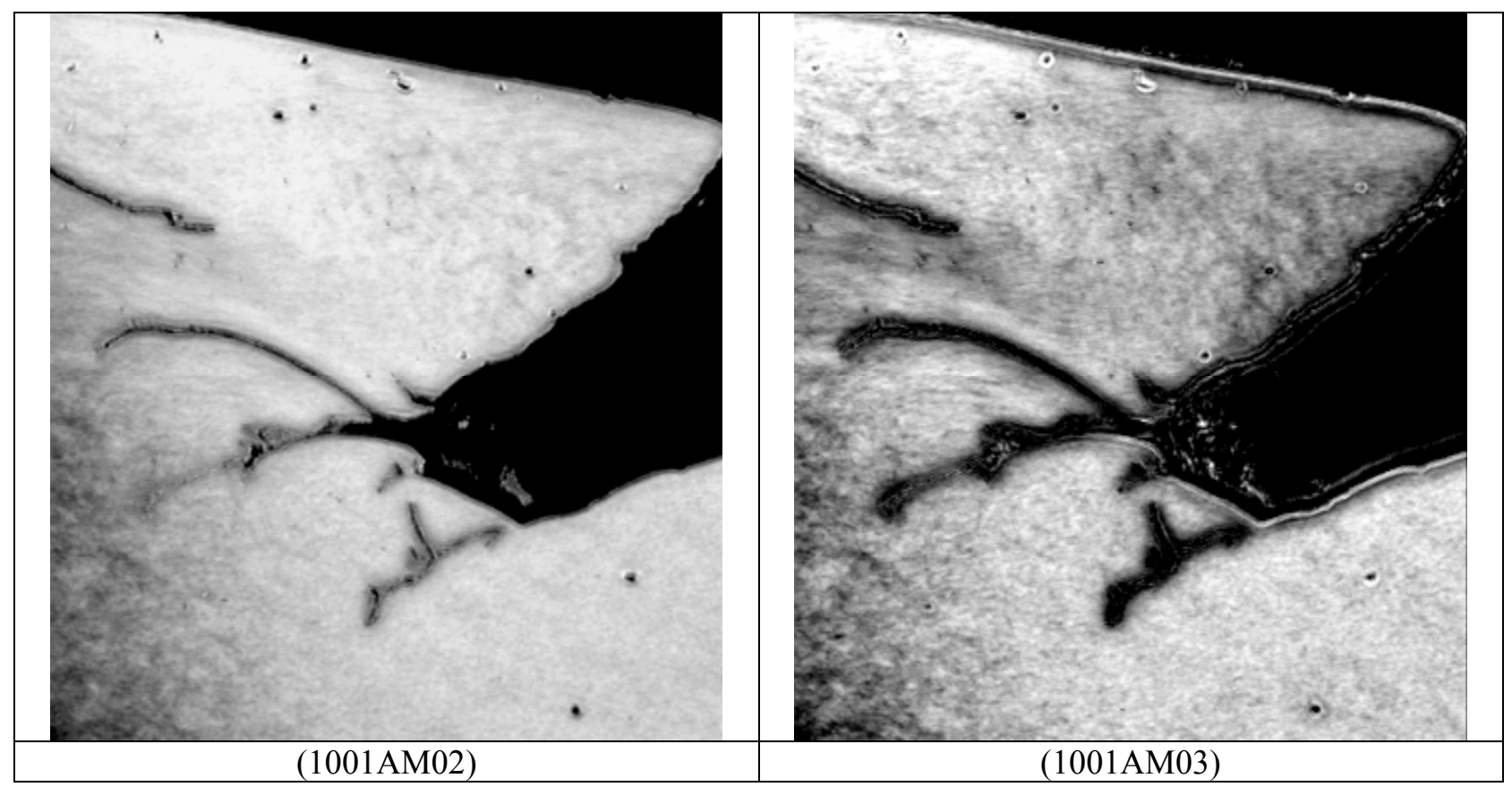

Photograph captions / notes:

(1001AM02) Scanning acoustic microscope image of the edge of a spall at $1 \mathrm{GHz}$ frequency and with a focus of $\mathrm{z}=-1.5 \mu \mathrm{m}$. The magnification is the same as that for Fig. (1001OM33). 
(1001AM03) Scanning acoustic microscope image of the edge of a spall at $1 \mathrm{GHz}$ frequency and with a focus of $\mathrm{z}=-3.0 \mu \mathrm{m}$. The magnification is the same as that for Fig. (1001OM33)

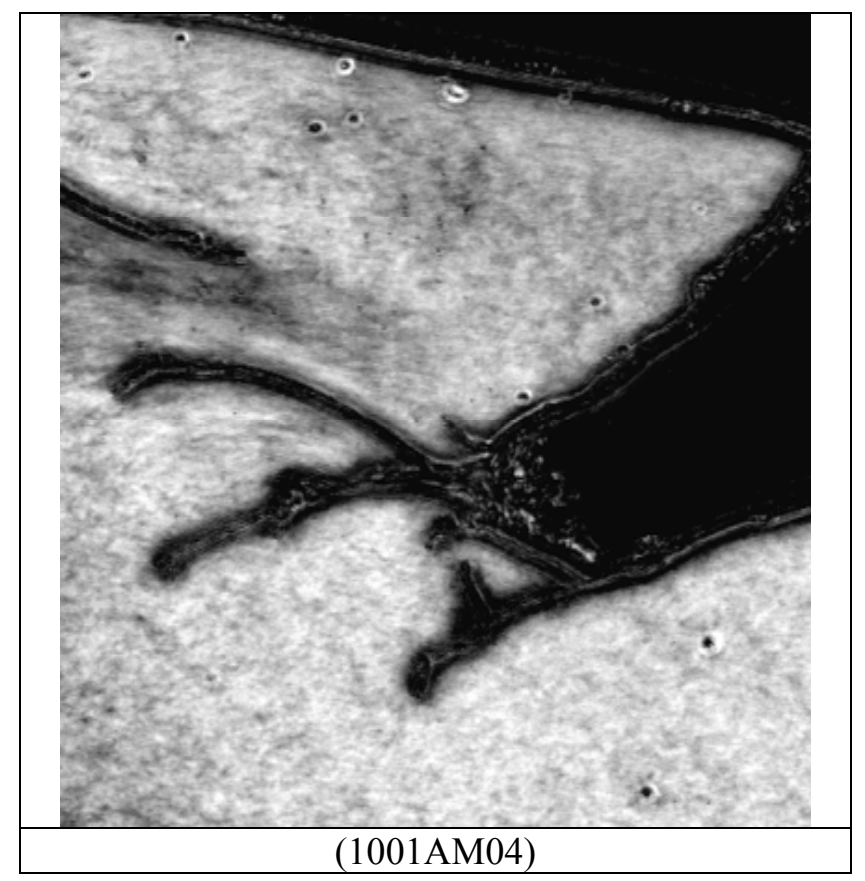

Photograph captions / notes:

(1001AM04) Scanning acoustic microscope image of the edge of a spall at $1 \mathrm{GHz}$ frequency and with a focus of $z=-4.5 \mu \mathrm{m}$. The magnification is the same as that for Fig. (1001OM33).

16) Property measurements.

\section{1) Macroindentation hardness.}

Rockwell C hardness was measured at the center of a polished, non-etched cross section of a severely worn rolling element. The three readings were HRC 61.1, 61.2, 61.3. Indentations were also placed at three different locations about $2 \mathrm{~mm}$ from the edge of the polished cross-section. These readings were about 2 HRC points lower; namely, 59.7, 59.1, 59.9. The lower readings in HRC near the surface were consistent with similar findings from Vickers microindentation tests on the same cross-section and reported in Section 14.2.

An etched image (Ralph's etch) of a Rockwell hardness test indentation near the center of a cross-section of the severely damaged rolling element bearing shows the pattern of deformation surrounding it. Note that the etchant fails to reveal the details in regions of highest deformation, nearest the edge of indentation. This suggests that the degree of etching is related to the degree of plastic deformation in the material. Vickers microindentations (see 14.2) were placed next to the impression of the Brale (diamond cone) indenter to study the relationship between etching characteristics and hardness of the lighter-etching zones in the microstructure. 


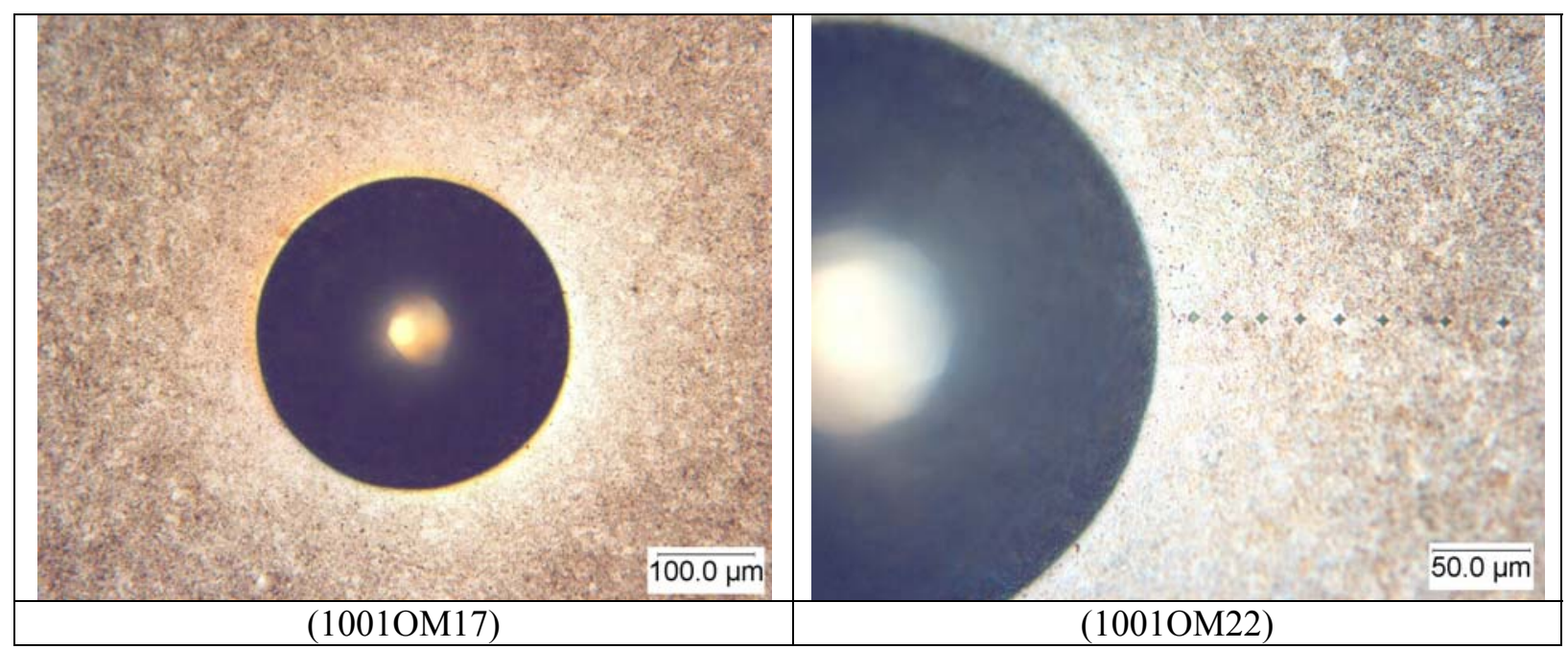

Photograph caption / notes:

(1001OM17) Etched Rockwell indentation near the center of a worn SRB element showing a halo of lighter-etching region. The higher the deformation, the less effect the etchant seems to have. We can infer that the white-etching layers shown in images of the near-surface zones of the bearings have also been highly deformed and cold-worked. (Ralph's etch).

(1001OM22) Vickers micro-indentations near the indentation shown in (1001OM17)

\section{2) Microindentation hardness.}

Figure 1001GR01 shows the Vickers microindentation hardness number (HV) as a function of the applied load, measured at the center of the cross-sectioned and polished roller (shown in Figs. 1001OM05-08). It displays the well-known 'indentation size effect' (ISE) in which lighter loads produce an apparently higher hardness number. The presence of an ISE in this material requires that a comparison of the microindentation hardness of various areas on the polished section (center, edges, etc.) be done at the same applied load.

Figure 1001GR02 shows the variation of HV with depth below the free surface on a polished SRB crosssection, obtained well away from the rougher surface features like those shown in 10010M05-08 and M11-14. The average hardness of the near surface layers was less that that of the bulk alloy at the center of the bearing, as indicated in the figure labels. Furthermore, there was no obvious hardness gradient as might be expected for a surface hardened component. It is therefore likely that the bearing was throughhardened. There was no obvious reason for the anomalously low HV point at a depth of about $83 \mu \mathrm{m}$ in Fig 1001GR02, but microscopy revealed a rumpled region of upset material around the impression, suggesting the presence of a single 'soft-spot' in the microstructure. Two other indentations placed at the same depth below the surface failed to display this low HV.

When the cross-section was acid-etched (see Figure 10010M09), the reasons for the variations in hardness become clear. On some regions just below the surface, there was a very highly-deformed whiteetching layer attached (see Figures 1001M11 to M14). The average and standard deviation in HV (100 g) for those white regions were 932.5 and $36.5 \mathrm{~kg} / \mathrm{mm}^{2}$, respectively, while the more heavily etched substrate below the white region had an average and standard deviation of HV of 488.2 and $9.67 \mathrm{~kg} / \mathrm{mm}^{2}$, respectively. Work-hardening during plastic shear of the near-surface material therefore produced a material with nearly twice the original bulk hardness, but these hard, near-surface areas were not always present and they also varied in thickness. The lack of a hardness gradient in Figure 100GR02 is because the profile was not near a deformed region. [Also note that the HV in 1001GR02 was obtained at a load of 
25 grams, not the 100 gram used to sample the near surface regions. As Figure 1001GR01 shows, the hardness as a lighter load, tends to he higher.]

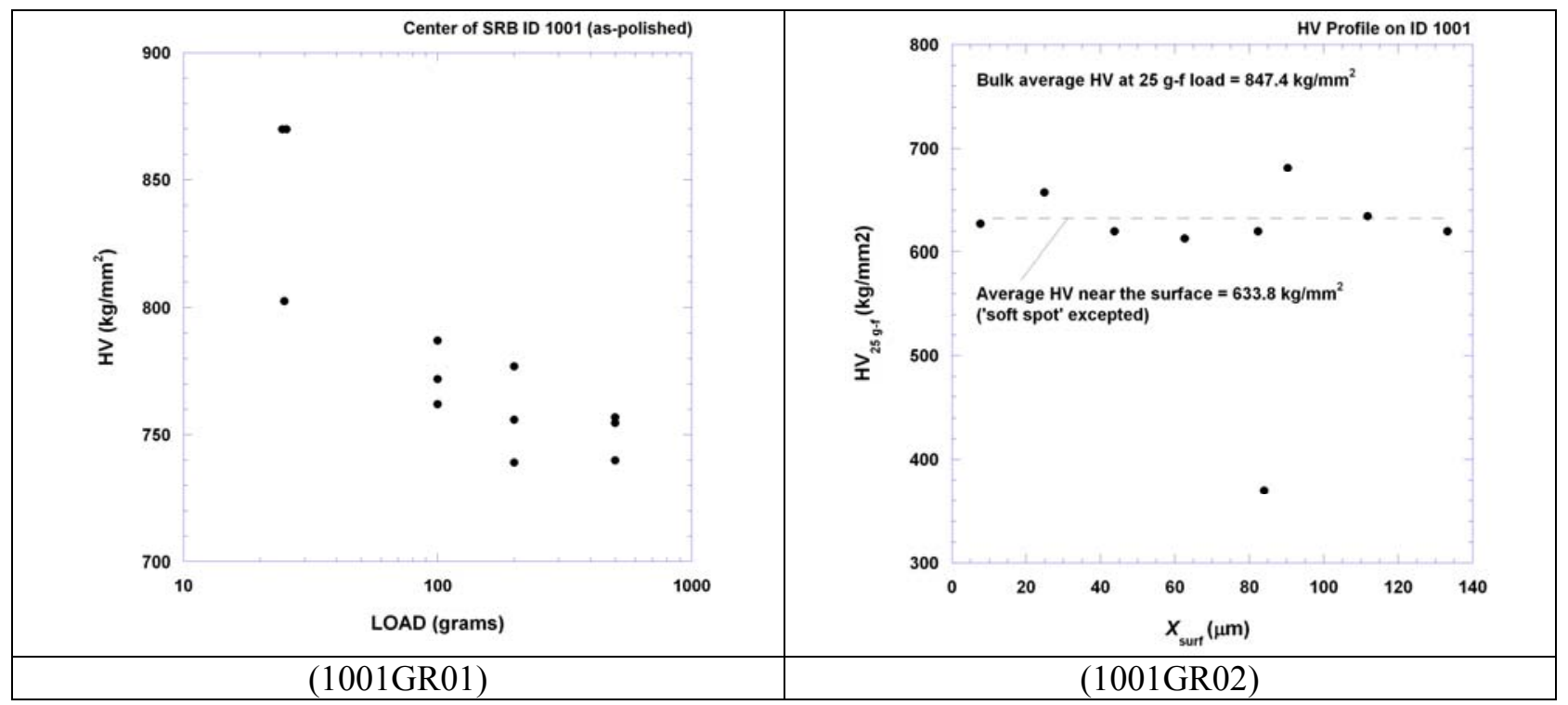

Captions / notes:

(1001GR01) Plot of HV versus load for a bulk area on an SRB roller.

(1001GR02) Plot of HV profile ( $25 \mathrm{~g}$-f load) well away from white layer.

The fact that lighter-etching zones had increased deformation was demonstrated using low load (25 g-f) Vickers indentations near a Rockwell C indentation [see Figure (1001OM22) for an image of the microindentations]. As shown in Figure (1001GR07), the lighter etching regions adjacent to the Rockwell impression are harder than the surrounding, darker-etching matrix. In addition, the hardness of the lighter-etching regions near edges the Rockwell C impression is similar to that of white-etching regions at the surfaces of the worn bearing surfaces, particularly when the effect of applied indenter load on hardness number is taken into account. Compensating for the effects of hardness on HV, as shown in Figure 1001GR01, the hardness of the area near to Rockwell impressions at $100 \mathrm{~g}$-f load would be about $8 \%$ lower than that obtained at $25 \mathrm{~g}-\mathrm{f}$ load, so the peak valves of $\sim 1000 \mathrm{~kg} / \mathrm{mm}^{2}$ (as shown in 1001GR07) would be reduced thusly: $(1000 / 1.08)=926 \mathrm{~kg} / \mathrm{mm}^{2}$ for a $100 \mathrm{~g}$-f load. This value compares favorably to the average $\mathrm{HV}$ of white layers $\left(\mathrm{HV}_{100 \mathrm{~g}-\mathrm{f}}=932 \mathrm{~kg} / \mathrm{mm}^{2}\right)$. 


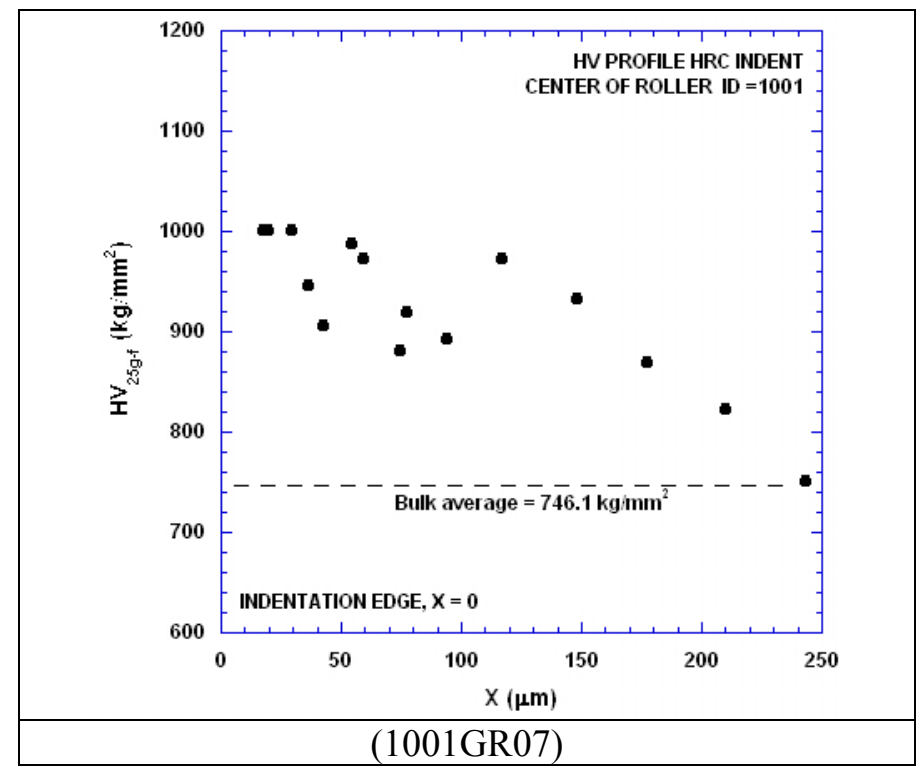

Caption: (1001GR07) Plot of HV versus distance from a Rockwell hardness impression.

17) Dimensional measurements.

\section{1) Coordinate measuring machine data}

An EMD Legend ${ }^{\mathrm{TM}}$ Coordinate Measuring Machine (CMM) was used to scan the circumference of a highly-worn spherical rolling element from the overloaded side, and one that was obtained from the opposite complement of 16 spherical rollers that showed much less surface damage. Figure 1001SP01 shows its variation in diameter. By contrast, Figure 1001SP02 shows the much larger variation in diameter (lobing) of the heavily worn roller. Note the larger scale on the tolerance circles on the lobed roller, reflecting is greater magnitude in peak-to-valley undulations.

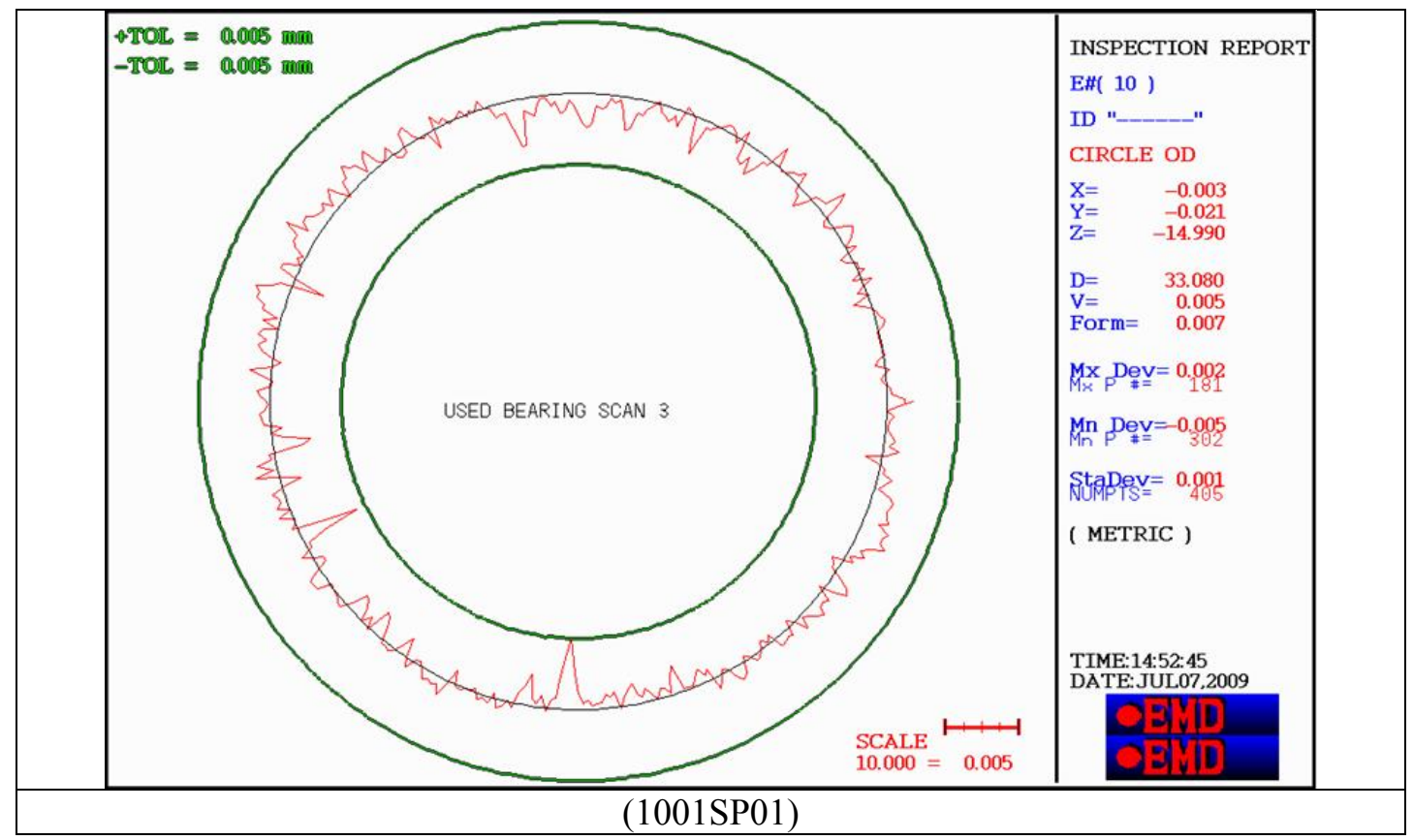




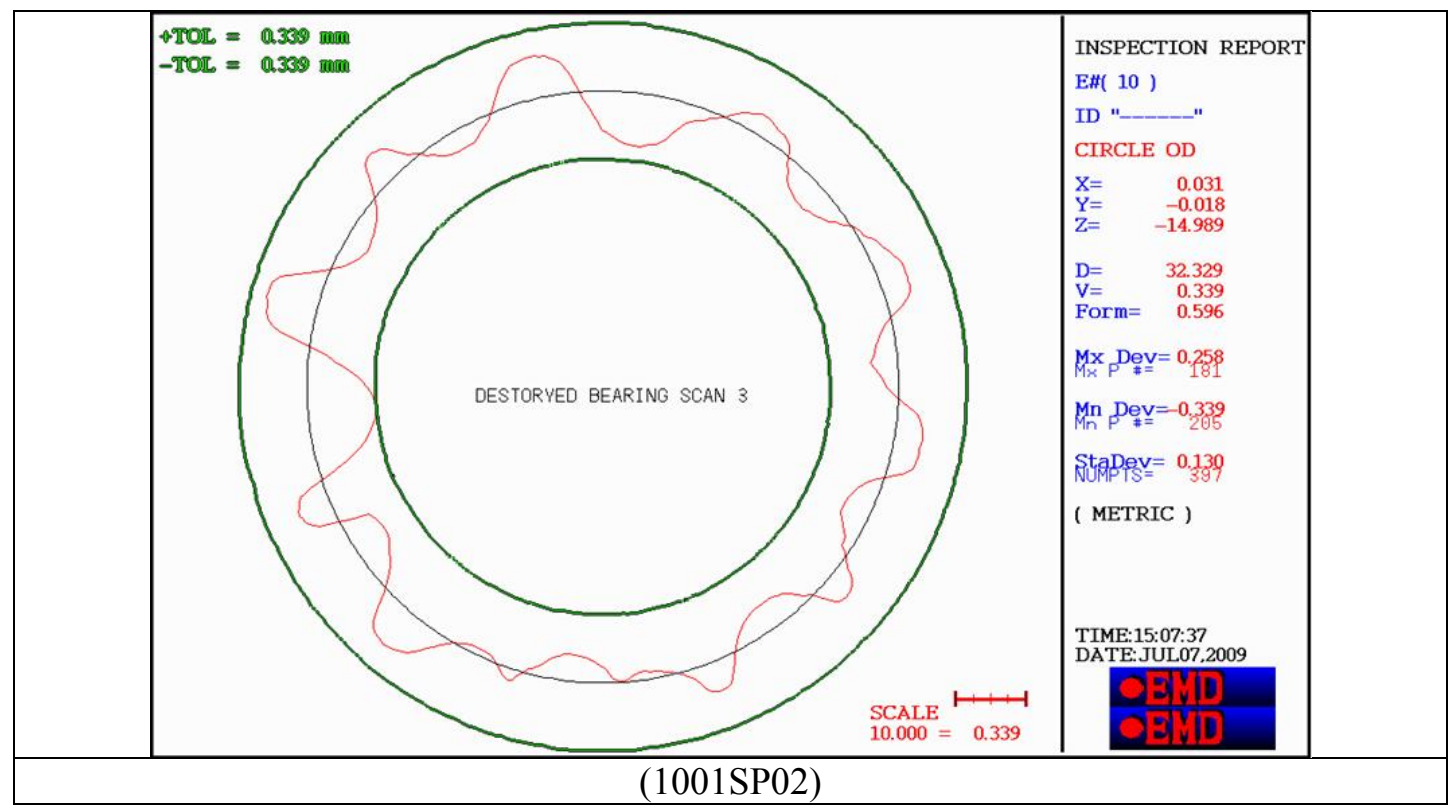

Captions / notes::

(1001SP01) Variation in height of surface features around a SRB sustaining minor damage.

(1001SP02) Undulations in the circumference of a SRB that sustained major plastic deformation.

\section{2) Stylus roughness traces.}

Stylus roughness traces of a highly worn SRB roller and a less-worn roller were obtained using a MahrSurf XR20 profiling unit with diamond stylus of $2.0 \mu \mathrm{m}$ tip radius, and $5.6 \mathrm{~mm}$ stroke. Data collected per stroke: 112000 points, with a $0.8 \mathrm{~mm}$ cut-off length. Figure 1001SP05 indicates a typical trace showing several indentations.

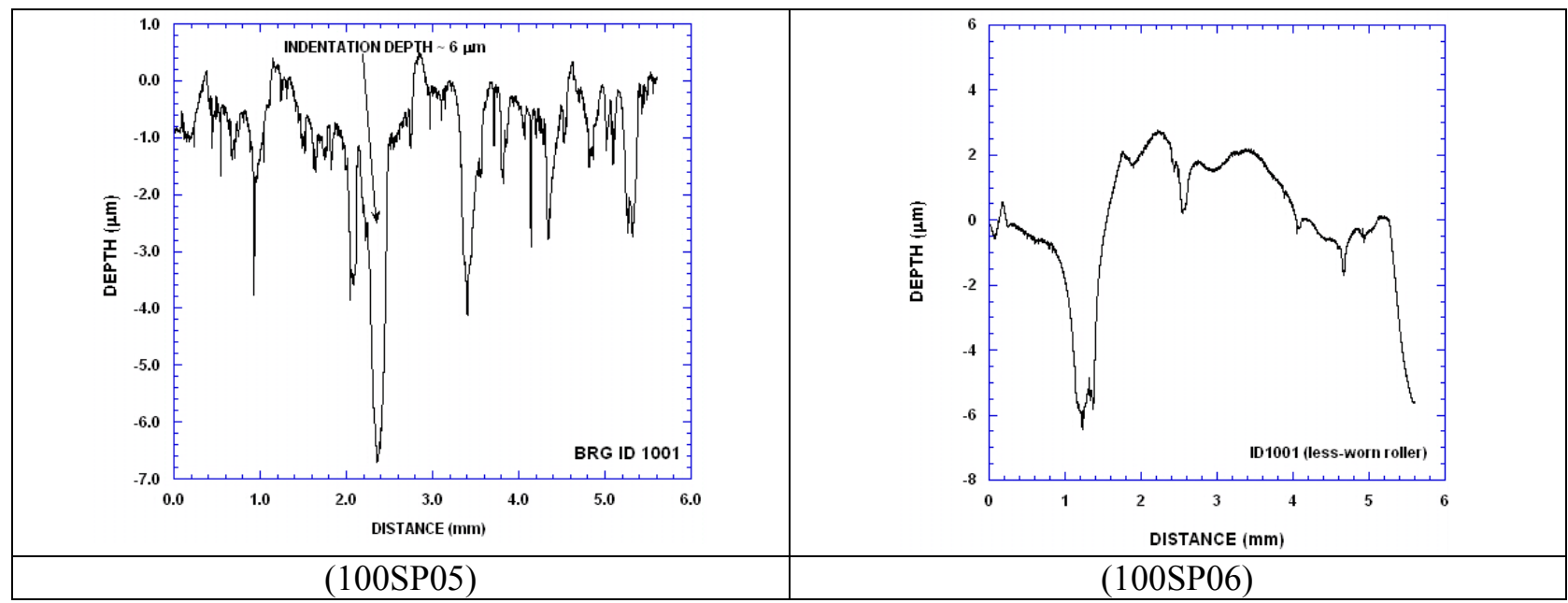

Profile captions / notes:

(1001SP05) Stylus trace along the surface of a worn roller. The trace direction is parallel to the axis of rotation and near the apex of the crown of the roller. 
(1001SP06) Stylus trace along the surface of a less-worn roller. The trace direction is parallel to the axis of rotation and near the apex of the crown of the roller. Note that the profile is smoother and the edges of the indents are more rounded.

\section{3) Vertical Scanning Interferometry}

Vertical scanning interferometry (VSI) 3D images were also obtained using a Wyko Model NT9100 system. Images were generated by progressive scanning of a selected region at steps in the vertical axis and post-processing of the data to construct three-dimensional representations of surface features with color coding of the feature heights. In the less worn rolling elements, the shallower indents, due to hardened wear particle crushing and embedment, were less than $1 \mu \mathrm{m}$ deep and the deepest were about 3 $\mu \mathrm{m}$ deep. Figures 1001SP03-04 show typical 3D VSI reconstructions of indented areas on the circumference of a SRP. Note the faint (blue) scratches in the lower center of image 1001SP03. They run in the circumferential direction of the roller.

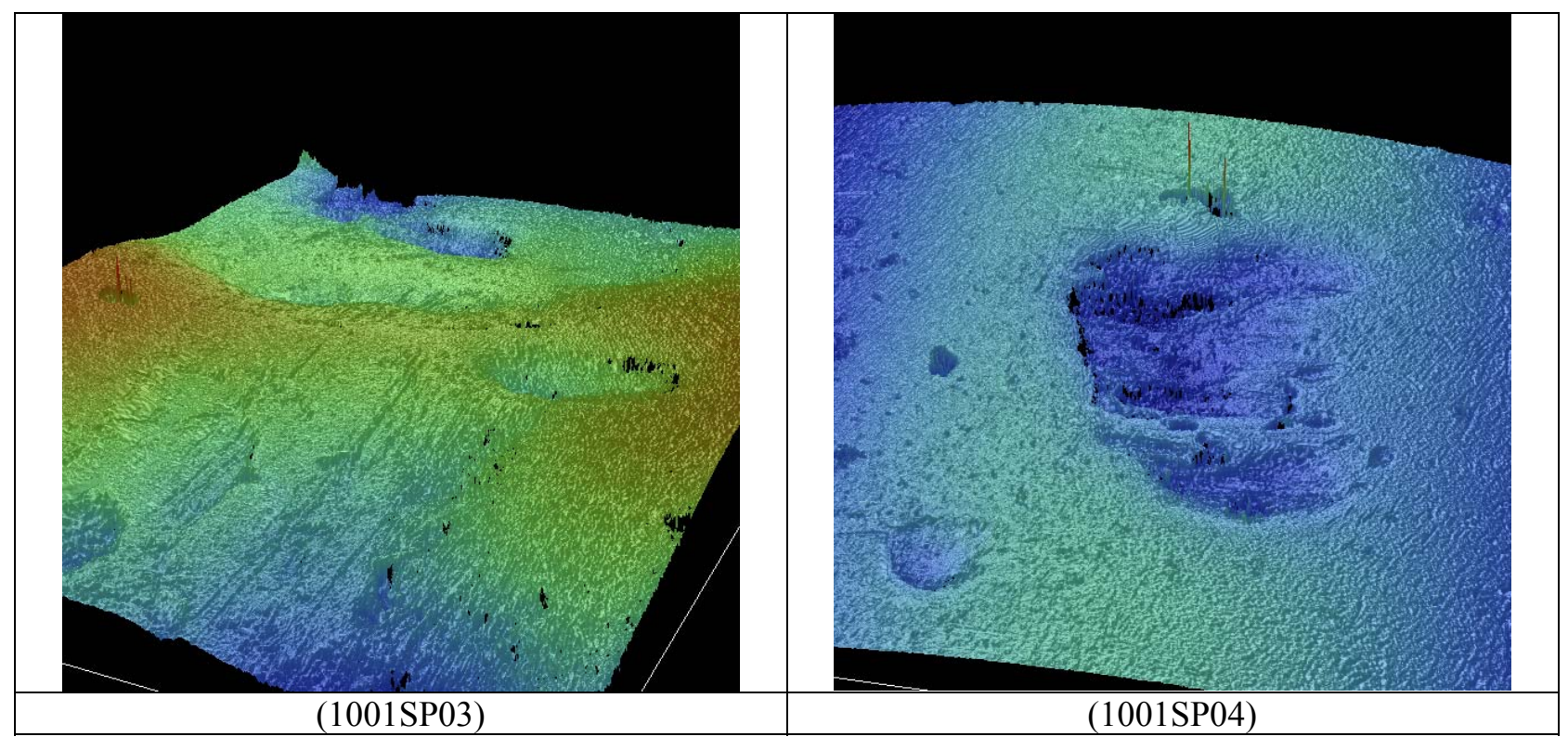

Photograph captions / notes:

(1001SP03) 3D map of indents on the surface of a less-worn bearing. The area of analysis for this scan is approximately $0.878 \mathrm{~mm}$ long x $0.657 \mathrm{~mm}$ wide. Depressions measured about 2-6 $\mu \mathrm{m}$ deep. The highest point to the lowest point on the entire figure (z-direction) is $40 \mu \mathrm{m}$.

(1001SP04) 3D map of a relatively large indentation in the curved surface of the less-worn bearing. The area of analysis for this scan is approximately $0.878 \mathrm{~mm}$ long $x 0.657 \mathrm{~mm}$ wide. Its depth is $\sim 6 \mu \mathrm{m}$.

18) Surface chemical analysis

Deep impressions in the surfaces of the severely damaged rolling elements were examine in a Hitachi S3400 environmental scanning electron microscope with backscattered imaging (BSE) and energy dispersive $\mathrm{x}$-ray chemical analysis (EDX). The accelerating voltage was $15 \mathrm{kV}$ and the working distance was approximately $12 \mathrm{~mm}$. One problem, when conducting surface chemical analyses, is that the bearing components were not protected from ambient exposure during storage and shipment. Therefore, it cannot be definitively stated that the detected trace elements came from the bearing alloy or the lubricant. They 
could also have come from external contaminants. Therefore, only one example will be shown of such analysis.

The first image presented below is a BSE image of a relatively large spalled area (1001EM01). Atomic number contrast causes heavier elements, like iron and copper, to appear brighter in the image.

Conversely, oxides and organic residues containing carbon, appear darker. The figures that follow the BSE image are EDX maps of the same area and at the same magnification. They were obtained by accumulating signals of specific characteristic x-ray energies for more than 30 minutes on the same area. Maps are shown for iron $(\mathrm{Fe})$, oxygen $(\mathrm{O})$, silicon $(\mathrm{Si})$, carbon $(\mathrm{C})$, and copper $(\mathrm{Cu})$. Maps were also obtained for $\mathrm{Al}, \mathrm{Mn}, \mathrm{Zn}, \mathrm{Ca}, \mathrm{K}, \mathrm{Na}, \mathrm{Mg}, \mathrm{Ba}$, and $\mathrm{Cl}$, but are not shown here. In these long-counting-time maps, the brighter the area on the image, the higher the concentration of the given element. Darkest areas are depleted in the element being recorded. Relative to the areas surrounding the spall, the Fe in the bottom of the spall is depleted. That low area could be filled with lubricant residues or wear debris from elsewhere in the bearing. $\mathrm{O}$ is concentrated in the granular deposit in the upper right-hand corner of the depression and is probably associated with oxides. Si seems localized into a few bright particles which also indicate oxygen. Therefore, they may be silica. C is located at the upper left of the spall, suggesting an organic constituent. It is too large to be a carbide from the microstructure of the alloy because the carbides are typically round and micrometer-sized. The copper may have come from the bronze bearing cage, but patterns on an EDX map for zinc did not correspond one-to-one with the bright spots for copper, suggesting a different source than the cage. 


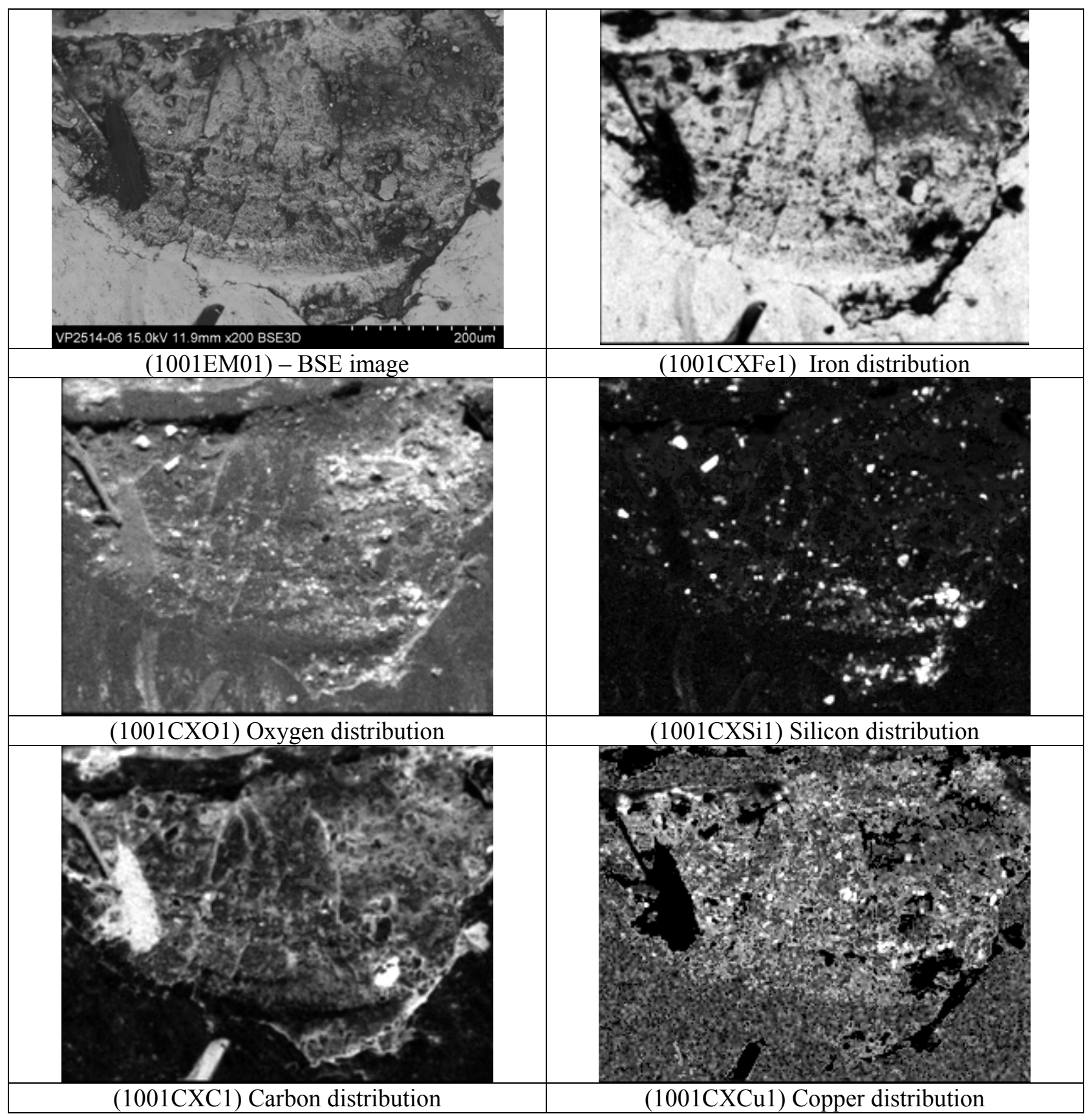

\section{9) Summary of analysis}

Rolling elements from a double-row, spherical roller bearing (SRB) assembly (ID 1001a) displayed clear indications of overload in the axial direction. A variety of surface damage features included (a) smearing of material by plastic shear deformation, (b) spallation from rolling contact fatigue, (c) roller and race indentations from wear particles, (d) particulate material transfer, and (e) gross, macroscopic scalloping (lobing) of the roller circumference from severe, periodic radial and axial over-loads that exceeded the elastic limit of the roller-on-race contact. 
Failure of this bearing was accompanied by breakage of the retainer on the row of rollers that faced in the direction of the high axial load, allowing the sixteen rollers in the ring to become loose. These rollers exhibited a variety of pits, spalls, fatigue markings, delamination, and subsurface cracking. At least of half of the loosened rollers exhibited relatively deep lobing, with depressions spaced periodically around the roller's equator.

Rollers in the ring that was inclined away from the direction of application of the high axial load remained largely intact, and exhibited much less damage, appearing shiny. Shallow dents in these lessdamaged rollers may have come from hardened debris particles or from particles of silica that were detected on surfaces using x-ray composition mapping. It is not clear whether these angular silica particles (from 1 to over $20 \mu \mathrm{m}$ across) were picked up before or after the bearing was removed from the gearbox. Therefore, their role in the initial failure process is not established. While the silica particles seem to have collected in surface depressions (spall pits), the same type of particles were not observed to be embedded in the crowned areas, so it is possible they were either in a residue from the used lubricant or they were picked up during post-removal bearing storage or transport. There were a few short, incidental scratches on roller surfaces, probably from wear particles that were momentarily caught between the roller and the race or separator.

The highly-damaged rollers were examined in polished cross-sections. Chemical etchants were selected to reveal various features in these sections. Macro and micro-hardness data were also obtained across the diameters of the rollers and near selected features below the worn surfaces. Etching studies with two different mixtures (5\% Nital and Ralph's Etch) revealed no indications of a case-hardened layer, suggesting that the rollers were through-hardened. Highly-smeared near surface regions were associated with shear deformation (smearing), and appeared as non-etching "white" layers that varied in thickness from zero to tens of micrometers deep. In some cases, material flow lines and branched microcracks were observed within the highly-deformed white layers. The Vickers microindentation hardness of white layers was approximately twice that of the underlying material. The steel was not chemically analyzed, but appeared to consist of tempered martensite with micrometer-sized, rounded carbides.

Hard fragments of cold-worked alloy, fractured from the white layers, could have resulted in the denting of the bearing surfaces on both the highly-worn and less-worn rollers. Such dents were as deep as 6-7 $\mu \mathrm{m}$ on the highly-damaged rollers and only about 3-4 $\mu \mathrm{m}$ deep on the less worn rollers. The dents on the less-worn rollers were also rounded at the edges, suggesting that subsequent rolling had smoothed the indentations. The absence of circumferential scratches on the less-heavily damaged rollers in the second ring, and their brightly-polished appearance in some places, suggested the absence of significant twobody abrasive wear (from embedded fragments in the counterface), but rather a gradual burnishing type of material removal.

X-ray mapping of the surface of a damaged roller revealed a variety of elements and suggests the presence of abrasive particles, like silica that could have scratched the bearing surfaces. However, since the rolling elements were exposed during handling and shipping, the origins of the elements collected in surface features cannot be determined with a high degree of certainty.

Most likely, the major damage resulted from an axial overload on the bearing from one direction, causing the acceleration of rolling contact fatigue, plastic smearing, and vibrations due to rolling element lobing. Hardened, heavily cold-worked wear particles from the heavily damaged bearing complement found their way to the second ring, producing debris denting, transfer of metallic particles, and incidental scratches. The cause for the axial overload should be investigated from operating data, which was not currently available.

20) Related analyses: See 2.2) ID1001b (inner race), 2.3) ID 1001c (outer race) 


\subsection{SPHERICAL ROLLER BEARING - INNER RACE}

\begin{tabular}{|l|l||l|l|}
\hline 1) Record number & $1001 \mathrm{~b}$ & 2) Source/Contact name & NREL/JJohnson \\
\hline $\begin{array}{l}\text { 3) Date rec'd } \\
\text { (yyyymmdd) }\end{array}$ & 20081230 & $\begin{array}{l}\text { 4) Turbine mfr (site } \\
\text { locale) }\end{array}$ & Micon 750 (Ponnequin farm, \#19) \\
\hline 5) Bearing mfr. & SKF & 6) Part cat. number or ID & $\begin{array}{l}\text { 22322 E (specs are available on- } \\
\text { line at: <www.skf.com>) }\end{array}$ \\
\hline 7) Bearing type & DR/SRB & $\begin{array}{l}\text { 8) Gearbox type / brg } \\
\text { location }\end{array}$ & Brooks and Hansen / high-speed \\
\hline $\begin{array}{l}\text { 9) Form of hardware } \\
\text { condition }\end{array}$ & FBS / LC & $\begin{array}{l}\text { 10) Specific component } \\
\text { type }\end{array}$ & Inner race \\
\hline
\end{tabular}

Notes: 1) Bearing types: $\mathrm{SR}=$ single row; $\mathrm{DR}=$ double row; $\mathrm{CRB}=$ cylindrical roller bearing; $\mathrm{TCB}=$ tapered cylindrical roller bearing, $\mathrm{SRB}=$ spherical roller bearing; $\mathrm{BB}=$ ball bearing; $\mathrm{ACB}=$ angular contact ball bearing

2) Specimen type: $\mathrm{FBS}=$ full bearing set; $\mathrm{RE}=$ rolling element, $\mathrm{OR}=$ outer race. $\mathrm{IR}=$ inner race, $\mathrm{SEP}=$ separator

3) Condition codes: $\mathrm{FB}=$ received as a fully-assembled bearing, $\mathrm{PD}=$ partially disassembled bearing, $\mathrm{LC}$

$=$ loose component (in tact), $\mathrm{BC}=$ broken piece(s) of a loose component, $\mathrm{X}=$ surface corroded, scratched, or otherwise marred when received

11) Construction Material and Condition: (Information not provided with the sample).

12) Lubricant and Method of Application: (Information not provided with the sample).

\begin{tabular}{|l|l|}
\hline 13) Running history & (unknown) \\
\hline $\begin{array}{c}\text { 14) Other description } \\
\text { of the component(s) } \\
\text { to be examined }\end{array}$ & $\begin{array}{l}\text { Description from the source: "One side of bearing (not marked as up or down } \\
\text { wind) is so badly damaged that the rollers were no longer caged. The cage } \\
\text { was completely ground up except for a single } 2 \text { mm wide ring of steel. The } \\
\text { rollers from this side were being dragged or skidded in the races (they were } \\
\text { not rolling). The other side of the bearing is in better condition, mostly } \\
\text { denting from debris on the rollers and races. There is severe fretting } \\
\text { corrosion on the OD of the outer race." }\end{array}$ \\
\hline
\end{tabular}

15) Photographs of components.

15.1) Digital camera images. 


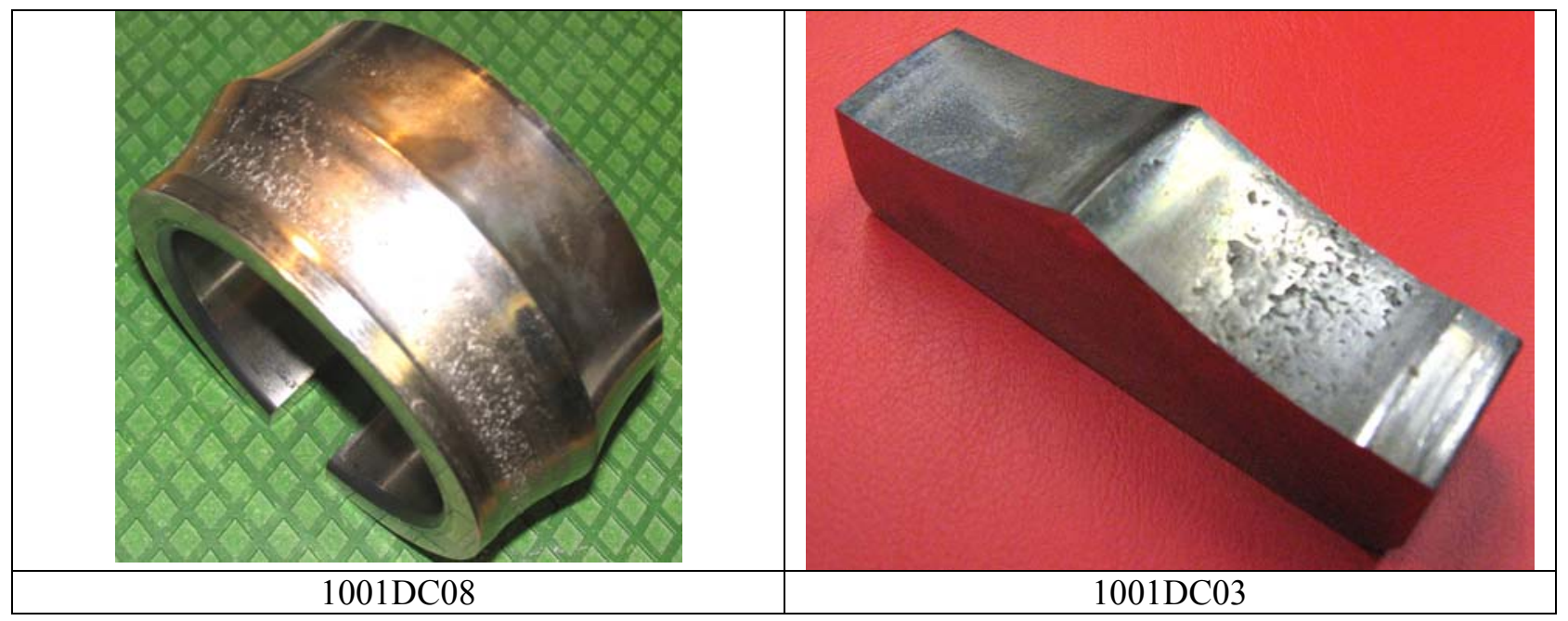

Photograph captions / notes:

(1001DC08) Inner ring showing where a slice was removed. The slice is shown in (1001DC03).

(1001DC03) Section of the inner race with more wear on one side than the other. The width of the cutout section is $20 \mathrm{~mm}$, its length is $80 \mathrm{~mm}$, and the height at the peak is $24 \mathrm{~mm}$.

A diagram of the zones and types of damage on the inner race is presented in Figure (1001SK02).

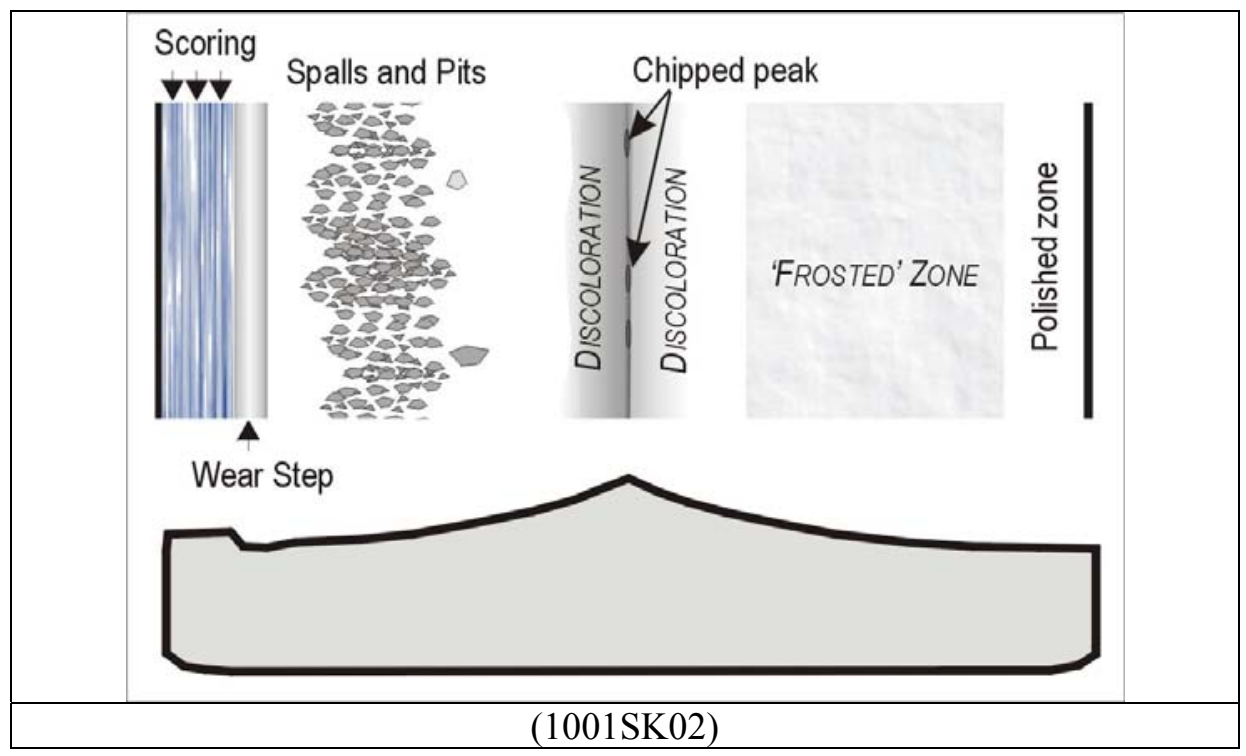

\section{2) Macroimages of surfaces. (Light optical)}

Images were obtained using a Nikon macro-zoom microscope. As shown in 1001DC03, one side of the race was rougher-appearing than the other and this is also evident in macro-scale images. The more damaged side was rife with pits, spalls, and smeared material, as well as a pronounced ridge near the outside edge. The less damaged side revealed considerable embedment of metallic fragments. 


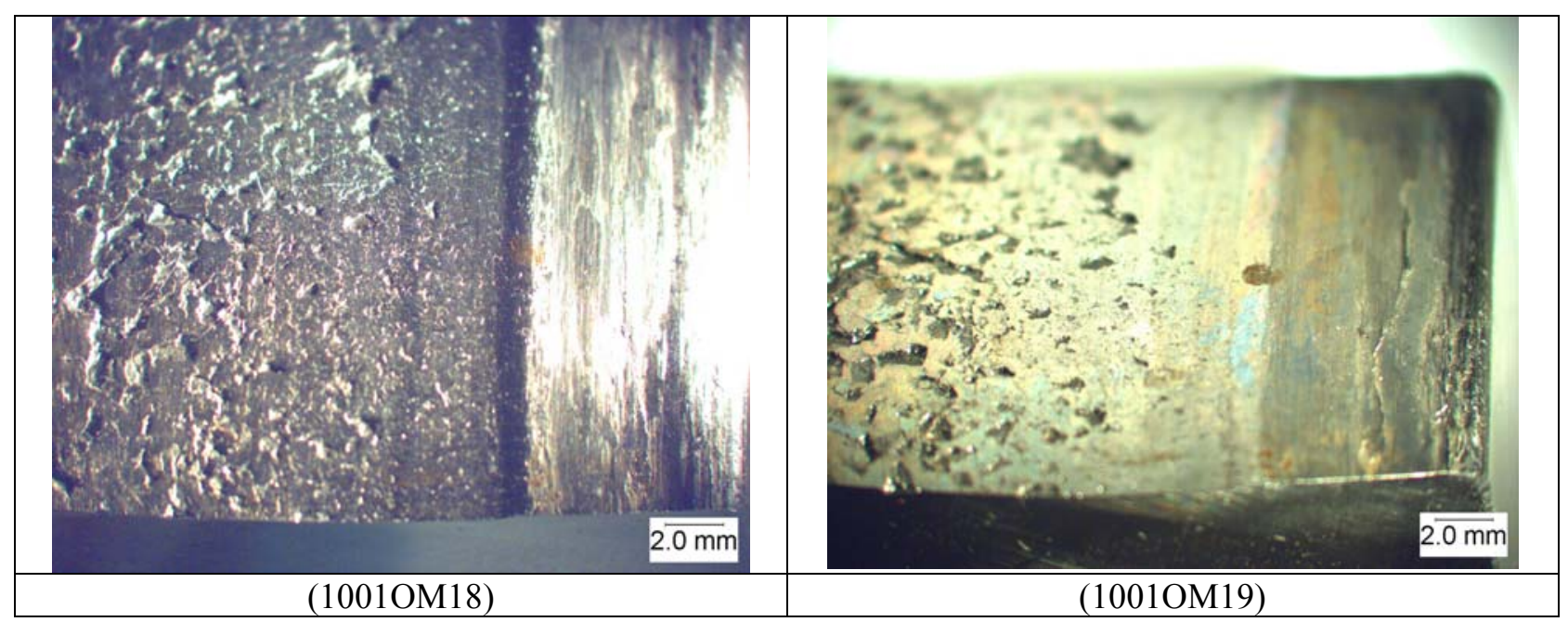

Photograph captions / notes:

(1001OM18) MacI of the deep ridge on the inner race, about 5-6 mm from the outer edge. Evidence for sliding in the circumferential direction is apparent (vertical flow lines on the right-hand third of the image suggest severe metallic wear) outboard of the wear step. At the left, there is obvious pitting and spalling. Image 1001OM19 shows an enlarged view of the area at the left of the image.

(1001OM19) Tilted view of the same area as 1001OM13 showing the wear step and a 'flap' of sheared material (to the left and above the scale bar) that indicates severe deformation near the edge of the contact.

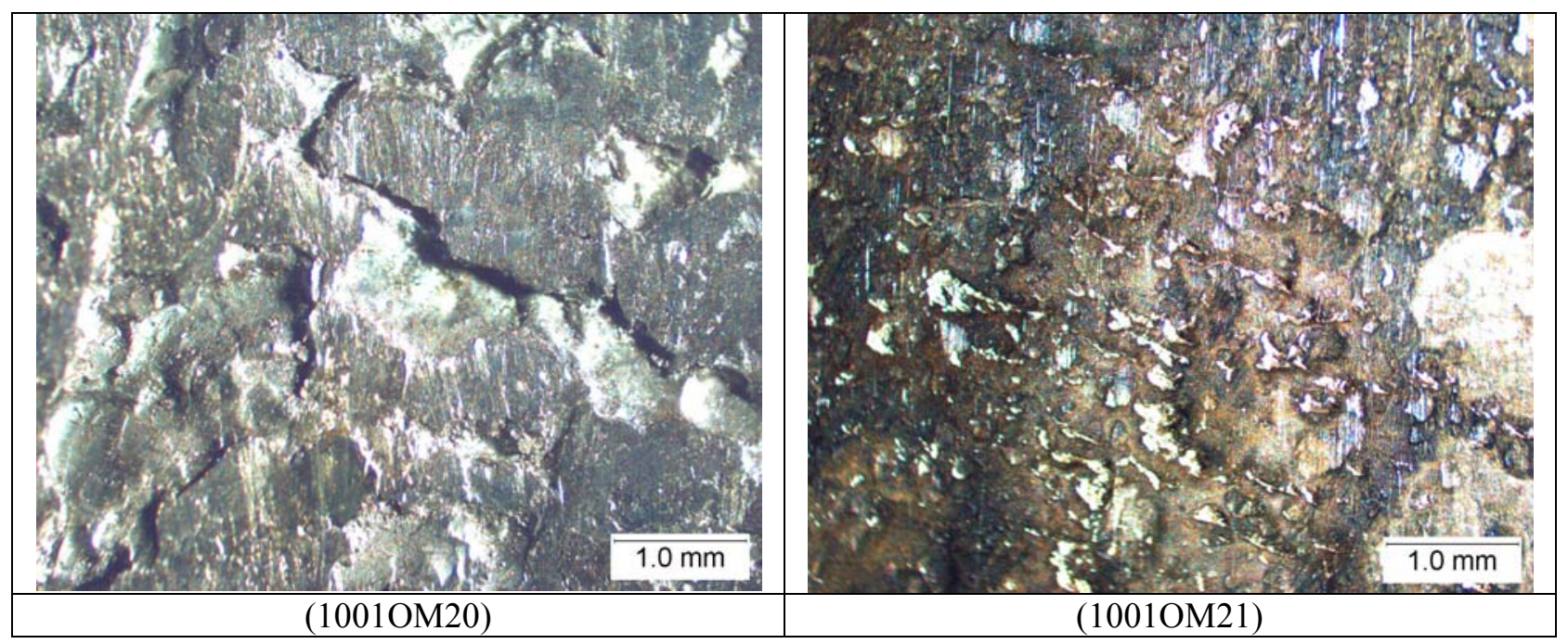

Image captions / notes:

(1001OM20) MacI of the damage on the inner race that showed more wear. Significant subsurface cracking and delamination of sheared material is expected in this area.

(1001OM21) Adhered, embedded fragments in the smoother-appearing inner race (by naked eye). Some were as long as $0.5 \mathrm{~mm}$, but others were less than $0.1 \mathrm{~mm}$ long. Evidence indicates two-body abrasion in the circumferential direction of the race, vertical in this image. 


\subsection{Polished cross-sections (Optical microscopy).}

A schematic diagram of the cross-section of the race shown in (1001DC03) is shown in Figure (1001SK01). This section was used for hardness tests and metallurgical studies. The more heavily worn side is indicated on the left of the cross section. The wear step is represented in the figure, and the dashed lines show the direction of the hardness profiles referenced from the contact surfaces toward the center shaft.

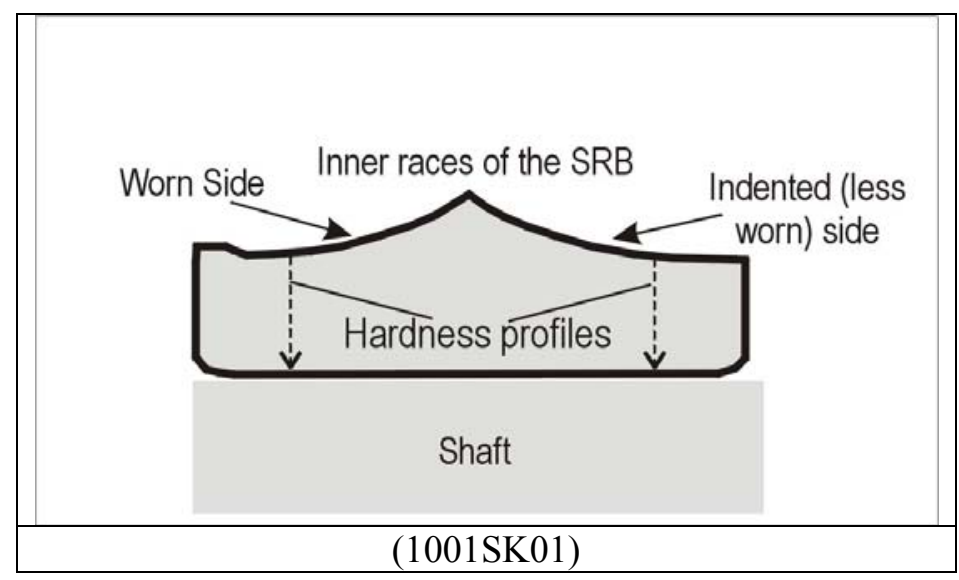

Below: polished cross-sections of the more heavily worn side of the inner race (left side of the schematic in (1001SK01), without etching.

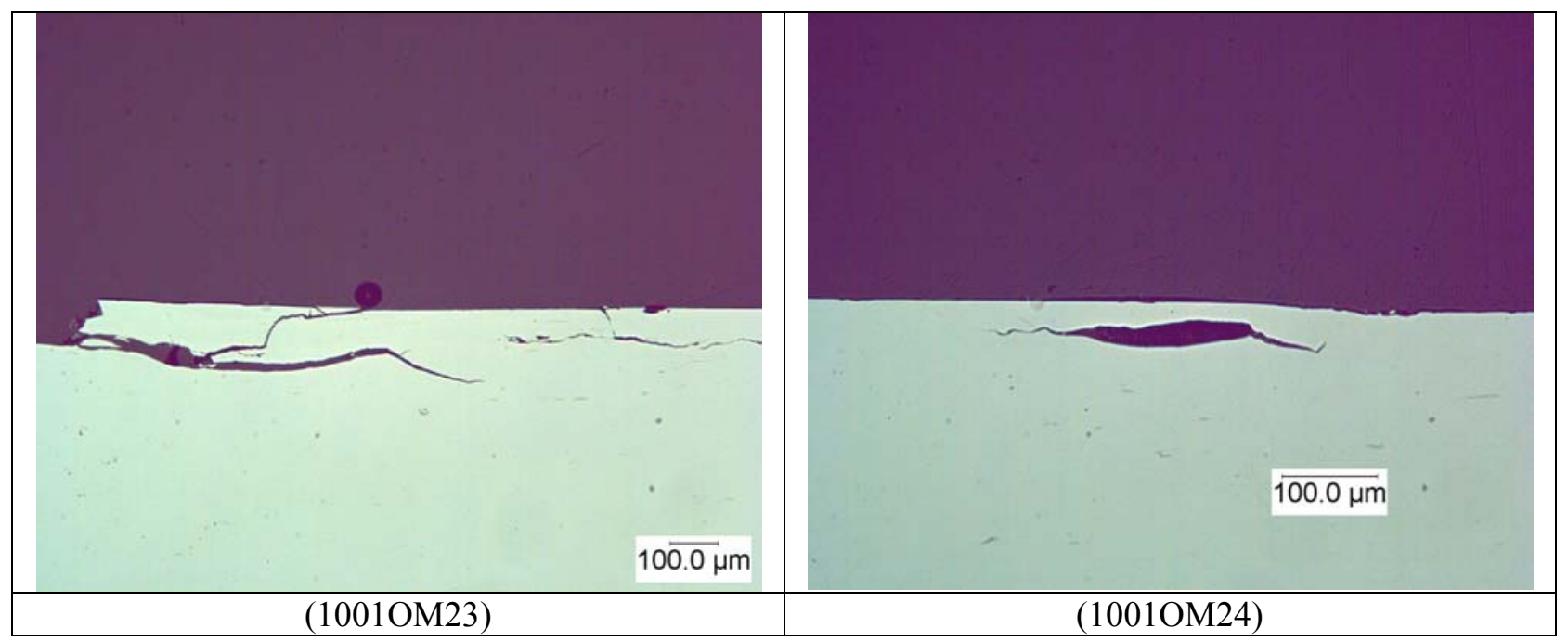

Image captions / notes:

(1001OM23) PXS showing surface material removal and subsurface cracks running approximately parallel to the load-bearing surface

(1001OM24) PXS showing nucleation and lateral propagation of subsurface cracks probably in the zone of maximum Hertzian (elastic) contact stress. Flexure of the material 'bridge' above the void probably drove the cracks outward at both ends.

Polished cross-sections of the less heavily worn side of the inner race, without etching. 


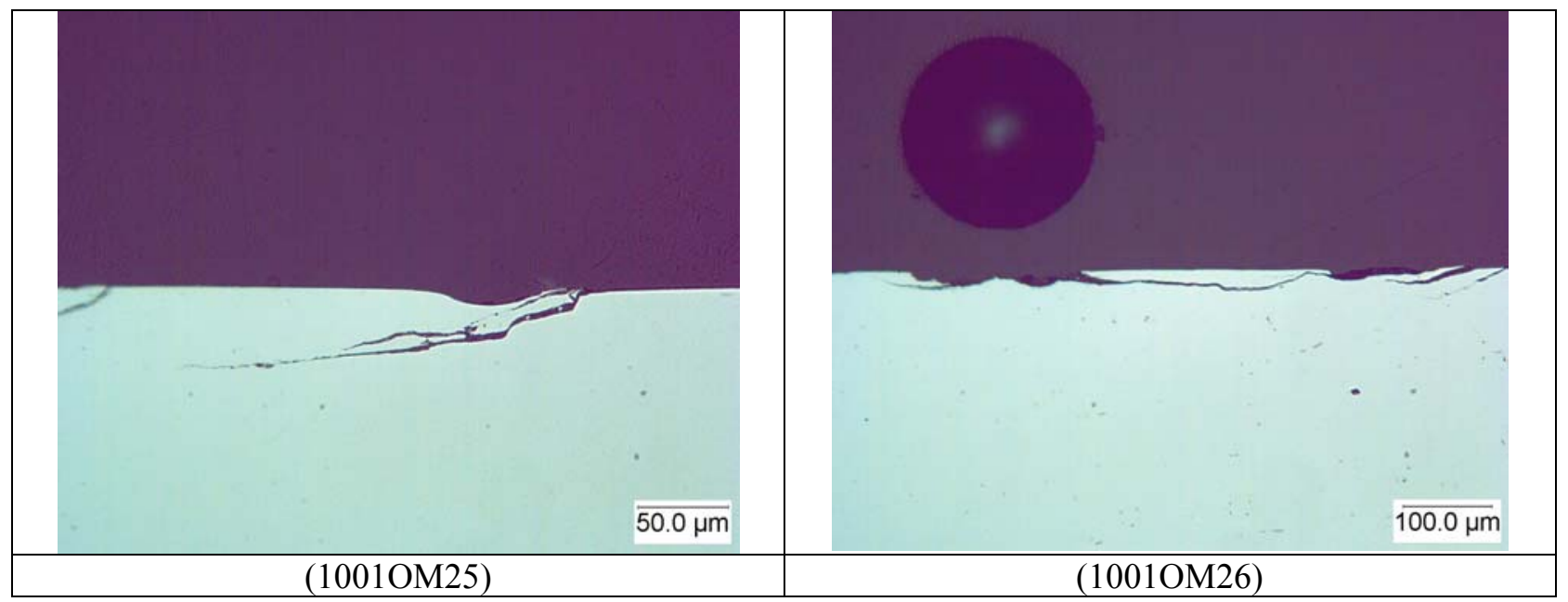

Image captions / notes:

(1001OM25) Surface-breaking cracks below a shallow debris indentation in the less-worn side of the race.

(1001OM26) Lateral propagation of subsurface cracks from high Hertz (elastic) contact stresses. The depth of the cracking was similar to the maximum depth of indentations on the race. One shallow platelet of material (across the center) appears ready to detach so as to form a pit.

Polished cross-sections were etched with Ralph's etch and re-examined. It was evident that the more worn side had extensive occurrences of white-etching layers. In contrast, the less-worn race had no white layers and only minor indications of micro-cracks. The latter were associated with small indentations, probably caused by hardened debris particles. Figure (1001OM27) shows the same region as the unetched surface in Figure (1001OM23) indicating that there was a highly-deformed zone, in some places approaching $100 \mu \mathrm{m}$ deep, and that the void with the dual micro-cracks was well within that white etching layer. A darker layer was immediately below the white layer. Microindentation hardness data, described in 14.2, indicated differences in hardness between layers of different etching characteristics.

White layers with plastic flow lines within them were also present at the surface of the wear step, indicating that severe sliding contact occurred there. These are shown in Figure (10010M28)

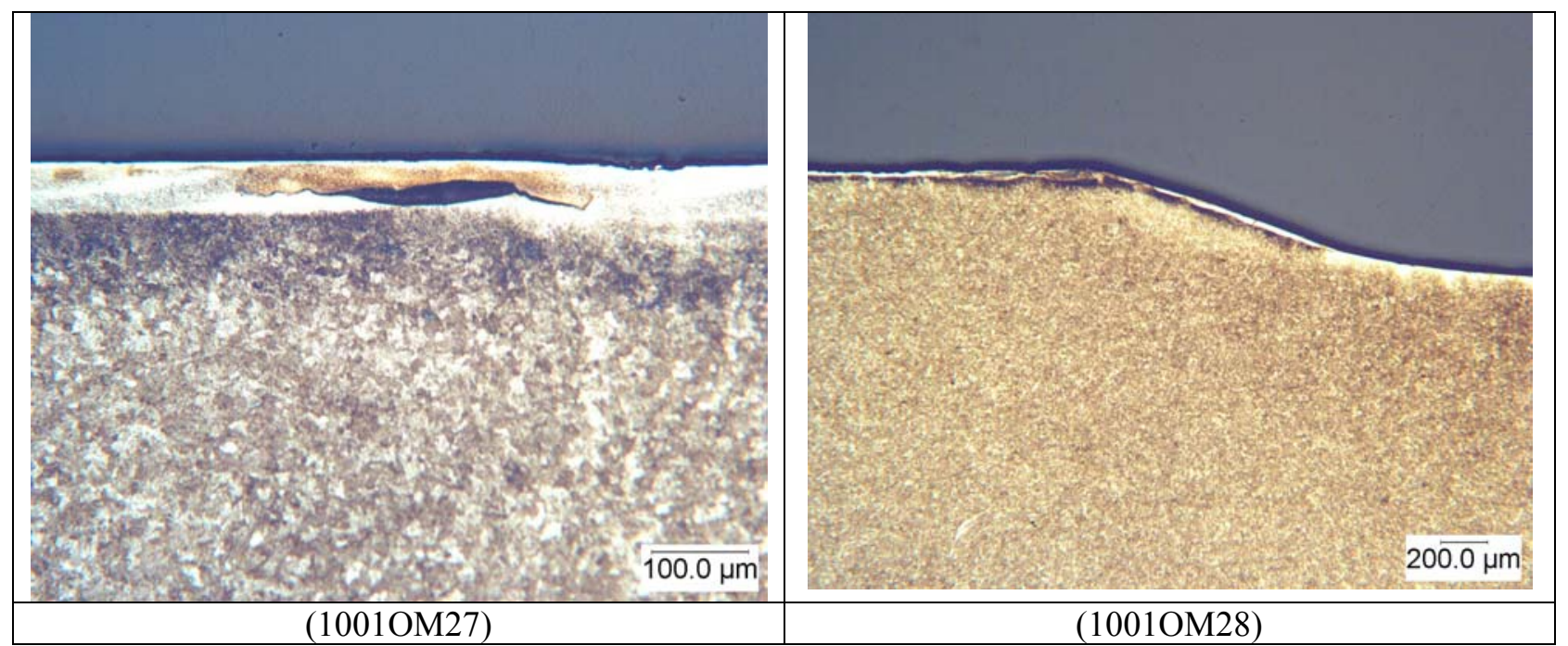


Image captions / notes:

(1001OM27) Etched area corresponding to the feature on 1001OM24

(1001OM28) White-etching layer on the side of the wear step and plateau region outboard of the wear step. An enlargement of the layer is shown in (1001OM29).

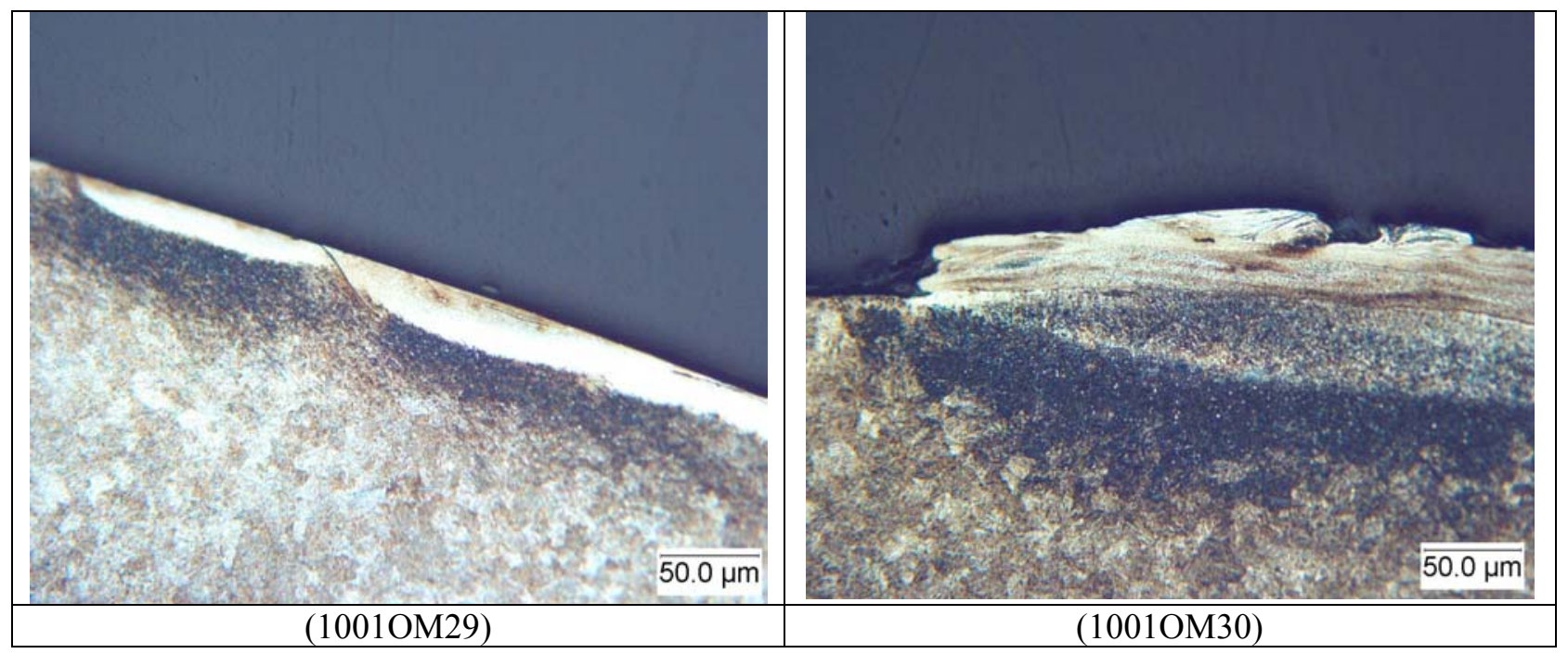

Image captions / notes:

(1001OM29) Higher magnification view of the flowed material shown in (1001M28).

(1001OM30) Adherent deposit on a flat zone outboard of the wear step. Several distinct microstructural zones are evident. The tip feature seemed to be adhered (transferred) material. Underlying that was a lighter gray zone of finer grain structure, and below that a quite dark zone. Finally, the grain structure of the bulk material is below the dark etching zone.

The less worn side of the inner race showed no evidence of white layers, but some of the shallow features associated with indentations were associated with micro-cracks. These microcracks were not nearly as long or deep as those on the more worn side (see below).

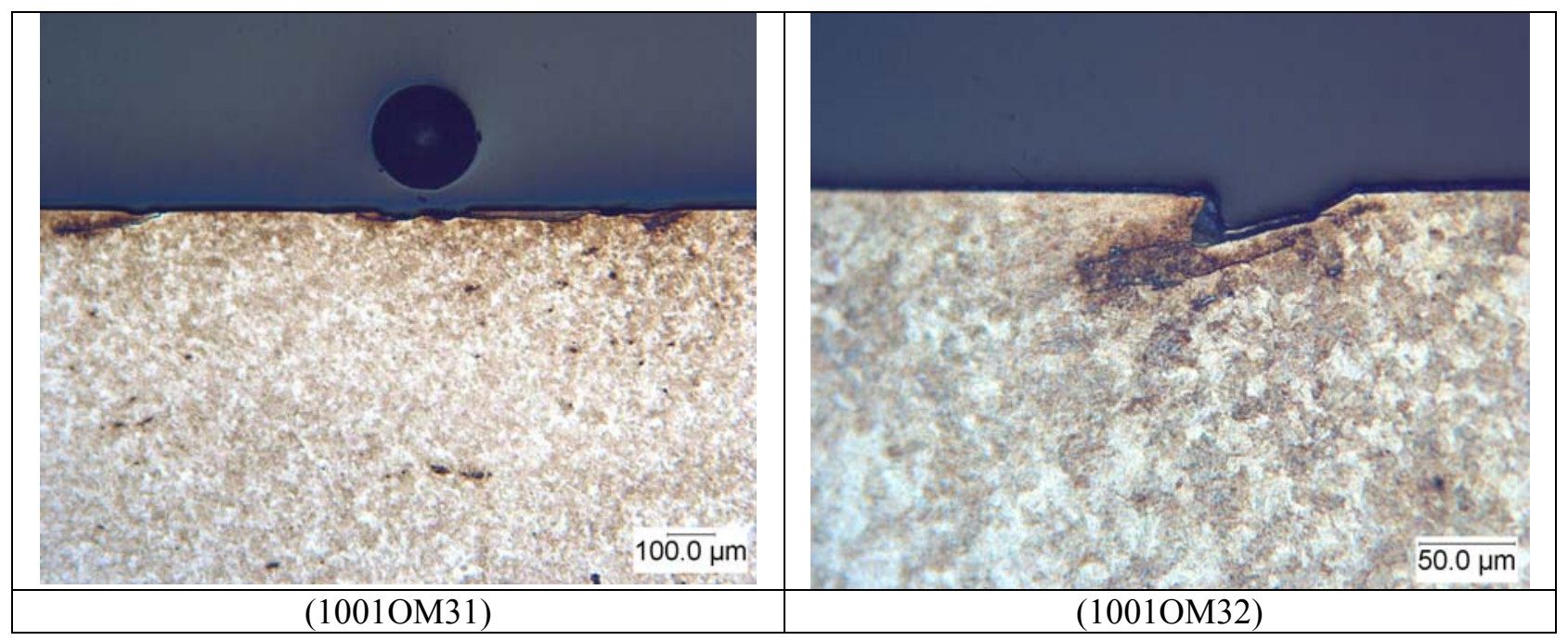

Image captions / notes:

(1001OM31) Etched area of the less worn race indicating some indenting, but no white layers. 
(1001OM32) Higher-magnification image of an angular debris indentation showing associated cracking parallel to the bottom of the feature.

16) Property measurements.

\section{1) Macroindentation hardness.}

The Rockwell C scale hardness on four places on the polished cross-section ranged from 57.9 to 59.1 with an average of HRC 58.3. This is similar to the HRC 59-61 range measured on the spherical rolling element. Localized hardness measurements described in Section 16.2, indicated differences in the nearsurface zones of the rolling elements and the races, so that the hardness of the material in the contact region between the races and the rolling elements is not necessarily reflected by data for the bulk alloys well away from the interface.

\section{2) Microindentation hardness.}

Using a Vickers indenter, hardness profiles at 100 gram load were obtained on polished, unetched crosssections in the directions shown in Figure (1001SK01). Two profiles, several millimeters apart were obtained below the more worn and less worn sides of the race. Results are plotted in Figures (1001GR03) and (1001GR04).

Average bulk HV (100g-f) of the ring material, below $5 \mathrm{~mm}$ from the bearing surfaces, was $673.9 \mathrm{~kg} / \mathrm{mm}^{2}$ for the worn side and $676.1 \mathrm{~kg} / \mathrm{mm}^{2}$ for the less worn side, an insignificant difference between the two sides. For all profile data below $5 \mathrm{~mm}$ from the surfaces on both sides ( 24 measurements), the average $\mathrm{HV}$ was $675.0 \mathrm{~kg} / \mathrm{mm}^{2}$ and the standard deviation of $\mathrm{HV}$ was $10.2 \mathrm{~kg} / \mathrm{mm}^{2}$.

The HV of the race relative to that of the rolling elements (see Record sheet 1001a) is compared in Table 1001b-1. Note that the center of the rolling element is approximately $100 \mathrm{HV}$ higher than the bulk material of the race and that the white-etching, smeared layers on the rolling elements was about $40 \%$ harder than the race. Therefore, abrasion and indentation of the race by fragments of detached white layers was likely and is consistent with observations.

Table 1001b-1. Comparison of Vickers Hardness of Bearing and Inner Race Materials from Bearing 1001.

\begin{tabular}{|c|c|}
\hline Location & $\begin{array}{c}\text { Average } \\
\text { HV }_{\text {100g-f }} \\
\left(\mathrm{kg} / \mathrm{mm}^{2}\right)\end{array}$ \\
\hline Center of rolling element & $773.6(12.6)^{*}$ \\
\hline $\begin{array}{l}\text { Near the outside surface of the roller and below the white-etching } \\
\text { zone }\end{array}$ & $488.2(9.7)^{*}$ \\
\hline In the white-etching zone of the roller & $932.5(36.5)^{*}$ \\
\hline Bulk material of the race & $675.0(13.4)^{*}$ \\
\hline
\end{tabular}




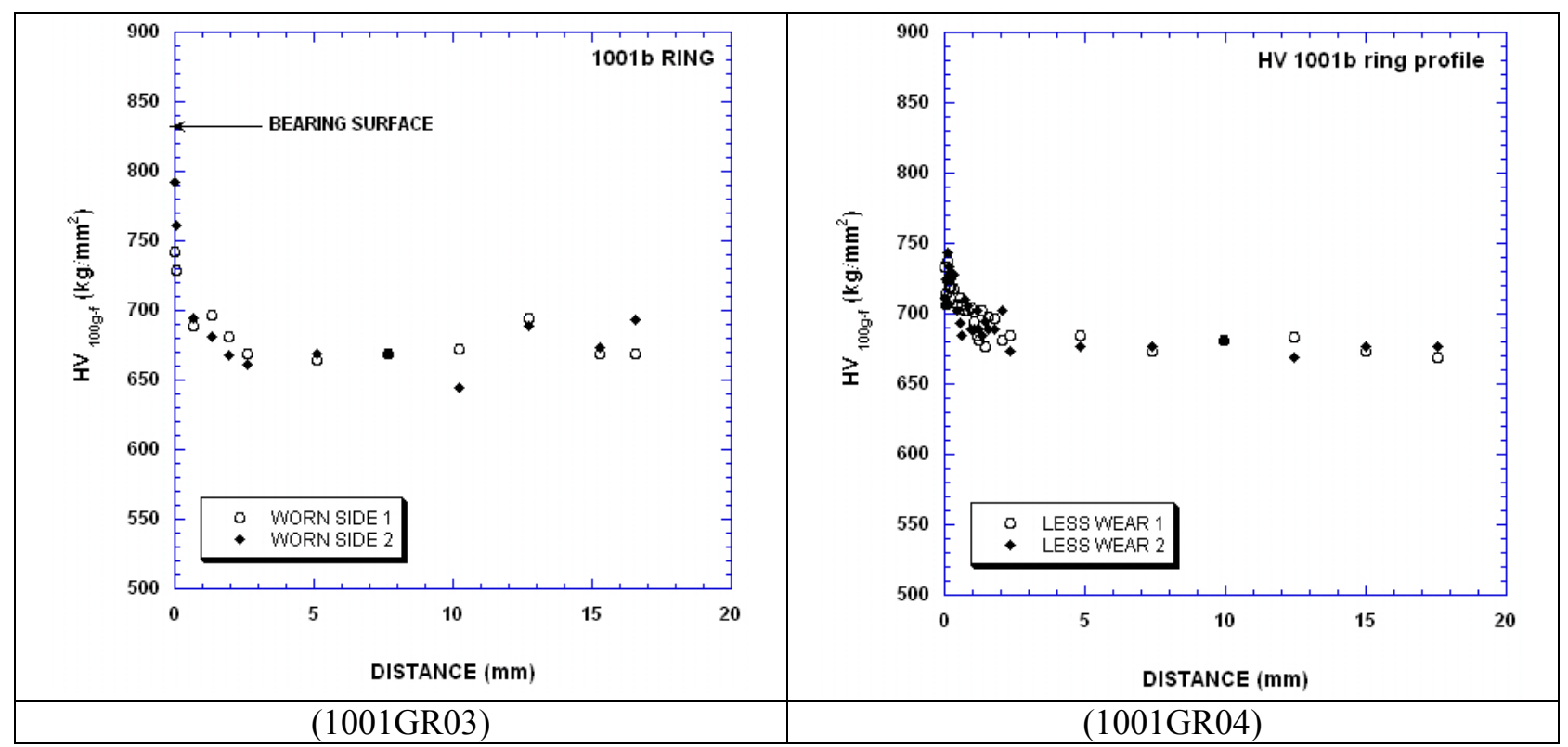

Graph captions / notes:

(1001GR03) Superimposed Vickers hardness versus depth traces below the surface on the more highly worn side. The hardness close to the surface is in the range 740 to $790 \mathrm{~kg} / \mathrm{mm}_{2}$, and the bulk valves are in the high $600 \mathrm{~s}$.

(1001GR04) Superimposed HV versus depth traces on the less worn side. The hardness close to the surface is in the range 710 to $740 \mathrm{~kg} / \mathrm{mm}_{2}$, and the bulk valves are in the high $600 \mathrm{~s}$. The hardness numbers nearest the surface are somewhat lower than those shown in (1001GR03). After these measurements, etching was done to reveal any microstructural differences of the near-surface materials.

For clarification, magnified plots of the areas closest to the surfaces in Figures (1001GR03) and (1001GR04), respectively, are shown in Figures (1001GR05) and (1001GR06). The slight increase in $\mathrm{HV}$ toward the surface begins at a depth less than about 1-1.5 mm. 


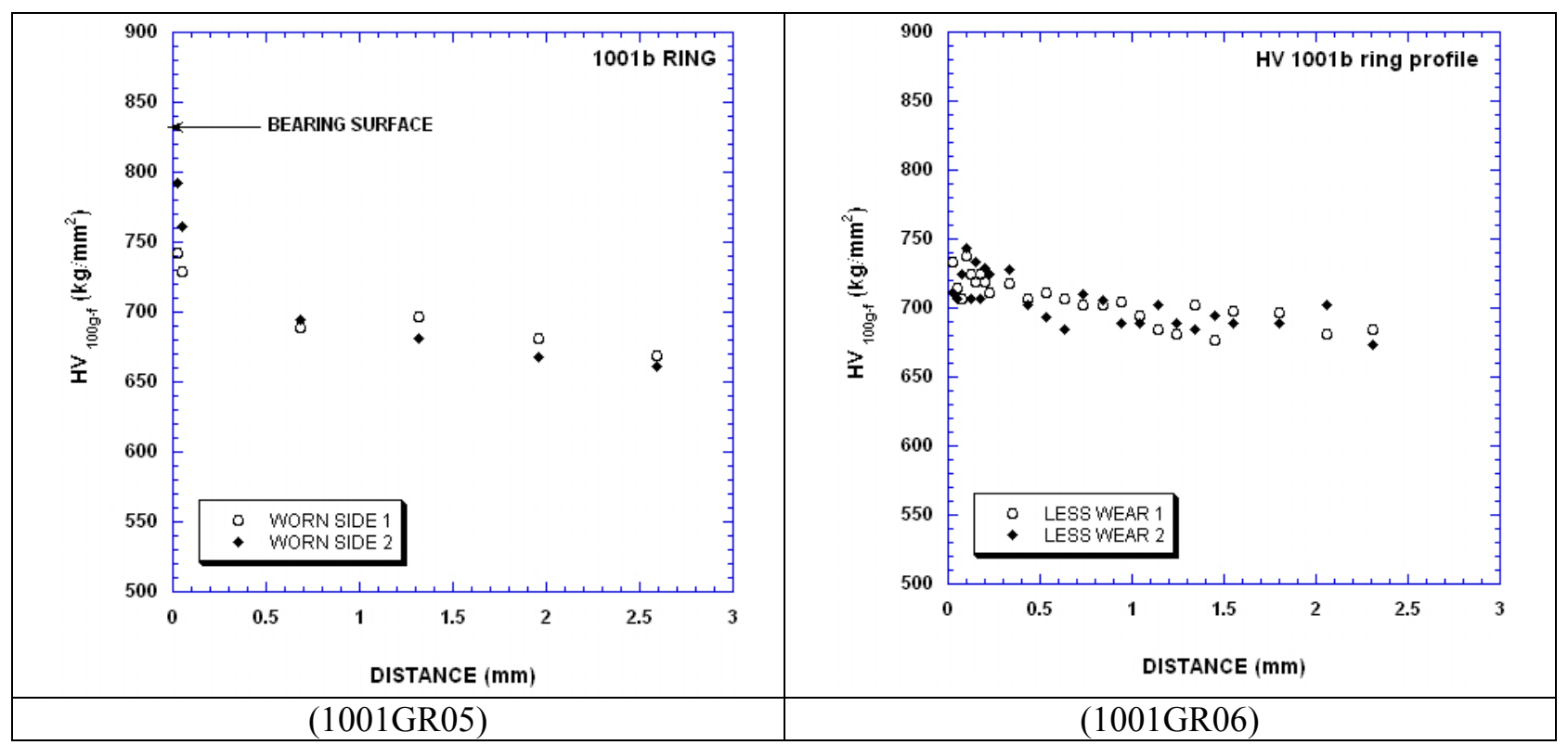

Graph captions / notes:

(1001GR05) Superimposed Vickers hardness versus depth traces corresponding to the first $3 \mathrm{~mm}$ of plot (1001GR03).

(1001GR06) Superimposed Vickers hardness versus depth traces corresponding to the first $3 \mathrm{~mm}$ of plot (1001GR04).

After polished cross sections were etched, the different microstructural regions became apparent, and further microindentation hardness tests were run. Table 1001b-2 summarizes those results. It was necessary to use a low load of $25 \mathrm{~g}$-f to ensure that the impressions were small enough to fit within the zones of interest in the microstructure. There was a correlation between the darkness of the etched regions and the HV. HV increased as the regions became increasingly resistant to etching. Therefore, it should be possible to infer relative hardness of regions based on their etching characteristics. 
Table 1001b-2. Vickers Microindentation Hardness of Bearing and Inner Race Materials. (data for an applied load of $25 \mathrm{~g}-\mathrm{f}$ on selected regions of etch specimens)

\begin{tabular}{|l|c|}
\hline \multicolumn{1}{|c|}{ Location } & $\begin{array}{c}\text { Average } \\
\mathbf{H V}_{\mathbf{2 5 g r - f}} \\
\left(\mathbf{k g} / \mathbf{m m}^{2} \mathbf{)}\right.\end{array}$ \\
\hline \hline Average of all white-etching layers on the more-worn side & $1119 .(121.3)^{*}$ \\
\hline $\begin{array}{l}\text { Average of white layers along the wear step of the more worn } \\
\text { side }\end{array}$ & $\begin{array}{c}1310 .(2 \\
\text { measurements) }\end{array}$ \\
\hline Average of bulk material well away from the surface & $863 .(47.1)^{*}$ \\
\hline $\begin{array}{l}\text { Average of dark etching region below the white layers but above } \\
\text { the bulk material }\end{array}$ & $598 .(106.7)^{*}$ \\
\hline Features shown in Figure (1001OM30): & \\
Light etching region at the top of the metallic protuberance & 1033. \\
Darker layer below the upper, light region & 752. \\
Medium gray area below the darker layer & 1017. \\
Darkest etching zone below the medium gray layer & 554. \\
Bulk material well below the darkest etching zone & 894. \\
\hline
\end{tabular}

* (standard deviation in parenthesis)

17) Dimensional Measurements

\section{1) Pit density and depth}

Indentations and pits on the contact surfaces of both the worn and less worn side of the inner ring were measured using a Mahr Perthometer X20 mechanical stylus tracing unit with a $2.0 \mu \mathrm{m}$ tip radius. A series of profile traces, each $5.6 \mathrm{~mm}$ long, were made in the circumferential direction on the inner race. Traces were placed at least $2 \mathrm{~mm}$ apart to avoid counting the same pit on subsequent traces. A 'pit' is broadly defined here as a localized, measurable depression in a contact surface that is not observed to be associated with the machining of the original surface. Therefore, by this definition, the counted pits could also be debris dents or scratches. After each $5.6 \mathrm{~mm}$ stylus trace, the maximum depth of each pit was measured and the total number of measured pits was counted. The Perthometer has a characteristic of plotting profile traces by adjusting the axis scaling to accommodate the largest feature. Therefore, if there was a large feature, it was difficult to measure the smaller ones on the profile. If any pit greater than 25 $\mu \mathrm{m}$ deep was displayed, a second trace was taken adjacent to that area to detect the shallower pits and the large pit was added to the count. Accuracy of pit depth measurement was also affected by the scaling function of the instrument display. Therefore, the minimum pit depth measurement precision was $0.5 \mu \mathrm{m}$. Consequently, detection of pits was to some extent subjective, especially when attempting to discern pits that were similar in depth to the machined surface roughness.

For purposes of comparison, a semi-quantitative parameter called the Linearized Circumferential Pit Density (LCPD) was defined as the total number of pits per meter of circumference, determined by at least six stylus profile traces in the circumferential direction within the contact zone. Thus,

$$
\mathrm{LCPD}=(\text { pits counted on a given } 5.6 \mathrm{~mm} \text { trace }) /(5.6 \mathrm{~mm})
$$

The LCPD units are given in (pits/mm). Data are summarized in Table 1001b-3. Note that data for the outer race are also included for the sake of comparison, and this table is repeated in the record ID 1001c for the outer race. 
For the more worn side of the inner race, the LCPD was comparable to that of the more worn outer race. The LCPD of the less worn inner race was higher than that from Side B of the outer race, but somewhat lower than side A of the less worn outer race. Note that Side A and Side B were cut from opposite sides of the outer race (See Report 1001c). A plot of the LCPD versus average, maximum, and minimum pit depth may also be found in Report 1001c, in which the outer race wear is more extensively characterized.

Table 1001b-3. Pit Density and Depth for Inner and Outer Bearing Races

\begin{tabular}{|l|c|c|c|}
\hline \multicolumn{1}{|c|}{ Race } & $\begin{array}{c}\text { LCPD } \\
(\mathbf{p i t s} / \mathbf{m m})\end{array}$ & $\begin{array}{c}\text { Average Pit } \\
\text { Depth } \\
(\mu \mathrm{m})\end{array}$ & $\begin{array}{c}\text { Std. Dev. of Pit } \\
\text { Depth } \\
(\mu \mathrm{m})\end{array}$ \\
\hline \hline Less worn inner race & 1.56 & 3.5 & 4.5 \\
\hline Less worn outer race (Side A) & 2.02 & 4.1 & 4.9 \\
\hline Less worn outer race (Side B) & 0.38 & 2.7 & 1.0 \\
\hline More worn inner race* & 1.64 & 13.7 & 12.3 \\
\hline $\begin{array}{l}\text { More worn outer race (Side } \\
\text { A)* }\end{array}$ & 1.96 & 11.7 & 11.5 \\
\hline $\begin{array}{l}\text { More worn outer race (Side } \\
\text { B)* }\end{array}$ & 1.38 & 1.7 & 1.0 \\
\hline
\end{tabular}

* Some regions were out of range of the stylus (too deep), so the average depth given is in essence a minimum average depth on measurable regions.

18) Surface chemical analysis: (none)

19) Summary of the analysis

Analysis of the inner race of the twin-row SRB (from bearing ID 1001) indicated differences in the surface condition of the rollers and races on opposite sides of the assembly. This situation is commonly due to an asymmetric axial loading on the bearing. One side was more heavily worn, with significant macro-pitting and associated spalling. The other side was less worn, but its surface indicated prevalent debris indenting and embedded metallic debris fragments, some as large as $0.5 \mathrm{~mm}$ in length. The more highly-worn side also had a distinct step around the circumference of the race near the outside edge of the contact suggesting that the roller profiles had been so degraded that the roller edges toward the outside face of the bearing wore into and scored the race. The rollers from the more worn side were themselves highly worn and deformed (see section (2.1) ID 1001a) corresponding to the side of the race which had more damage.

Relative to the bulk material in the race, the steel comprising the roller was about $15 \%$ harder. However, the major abrasion and indenting damage to the race was more likely to have come from highly sheared and work-hardened wear debris particles and the damaged surfaces of the rollers. White-etching, nearsurface material on the rollers fatigued under Hertzian contact and deformed under shear loads (during slip or roller skidding) produced loose fragments with a hardness number about $40 \%$ greater than that of the bulk material of the race. According to the work of D. Tabor (1951, 'Hardness of Metals', Oxford Press) a hardness difference of about $20 \%$ is required for significant abrasion to occur on the softer of two contacting metals. Therefore, there was sufficient hardness due to interface processing of the debris to produce indentation and abrasion of the race surfaces.

20) Related analyses: See 2.1) ID 1001a (rolling elements), 2.3) ID 1001c (outer race) 


\subsection{SPHERICAL ROLLER BEARING - OUTER RACE}

\begin{tabular}{|l|l||l|l|}
\hline 1) Record number & $1001 \mathrm{~b}$ & 2) Source/Contact name & NREL/JJohnson \\
\hline $\begin{array}{l}\text { 3) Date rec'd } \\
\text { (yyyymmdd) }\end{array}$ & 20081230 & $\begin{array}{l}\text { 4) Turbine mfr (site } \\
\text { locale) }\end{array}$ & Micon 750 (Ponnequin farm, \#19) \\
\hline 5) Bearing mfr. & SKF & 6) Part cat. number or ID & $\begin{array}{l}\text { 22322 E (specs are available on- } \\
\text { line at: <www.skf.com>) }\end{array}$ \\
\hline 7) Bearing type & DR/SRB & $\begin{array}{l}\text { 8) Gearbox type / brg } \\
\text { location }\end{array}$ & Brooks and Hansen / high-speed \\
\hline $\begin{array}{l}\text { 9) Form of hardware } \\
\text { condition }\end{array}$ & FBS / LC & $\begin{array}{l}\text { 10) Specific component } \\
\text { type** }\end{array}$ & OR \\
\hline
\end{tabular}

Notes: 1) Bearing types: $\mathrm{SR}=$ single row; $\mathrm{DR}=$ double row; $\mathrm{CRB}=$ cylindrical roller bearing; $\mathrm{TCB}=$ tapered cylindrical roller bearing, $\mathrm{SRB}=$ spherical roller bearing; $\mathrm{BB}=$ ball bearing; $\mathrm{ACB}=$ angular contact ball bearing

2) Specimen type: $\mathrm{FBS}=$ full bearing set; $\mathrm{RE}=$ rolling element, $\mathrm{OR}=$ outer race. $\mathrm{IR}=$ inner race, $\mathrm{SEP}=$ separator

3) Condition codes: $\mathrm{FB}=$ received as a fully-assembled bearing, $\mathrm{PD}=$ partially disassembled bearing, $\mathrm{LC}$

$=$ loose component (in tact), $\mathrm{BC}=$ broken piece(s) of a loose component, $\mathrm{X}=$ surface corroded, scratched, or otherwise marred when received

11) Construction Material and Condition: (Information not provided with the sample).

12) Lubricant and Method of Application: (Information not provided with the sample).

\begin{tabular}{|l|l|}
\hline 13) Running history & (unknown) \\
\hline $\begin{array}{l}\text { 14) Other description } \\
\text { of the component(s) } \\
\text { to be examined }\end{array}$ & $\begin{array}{l}\text { Description from the source: "One side of bearing (not marked as up or down } \\
\text { wind) is so badly damaged that the rollers were no longer caged. The cage } \\
\text { was completely ground up except for a single } 2 \mathrm{~mm} \text { wide ring of steel. The } \\
\text { rollers from this side were being dragged or skidded in the races (they were } \\
\text { not rolling). The other side of the bearing is in better condition, mostly } \\
\text { denting from debris on the rollers and races. There is severe fretting } \\
\text { corrosion on the OD of the outer race." }\end{array}$ \\
\hline
\end{tabular}

15) Photographs of components.

15.1) Digital camera images. 


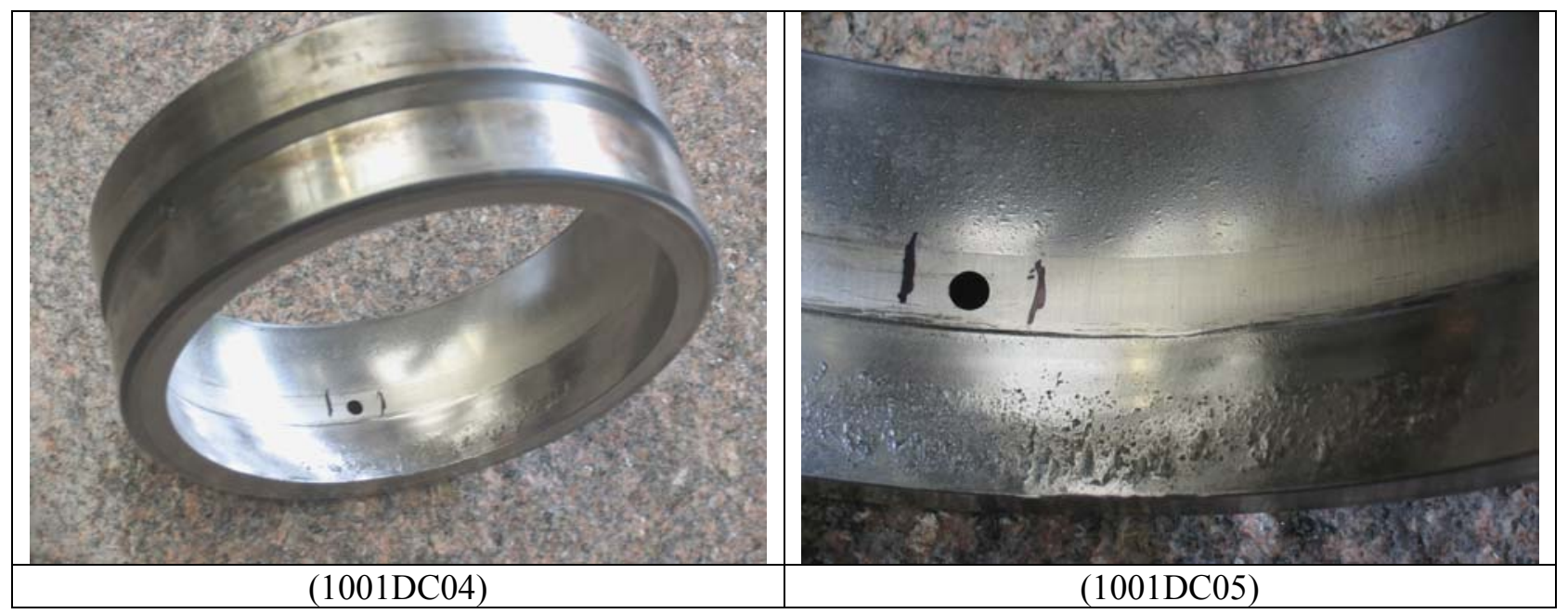

Photograph captions / notes:

(1001DC04) Contact surface of the outer race of the SRB shown in Figure (1001DC01) in record ID 1001a-1.

(1001DC05) Close-up view of the differences in surface damage on the twin races (lubrication hole clearly visible).

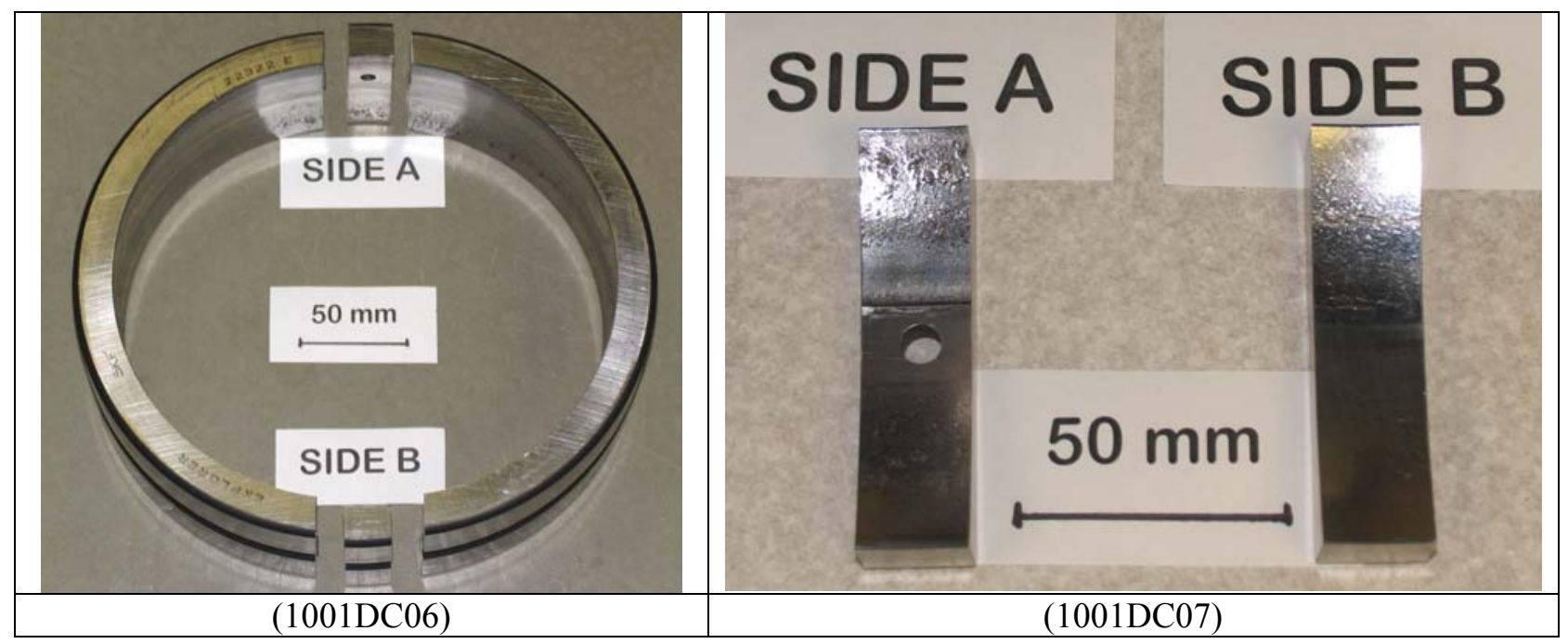

Photograph captions / notes:

(1001DC06) OR showing cuts labeled "A" and "B" taken from opposite sides of the ring..

(1001DC07) Sections A and B cut from the side of the OR approximately 180 degrees from that in (1001DC06). In this view, the top of the double row is the one that showed the most damage.

\section{2) Macroimages of surfaces. (Light optical)}

Magnified images were obtained of sections A and B, cut from the outer ring, using a Nikon macro-zoom microscope. .As with the inner ring, damage was more severe on one side of the dual race than it was on the other. 


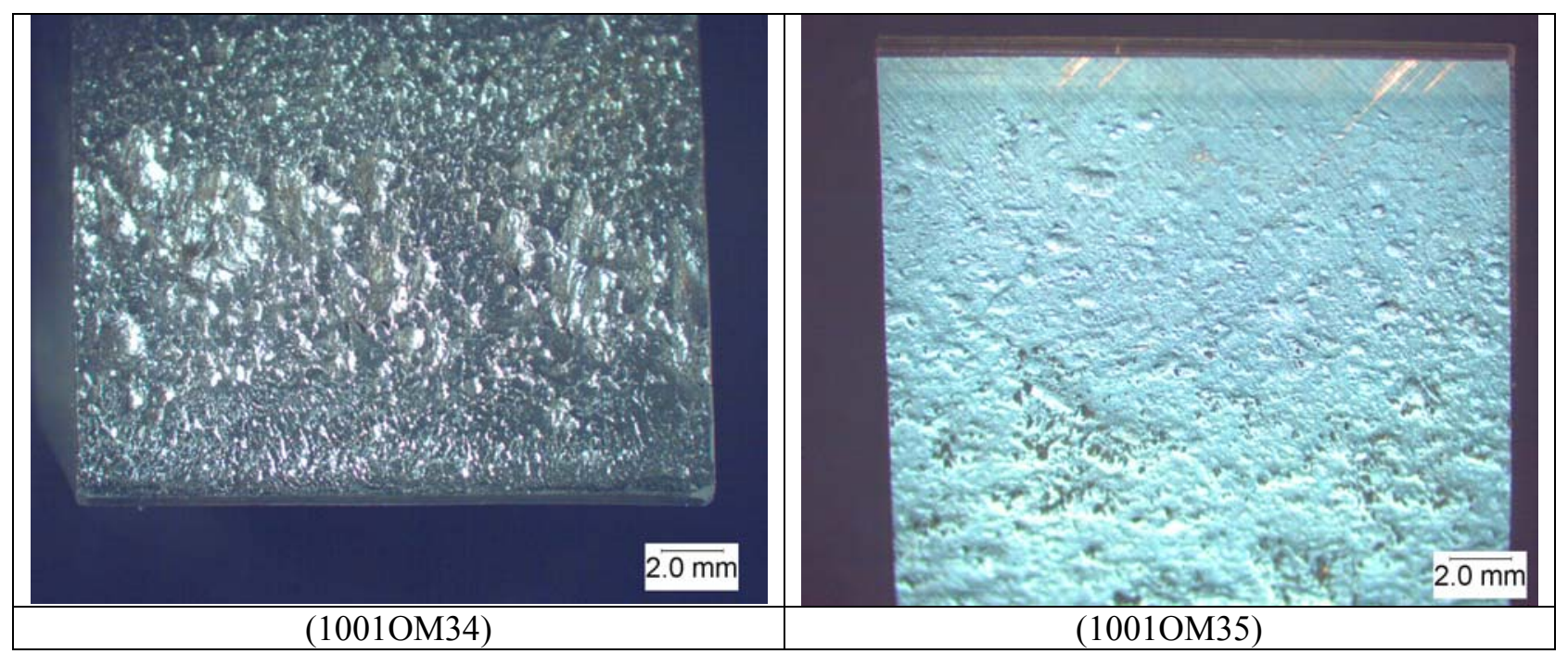

Photograph captions / notes:

(1001OM34) Enlarged area of the more worn outer race on the section cut from Side A..

(1001OM35) Enlarged area of the less worn race on Side A, 180 degrees from the higher wear location.

Denting and surface distress are evident even though the pitting is not as deep as on the more worn side.

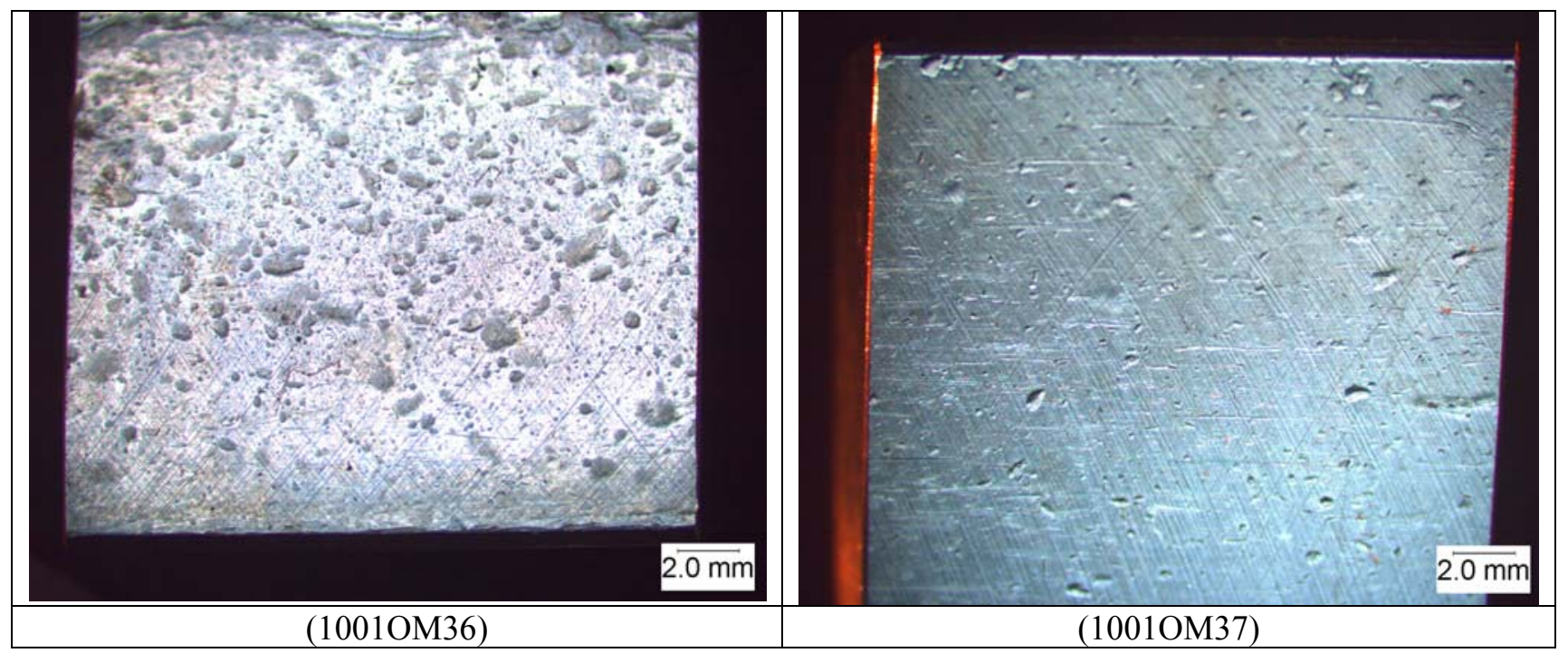

Photograph captions / notes:

(1001OM36) Enlarged area of the more worn race on Side B. While there was obvious debris denting, the surface didn't seem to be quite as severely damaged as the section cut from the opposite side of the ring.

(1001OM37) Enlarged area of the less worn race on Side B. There was less damage than on the same race on Side A. 


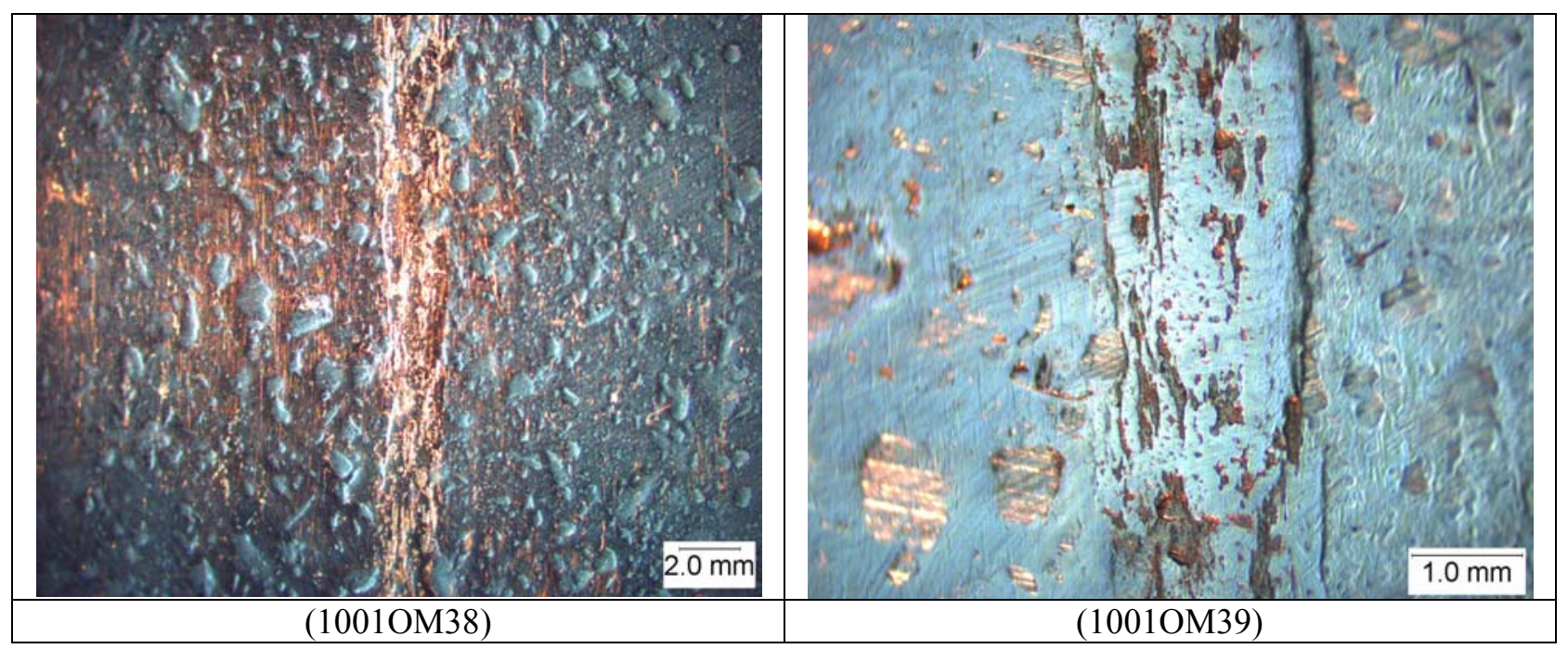

Photograph captions / notes:

(1001OM38) Prominent groove on the centerline of the more worn race on Side B.

(1001OM39) Enlarged area of the groove in (1001OM38) showing severe plastic deformation.

16) Property measurements.

\section{1) Macroindentation hardness.}

Rockwell C scale hardness was measured using a Wilson Series B2000 hardness testing machine at several locations on cross-sections of opposite (180 degrees apart) sides of the outer race. Results are given in Table 1001c-1. The hardness was extremely uniform on all areas sampled except for a minor variation in HRC near the contact surfaces. However, it is difficult to ascribe much significance to this deviation. Most differences in hardness associated with mechanical contact were observed by microindentation studies on polished sections within a few tens of micrometers from the surfaces (See 1001a, 1001b). 
Table 1001c-1. Rockwell Hardness of the Outer Races

(Cross-sectioned, ground, hand lapped to 400 grit finish)

\begin{tabular}{|c|l|l|c|}
\hline Side & Condition & \multicolumn{1}{|c|}{ Location } & HRC \\
\hline A & less worn & $1-2 \mathrm{~mm}$ from the contact surface & 59.8 \\
\hline & & & 60.1 \\
\hline & & & 60.1 \\
\hline B & less worn & $1-2 \mathrm{~mm}$ from the contact surface & 56.9 \\
\hline & & & 59.6 \\
\hline A & more worn & $1-2 \mathrm{~mm}$ from the contact surface & 60.0 \\
\hline & & & 60.1 \\
\hline & & & 60.2 \\
\hline B & more worn & $1-2$ mm from the contact surface & 59.8 \\
\hline & & & 59.2 \\
\hline & & & 59.6 \\
\hline A & interior & bulk area remote from the race & 59.3 \\
\hline & & & 60.2 \\
\hline & & & 60.2 \\
\hline B & interior & bulk area remote from the race & 60.2 \\
\hline & & & 60.1 \\
\hline & & & 60.1 \\
\hline A & & Average of all HRC readings on this piece & 60.1 \\
\hline & & Standard deviation & 60.1 \\
\hline \hline B & & Average of all HRC readings on this piece & 0.2 \\
\hline & & Standard deviation & 59.4 \\
\hline
\end{tabular}

16.2) Microindentation hardness. (no measurements)

17) Dimensional Measurements

\section{1) Pit density and depth}

Indentations and pits on the contact surfaces of both the worn and less worn side of the inner ring were measured using a Mahr Perthometer X20 mechanical stylus tracing unit with a $2.0 \mu \mathrm{m}$ tip radius. A set of profile traces, $5.6 \mathrm{~mm}$ long, were made in the circumferential direction on the inner race. Traces were placed at least $2 \mathrm{~mm}$ apart to avoid counting the same pit on subsequent traces. A 'pit' is broadly defined here as a localized, measurable depression in a contact surface that is not observed to be associated with the machining of the original surface. Therefore, by this definition, the counted pits could also be debris dents or scratches. After each $5.6 \mathrm{~mm}$ stylus trace, the maximum depth of each pit was measured and the total number of measured pits was counted. The Perthometer has a characteristic of plotting profile traces by adjusting the axis scaling to accommodate the largest feature. Therefore, if there was a large feature, it was difficult to measure the smaller ones on the profile. If any pit greater than $25 \mu \mathrm{m}$ deep was displayed, a second trace was taken adjacent to that area to detect the shallower pits and the large pit was added to the count. Accuracy of pit depth measurement was also affected by the scaling function of the instrument display. Therefore, the minimum pit depth measurement precision was $0.5 \mu \mathrm{m}$. Consequently, detection of pits was to some extent subjective, especially when attempting to discern pits that were similar in depth to the machined surface roughness. 
For purposes of comparison, a semi-quantitative parameter called the Linearized Circumferential Pit Density (LCPD) was defined as the total number of pits per meter of circumference, determined by at least six stylus profile traces in the circumferential direction within the contact zone. Thus,

$$
\mathrm{LCPD}=(\text { pits counted on a given } 5.6 \mathrm{~mm} \text { trace }) /(5.6 \mathrm{~mm})
$$

The LCPD units are given in (pits/mm). Data are summarized in Table 1001b-3. Note that data for the inner race are also included for comparison, and that this table is repeated in the record ID 1001b for the inner race. Pit density and depth were measured on the outer race of bearing ID 1001 in the manner described in Section 2.2, part 17.1. Table 1001b-1, listing the linearized circumferential pit density (LCPD) and average pit depth, is repeated here to enable comparison of outer race data with similar measurements on the inner race.

Table 1001b-3. Pit Density and Depth for Inner and Outer Bearing Races

\begin{tabular}{|l|c|c|c|}
\hline \multicolumn{1}{|c|}{ Race } & $\begin{array}{c}\text { LCPD } \\
(\mathbf{p i t s} / \mathbf{m m})\end{array}$ & $\begin{array}{c}\text { Average Pit } \\
\text { Depth } \\
(\mu \mathrm{m})\end{array}$ & $\begin{array}{c}\text { Std. Dev. of Pit } \\
\text { Depth } \\
(\mu \mathrm{m})\end{array}$ \\
\hline \hline Less worn inner race & 1.56 & 3.5 & 4.5 \\
\hline Less worn outer race (Side A) & 2.02 & 4.1 & 4.9 \\
\hline Less worn outer race (Side B) & 0.38 & 2.7 & 1.0 \\
\hline More worn inner race* & 1.64 & 13.7 & 12.3 \\
\hline $\begin{array}{l}\text { More worn outer race (Side } \\
\text { A)* }\end{array}$ & 1.96 & 11.7 & 11.5 \\
\hline $\begin{array}{l}\text { More worn outer race (Side } \\
\text { B)* }\end{array}$ & 1.38 & 1.7 & 1.0 \\
\hline
\end{tabular}

* Some regions were out of range of the stylus (too deep), so the average depth given is in essence a minimum average depth on

Clearly, the damage to side A of the outer race was significantly greater than that of Side B, 180 degrees from it. A semi-log plot of the maximum, minimum, and average pit depth versus PCPD is shown in Figure 1001GR08. Note that the lowest practical precision of pit detection by this method was about 0.5 $\mu \mathrm{m}$ and that this limitation was compounded by the auto-scaling feature of the instrument display that scales to the largest depth feature, making smaller features less prominent and difficult to detect.

For the given bearing races, the shallowest and least numerous pits were found on Side B of the less-worn outer ring. This difference in wear severity can also be seen in Figure 1001DC07 in Section 15.1 of this report. This supports the conclusion that there was non-uniform axial loading on the bearings. The deeper pits $(>\sim 10 \mu \mathrm{m}$ deep) tended to be fatigue-induced spalls while the shallower pits $(<\sim 10 \mu \mathrm{m}$ deep) were mainly debris indentations. Furthermore, as the diameter of the pits becomes larger, there are fewer possible pits within a $\mathrm{mm}$ of traverse distance. Therefore, the magnitude of the LCPD parameter is not a direct measurement of damage severity when large pits are concerned, but maybe more useful in situations like micropitting. 


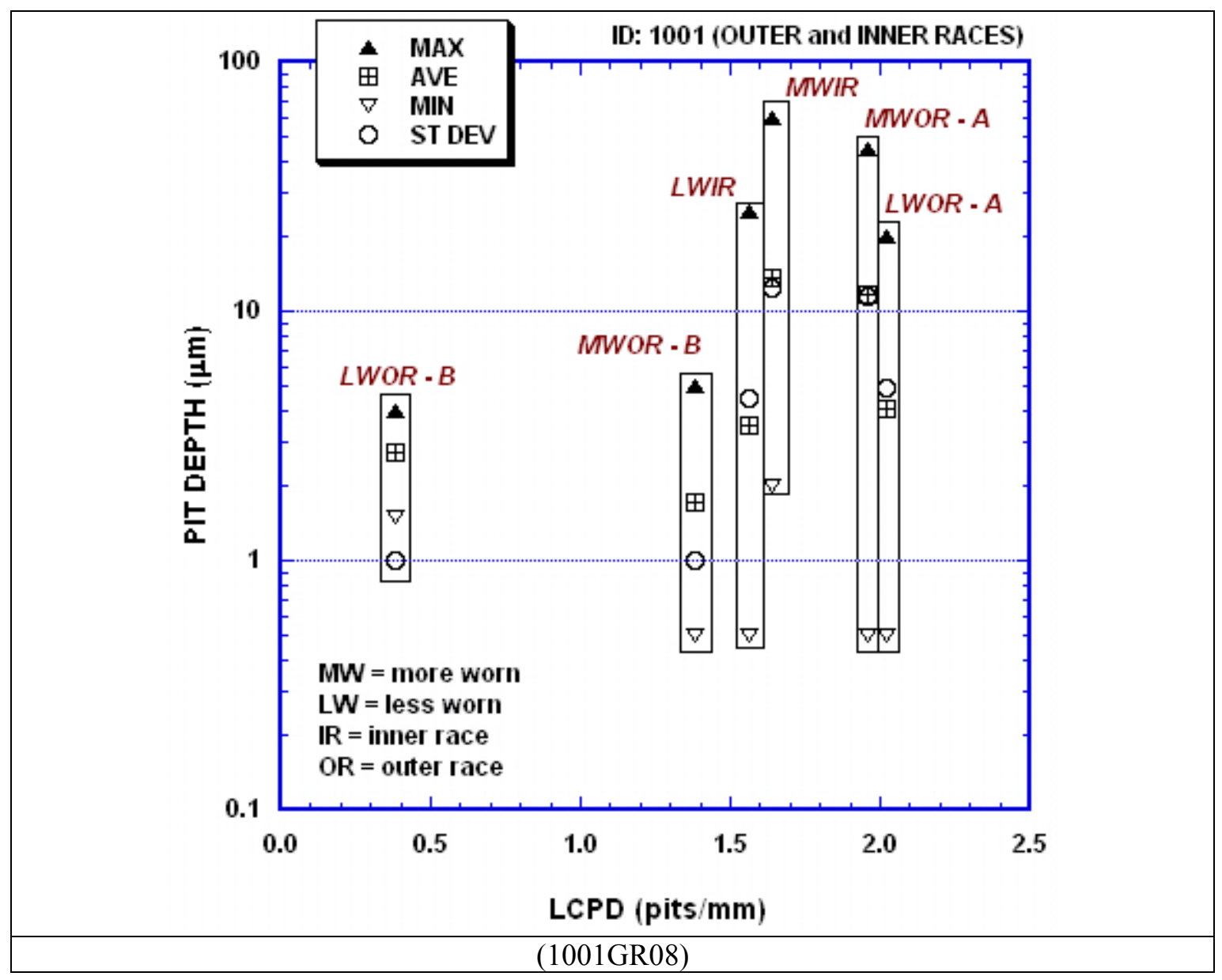

Caption / notes:

(1001GR08) Plot of linear circumferential pit density versus pit depth. Data corresponding to more worn or less worn areas on the inner and outer races are indicated.

18) Surface chemical analysis: (none)

19) Summary of the analysis

The outer race of a double row, SRB displayed different degrees of wear associated with the two rows of rollers. On the more worn side, there was extensive pitting, spalling, and evidence of severe metallic wear that produced a groove near the outside edge. On the race on the other side, there was light frosting, with some micropitting damage. Pit depths on the more worn side were about 3 times those on the less worn size. Within each individual race, there were differences in the degree of wear as well, with more damage on the side closest to the lubricant access port. Rockwell hardness testing of both sides of the race gave values of HRC 59-60. Evidently, the asymmetry in wear resulted from an axial overload on the bearing.

20) Related analyses: See ID 1001a (rolling elements), ID 100b (inner race) 


\subsection{CYLINDRICAL ROLLER BEARING - INNER AND OUTER RACES}

\begin{tabular}{|l|l||l|l|}
\hline 1) Record number & $1003 \mathrm{a}$ & 2) Source/Contact name & NREL/JJohnson \\
\hline $\begin{array}{l}\text { 3) Date rec'd } \\
\text { (yyyymmdd) }\end{array}$ & 20081230 & $\begin{array}{l}\text { 4) Turbine mfr (site } \\
\text { locale) }\end{array}$ & $\begin{array}{l}\text { Vestas V47, W11W Explorer } \\
\text { (from EMS, Howard SD) }\end{array}$ \\
\hline 5) Bearing mfr. & SKF & 6) Part cat. number or ID & $\begin{array}{l}\text { NJ2222 ECML/C3, 061A } \\
\text { Explorer, Germany (specs are } \\
\text { available on-line at: } \\
\text { <www.skf.com }>\text { ) }\end{array}$ \\
\hline 7) Bearing type* & SR/CRB & $\begin{array}{l}\text { 8) Gearbox type/ brg } \\
\text { location }\end{array}$ & Planetary \\
\hline $\begin{array}{l}\text { 9) Specimen type **/ } \\
\text { Condition*** }\end{array}$ & FBS/FB & $\begin{array}{l}\text { 10) Specific component } \\
\text { type** }\end{array}$ & IR and OR \\
\hline
\end{tabular}

Notes: 1) Bearing types: $\mathrm{SR}=$ single row; $\mathrm{DR}=$ double row; $\mathrm{CRB}=$ cylindrical roller bearing; $\mathrm{TCB}=$ tapered cylindrical roller bearing, $\mathrm{SRB}=$ spherical roller bearing; $\mathrm{BB}=$ ball bearing; $\mathrm{ACB}=$ angular contact ball bearing

2) Specimen type: $\mathrm{FBS}=$ full bearing set; $\mathrm{RE}=$ rolling element, $\mathrm{OR}=$ outer race. $\mathrm{IR}=$ inner race, $\mathrm{SEP}=$ separator

3) Condition codes: $\mathrm{FB}=$ received as a fully-assembled bearing, $\mathrm{PD}=$ partially disassembled bearing, $\mathrm{LC}$

$=$ loose component (in tact), $\mathrm{BC}=$ broken piece(s) of a loose component, $\mathrm{X}=$ surface corroded, scratched, or otherwise marred when received

11) Construction Material and Condition: (Information not provided with the sample).

12) Lubricant and Method of Application: (Information not provided with the sample).

\begin{tabular}{|l|l|}
\hline 13) Running history & (unknown) \\
\hline $\begin{array}{l}\text { 14) Other description } \\
\text { of the component(s) } \\
\text { to be examined }\end{array}$ & $\begin{array}{l}\text { Description provided by source contact: "There is mild debris denting on } \\
\text { inner race and rollers. We're unable to disassemble to inspect the outer race } \\
\text { and there is evidence of outer race spinning on its OD (no fretting corrosion } \\
\text { though)." }\end{array}$ \\
\hline
\end{tabular}

15) Photograph of component(s)

15.1) Digital camera images. 


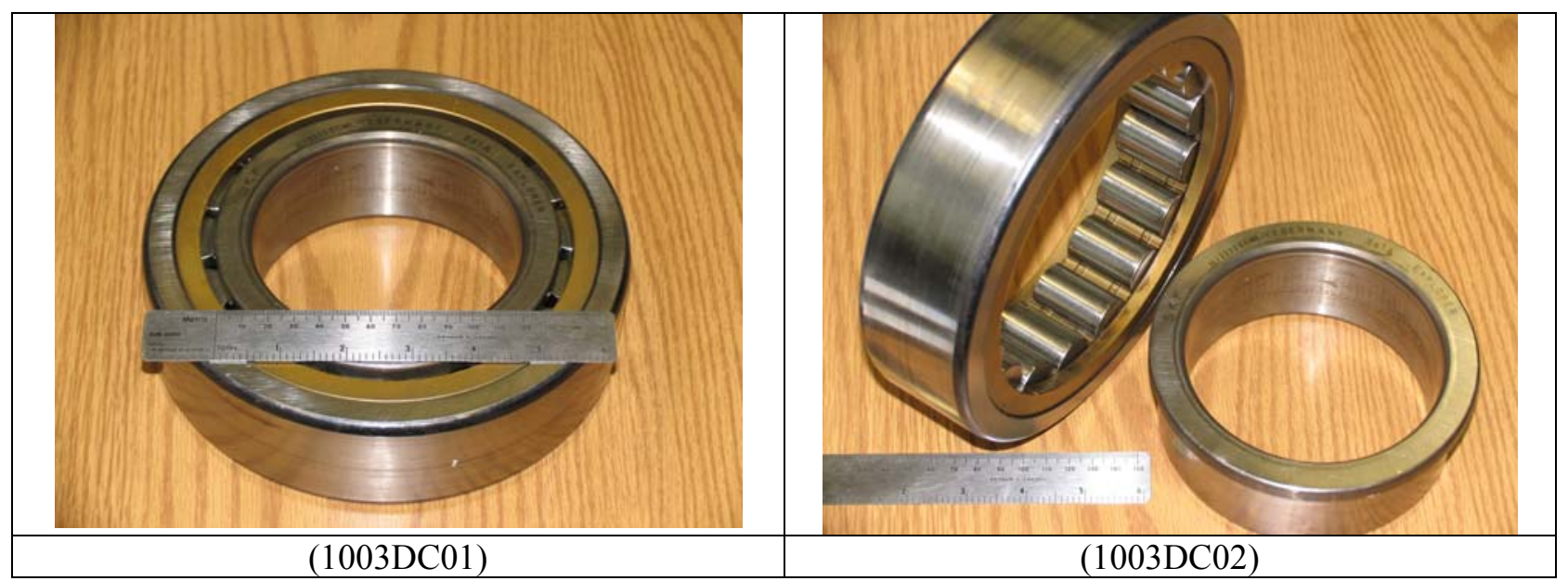

Photograph captions / notes:

(1003DC01) Bearing assembly (20 mm outside diameter, $11 \mathrm{~mm}$ inside diameter)

(1003DC02) Bearing assembly with the inner race removed.

\section{2) Macroimages of surfaces. (Light optical)}

Close-up images of shallow indentations in the outer race were obtained using a Nikon macro-zoom microscope after a section of the rollers and separator ring had been removed, as shown in Section 2.5 Fig. (1003DC04). The two most prominent features were the debris dents and the fine abrasion markings in the circumferential direction. The figures below show several areas of indentations that ranged in size from less than $100 \mu \mathrm{m}$ to over $1 \mathrm{~mm}$. High concentrations of metallic debris were confirmed by studies of the rolling elements and separator (see section 2.5). The inner race had similar features.

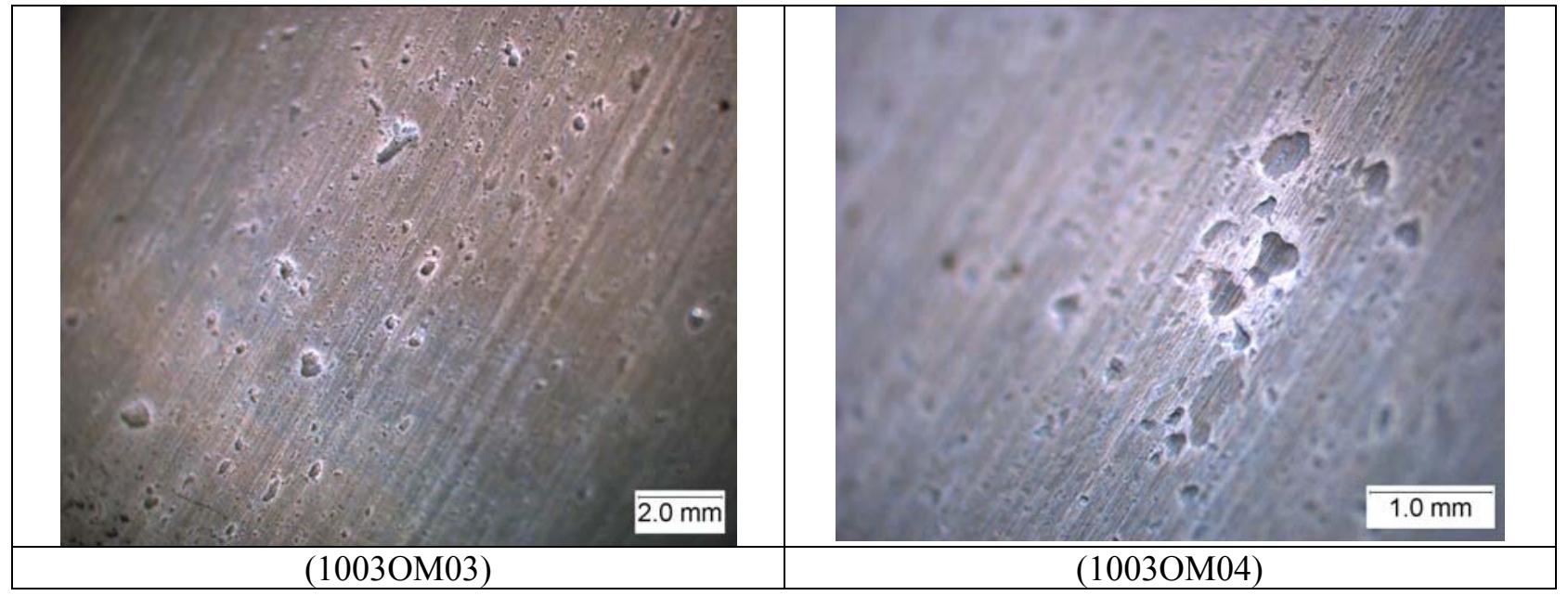

Photograph captions / notes:

(1003OM03) Contact surface of the outer race showing shallow indentations from debris denting and circumferential scratches from debris that was dragged along through the interface by the rolling elements.

(1003OM04) Shallow pits and scratches nearby the area that shown in (1003OM03). 
16) Property measurements. (none)

17) Dimensional or surface roughness measurements

A Mahr X20 mechanical profiling instrument with a diamond stylus (2.0 mm tip radius), $5.6 \mathrm{~mm}$ stroke, 11200 points per trace, and $0.8 \mathrm{~mm}$ cut-off, was used to obtain roughness profiles parallel to the axial direction on the inner race (cross-wise to the circumferential direction). These profiles are provided in Figures (1003SP01, 02, 03, and 05). Some of the indentations were as deep as 4-6 $\mu \mathrm{m}$, but a few exceeded $10 \mu \mathrm{m}$ in depth. Also, as shown in Fig. (1003SP03 and 05), there was evidence that the gouging nature of debris embedment created lips at one end of the resulting dimple. Such lips of material can exceed the oil film thickness in the bearing, and lead to localized solid-solid contact with the concomitant abrasion of the counterface. Such abrasion is substantiated by multiple circumferential scratches on the rolling elements as well.

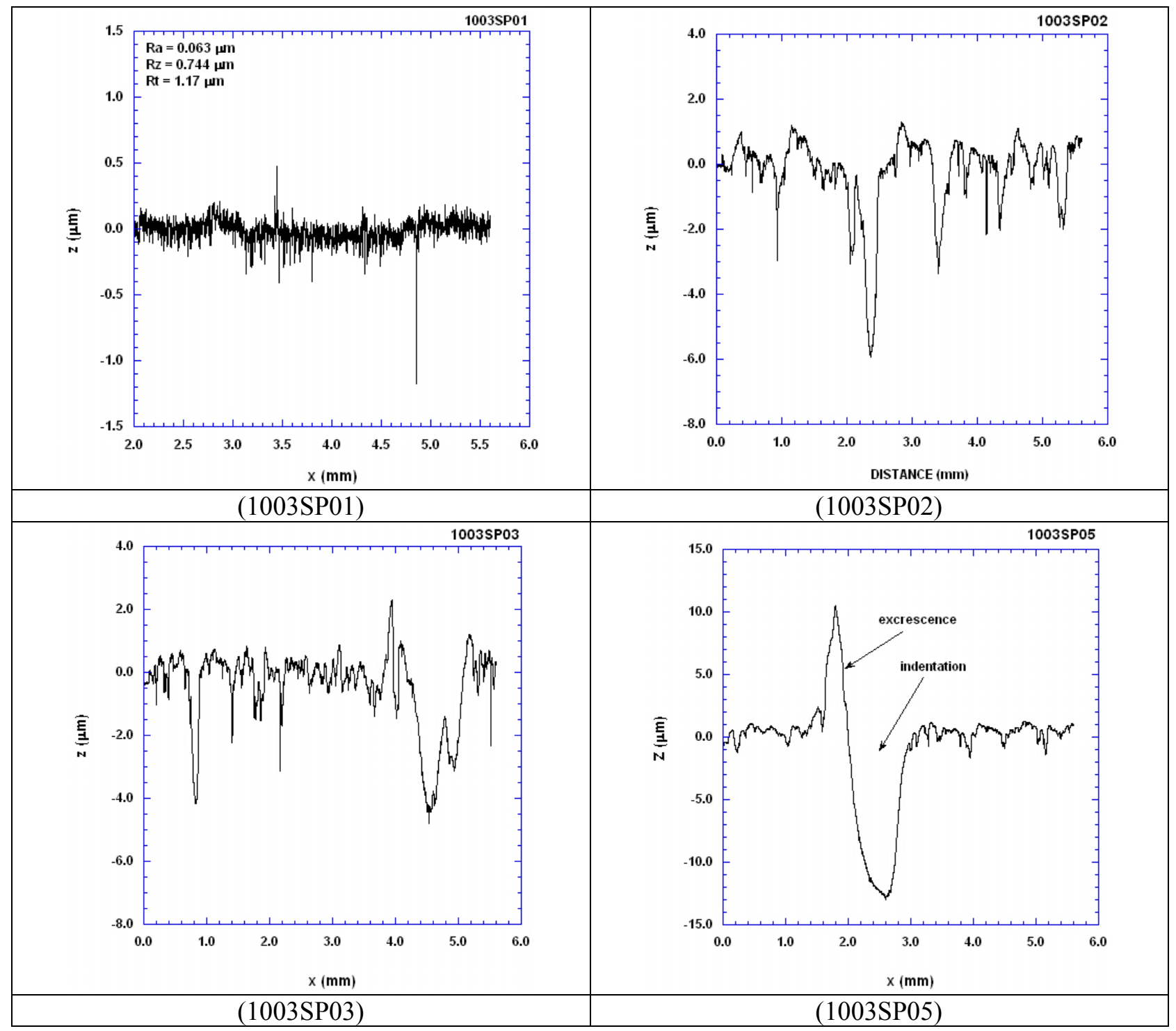

(1003SP01) Roughness measurement of the shiny, non-indented area of the inner race OD. (1003SP02) Profile across an indented area A, parallel to the bearing axis. 
(1003SP03) Profile across another indented area B, parallel to the bearing axis.

(1003SP05) Profile across one of the larger indentations showing a raised portion, probably resulting from gouging by a hard particle that became trapped momentarily in the roller/race interface (approximately $13 \mu \mathrm{m}$ deep).

18) Surface chemical analysis (none)

19) Summary of analysis.

The cylindrical roller bearing examined here showed no evidence for the kind of gross fatigue spalling that was observed on the SRBs. The primary damage observed on inner and outer races resulted from debris particles entrapped between the rolling element and the race surface. Dents were typically shallow, less than 6-10 $\mu \mathrm{m}$ deep, but can be as long as $1 \mathrm{~mm}$. Raised lips surrounding the dents can penetrate the lubricant film, causing intermittent solid contact and abrasion of the counterface. This kind of damage is common and is typically mitigated by filtration systems of various types. However, in order for the filtration system to function, the debris must escape from the bearing into the recirculation system. If it remains trapped in the bearing for too long, it can become permanently embedded into the contact surfaces. (see Section 2.5 for additional discussion and examples of debris embedment.)

20) Related analyses: See 2.5) roller and separator 


\subsection{CYLINDRICAL ROLLER BEARING - ROLLING ELEMENT AND SEPARATOR}

\begin{tabular}{|l|l||l|l|}
\hline 1) Record number & $1003 \mathrm{a}$ & 2) Source/Contact name & NREL/JJohnson \\
\hline $\begin{array}{l}\text { 3) Date rec'd } \\
\text { (yyyymmdd) }\end{array}$ & 20081230 & $\begin{array}{l}\text { 4) Turbine mfr (site } \\
\text { locale) }\end{array}$ & $\begin{array}{l}\text { Vestas V47, W11W Explorer } \\
\text { (from EMS, Howard SD) }\end{array}$ \\
\hline 5) Bearing mfr. & SKF & 6) Part cat. number or ID & $\begin{array}{l}\text { NJ2222 ECML/C3, 061A } \\
\text { Explorer, Germany (specs are } \\
\text { available on-line at: } \\
\text { <www.skf.com>) }\end{array}$ \\
\hline 7) Bearing type & SR/CRB & $\begin{array}{l}\text { 8) Gearbox type/ brg } \\
\text { location }\end{array}$ & Planetary \\
\hline $\begin{array}{l}\text { 9) Specimen type } \\
\text { Condition }\end{array}$ & FBS/FB & $\begin{array}{l}\text { 10) Specific component } \\
\text { type }\end{array}$ & RE and SEP \\
\hline
\end{tabular}

Notes: 1) Bearing types: $\mathrm{SR}=$ single row; $\mathrm{DR}=$ double row; $\mathrm{CRB}=$ cylindrical roller bearing; $\mathrm{TCB}=$ tapered cylindrical roller bearing, $\mathrm{SRB}=$ spherical roller bearing; $\mathrm{BB}=$ ball bearing; $\mathrm{ACB}=$ angular contact ball bearing

2) Specimen type: $\mathrm{FBS}=$ full bearing set; $\mathrm{RE}=$ rolling element, $\mathrm{OR}=$ outer race. $\mathrm{IR}=$ inner race, $\mathrm{SEP}=$ separator

3) Condition codes: $\mathrm{FB}=$ received as a fully-assembled bearing, $\mathrm{PD}=$ partially disassembled bearing, $\mathrm{LC}$ $=$ loose component (in tact), $\mathrm{BC}=$ broken piece(s) of a loose component, $\mathrm{X}=$ surface corroded, scratched, or otherwise marred when received

11) Construction Material and Condition: (Information not provided with the sample).

12) Lubricant and Method of Application: (Information not provided with the sample).

\begin{tabular}{|l|l|}
\hline 13$)$ Running history & (unknown) \\
\hline $\begin{array}{c}\text { 14) Other description } \\
\text { of the component(s) } \\
\text { to be examined }\end{array}$ & (See 1003a) \\
\hline
\end{tabular}

15) Photograph of component(s)

\section{1) Digital camera images.}

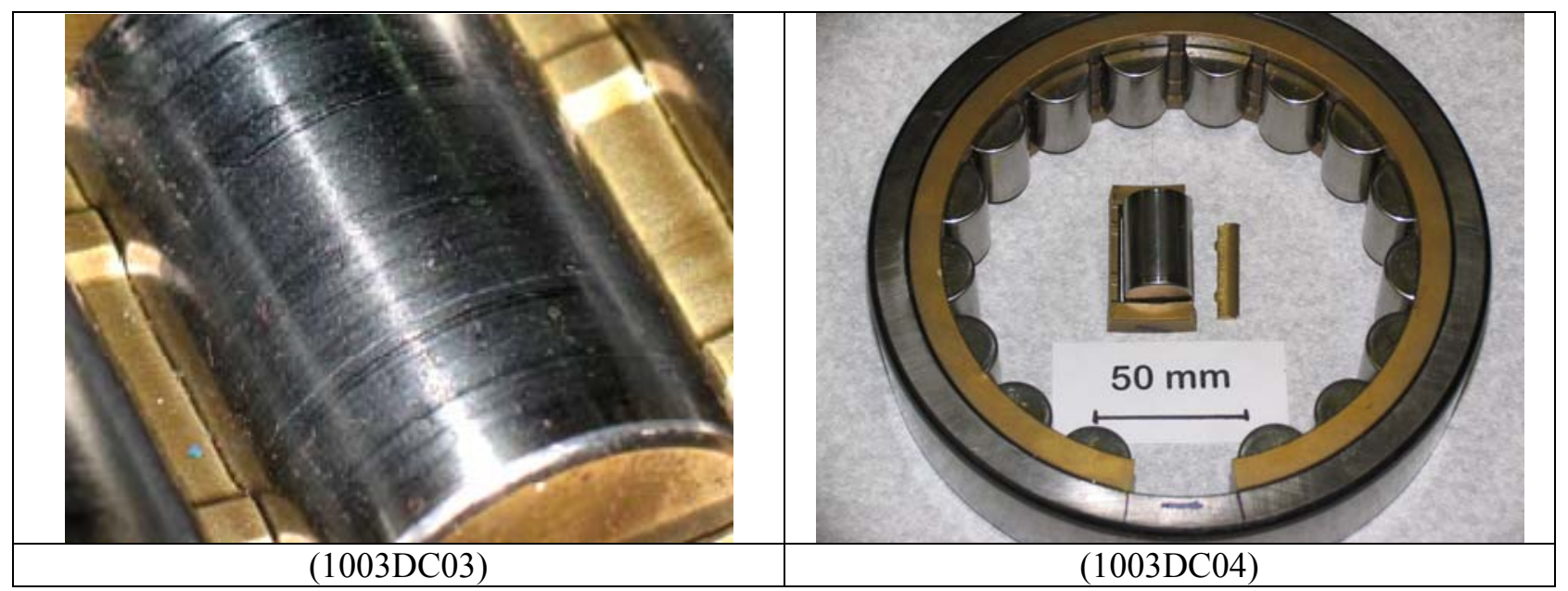


Photograph captions / notes:

(1003DC03) Close-up of a cylindrical roller in the bronze separator.

(1003DC04) Overview of the bearing with a section cut from the separator to allow removal of a roller.

\section{2) Macroimages of surfaces. (Light optical)}

Close-up images of a cylindrical roller and the adjacent, inside, facing surface of the bronze separator adjacent to it were obtained using a Nikon macro-zoom microscope. The roller showed evidence for debris denting and circumferential scoring [Figure (1003OM01)]. The depth of these score marks, from mechanical stylus traces, was approximately 3-6 $\mu \mathrm{m}$. The average pit depth for 34 depressions on 4 traces (each trace was $5.6 \mathrm{~mm}$ in length), was $2.50 \mu \mathrm{m}$ (std. dev. $1.05 \mu \mathrm{m}$ ). With a lower limit on the measurable pit depth of $0.8 \mu \mathrm{m}$, the average pit density along those traces was $1.52 / \mathrm{mm}$. Indentation depth profiles showing indications of pits and circumferential scratches may be found in section 17.0.

Figure (1003OM02) shows several fragments of steel embedded into the surface of the separator. Chatter marks in the softer bronze show how the fragments were dragged into the space between the roller and separator as the assembly turned, causing irregular, curved scratches in the bronze.

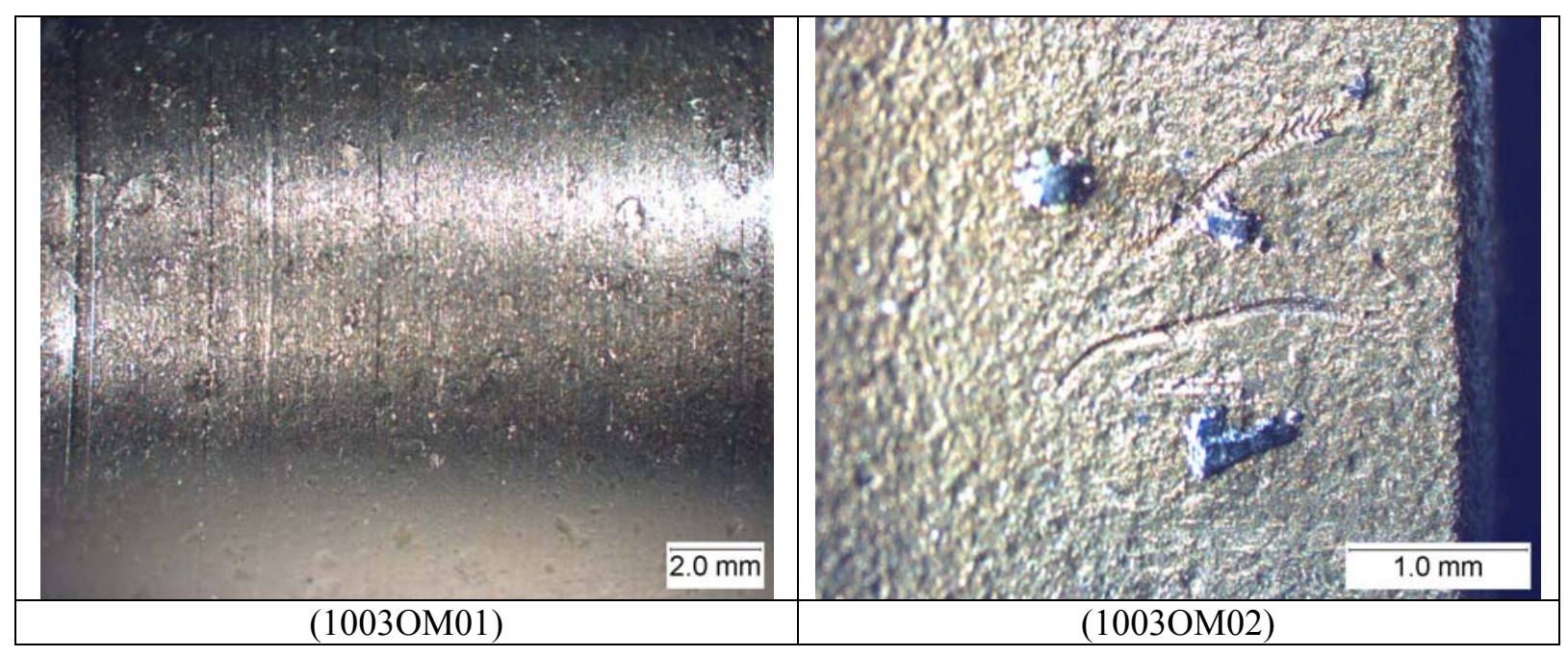

Photograph captions / notes:

(1003OM01) MacI of a cylindrical roller showing numerous debris indentations and circumferential score marks of various depths and widths.

(1003OM02) MacI of the bronze separator showing embedded wear particles on the surface as well as curved scratches ('worm tracks') from similar entrainment events.

16) Property measurements. (none)

17) Dimensional or surface roughness measurements

\subsection{Surface roughness.}

A Mahr Perthometer X20 mechanical profiling instrument with a diamond stylus (2.0 $\mu \mathrm{m}$ tip radius), 5.6 $\mathrm{mm}$ stroke, 112000 points per trace, and $0.8 \mathrm{~mm}$ cut-off, was used to obtain roughness profiles parallel to the axial director on a cylindrical roller. Arithmetic average roughness $(\mathrm{Ra}, \mu \mathrm{m})$, ten-point height $(\mathrm{Rz}$, $\mu \mathrm{m})$ and maximum peak to valley in a 5.6 profile $(\mathrm{Rt}, \mu \mathrm{m})$ are given in Table 1003b-1. 
Table 1003b-1. Surface Roughness of a Cylindrical Roller

\begin{tabular}{|c|c|c|c|l|}
\hline Trace number & $\mathrm{Ra}(\mu \mathrm{m})$ & $\mathrm{Rz}(\mu \mathrm{m})$ & $\mathrm{Rt}(\mu \mathrm{m})$ & \multicolumn{1}{|c|}{ Comment } \\
\hline \hline 1 & 0.931 & 5.366 & 8.94 & see Figure (1003SP06) \\
\hline 2 & 0.524 & 3.755 & 7.15 & near one end of the roller \\
\hline 3 & 0.435 & 3.014 & 5.16 & near the center \\
\hline 4 & 0.507 & 3.176 & 5.21 & near the center \\
\hline 5 & 0.686 & 5.368 & 8.91 & near the opposite end from 2 \\
\hline 6 & 0.446 & 2.778 & 3.32 & near the opposite end from 2 \\
\hline 7 & 0.971 & 5.703 & 8.38 & near a circumferential groove \\
\hline Average & 0.643 & 4.166 & 6.72 & \\
\hline Std deviation & 0.226 & 1.268 & 2.20 & \\
\hline
\end{tabular}

Typical surface profile traces are shown in Figures (1003SP06, 07, and 08). The first shows a typical trace and the second shows profiles of one of the deeper circumferential scratches. Figure (1003SP08) shows a rather deep indentation from debris.

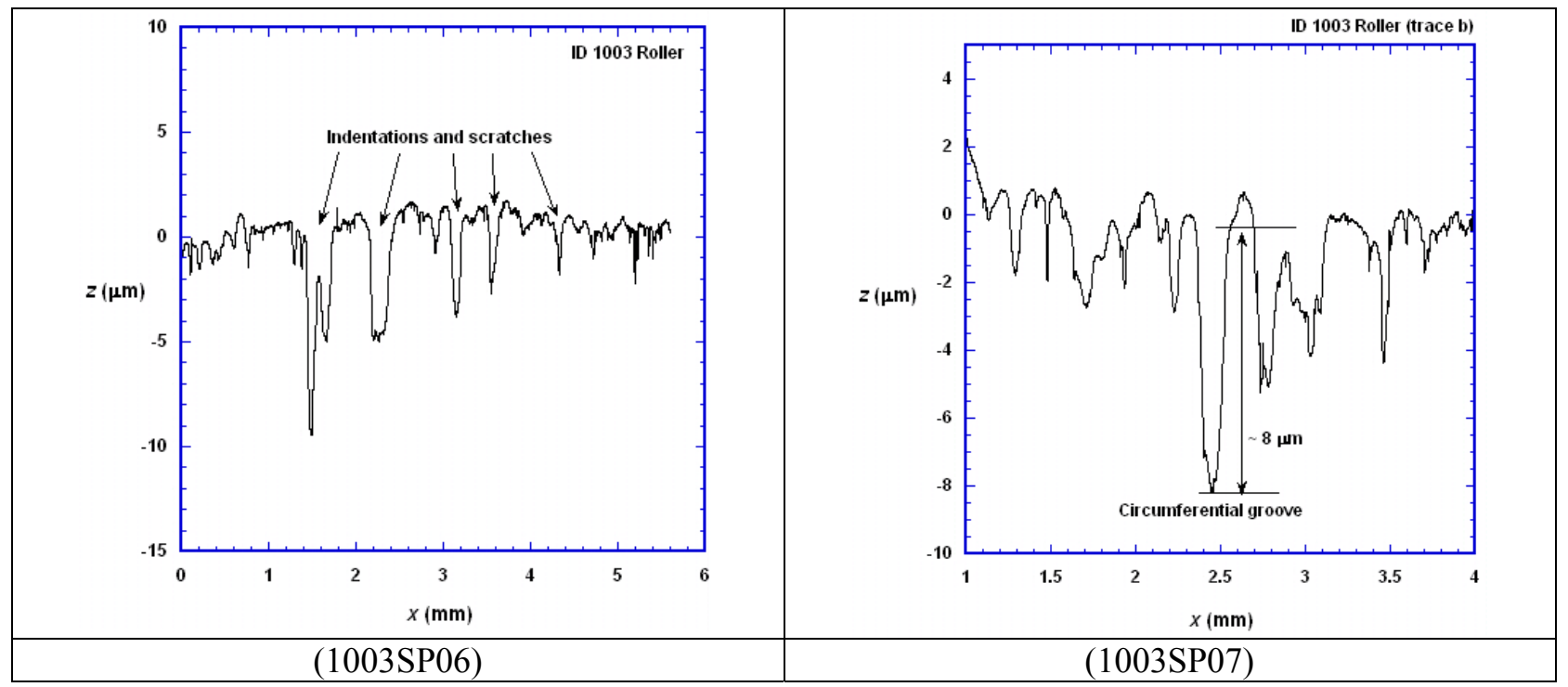

Figure captions / notes:

(1003SP06) Profile along the center of the roller, with the trace direction approximately parallel to the axis of the roller. Minor curvature is due to a slight misalignment of the trace direction with the roller axis.

(1003SP07) Profile across one of the more prominent circumferential scratches on the roller. 


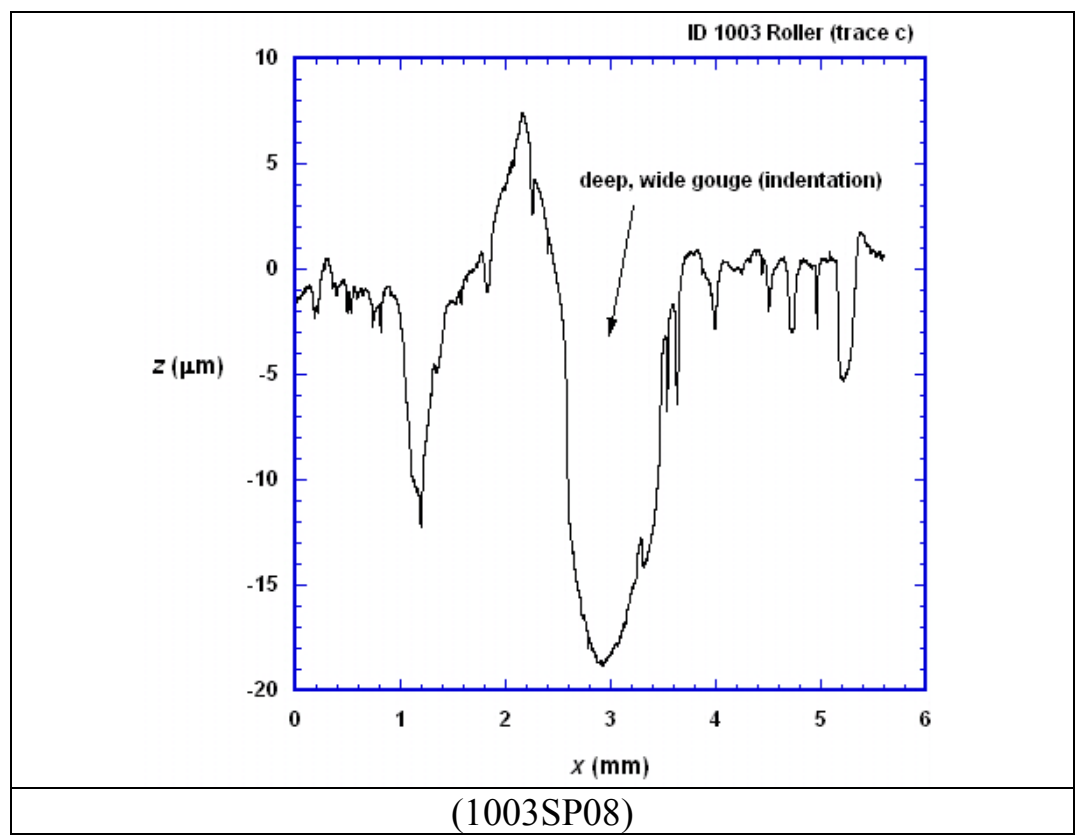

Figure captions / notes:

(1003SP08) Enlarged portion of a surface profile at one of the larger indentations in the surface of the roller. A three-dimensional version of the area on which this type of deep feature occurs is shown in Section 17.2.

\subsection{Vertical Scanning Interferometry}

Vertical scanning interferometry (VSI) 3D images and profiles of indentations on the roller and particles of steel debris embedded in the bronze separator were obtained using a Wyko Model NT9100 system. Images were generated by progressive scanning of a selected region at steps in the vertical axis and postprocessing of the data to construct three-dimensional representations of surface features with color coding of the feature heights. Figure (1003SP09) shows a region of the contact surface of the cylindrical roller shown at the center of Figure (1003DC04). It has been inclined to show the direction along the cylindrical surface and parallel to the roller axis. Several deep pits are evident at the center, right side, and forward edge of the field of view. As indicated in 17.1, these pits, caused by hard debris particles trapped between the roller and the race or the roller and the separator are typically from 2-15 $\mu \mathrm{m}$ deep. A corresponding image of the same area of the roller in 2D measurement mode is shown in Figure (1003SP10).

In the case of profiles, $\mathrm{X}-\mathrm{Y}$ electronic cursors were placed over a region of interest and the profiles were computed from those locations. The electronic cursor can be adjusted to average the depth and to reduce spurious signals (drop-outs) from areas in which the interference fringes were lost.

Hard debris particles were observed to be embedded on the bronze separator in bearing 1003 [see Figure (1003OM02)]. VSI images and measurements were also obtained for these features, as shown in Figures (1003SP11 and 12). 


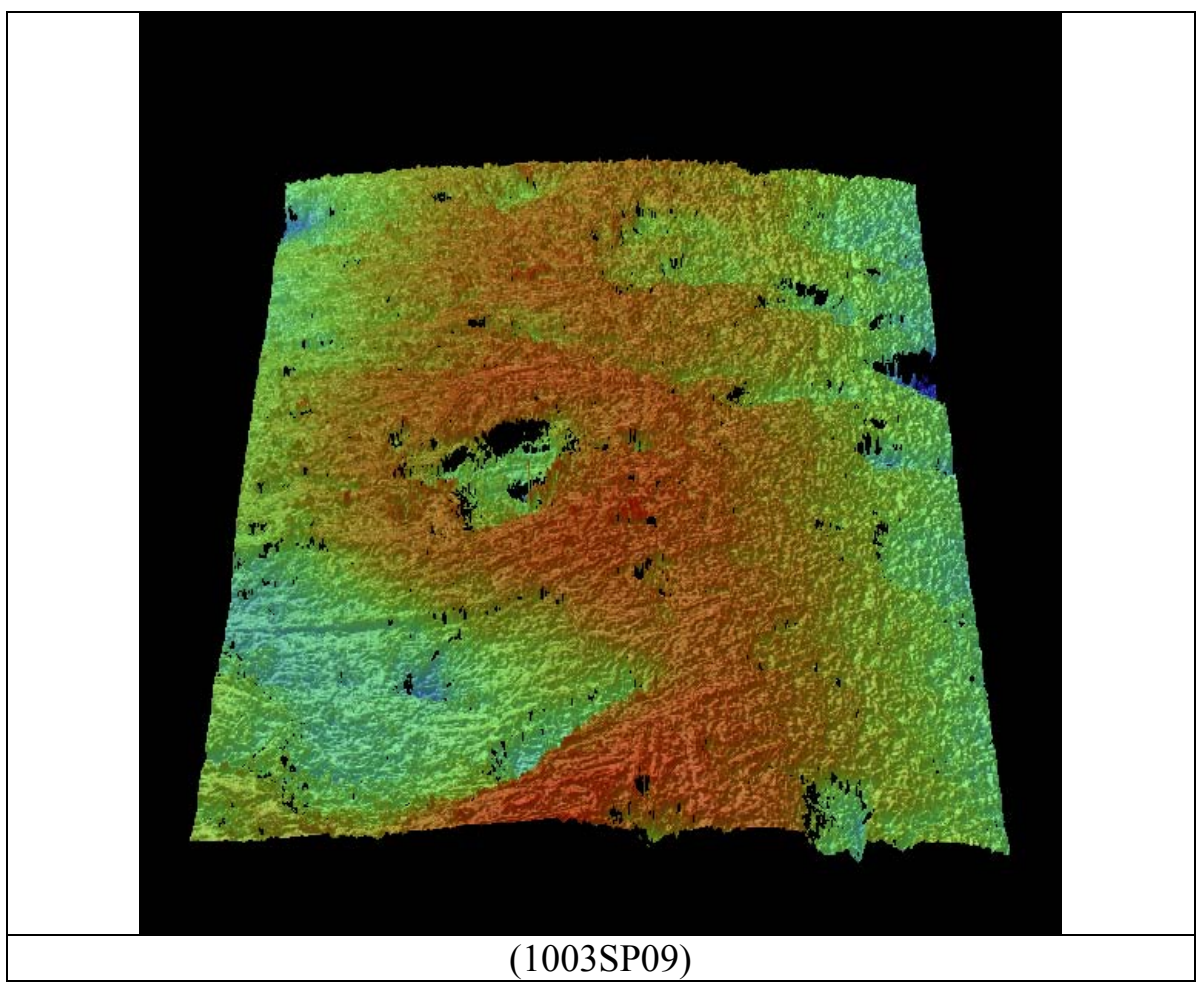

Figure caption / notes:

(1003SP09) 3D reconstruction of the surface of a cylindrical roller such as that profiled in $1003 \mathrm{SP} 06$ and $1003 \mathrm{SP} 08$. 


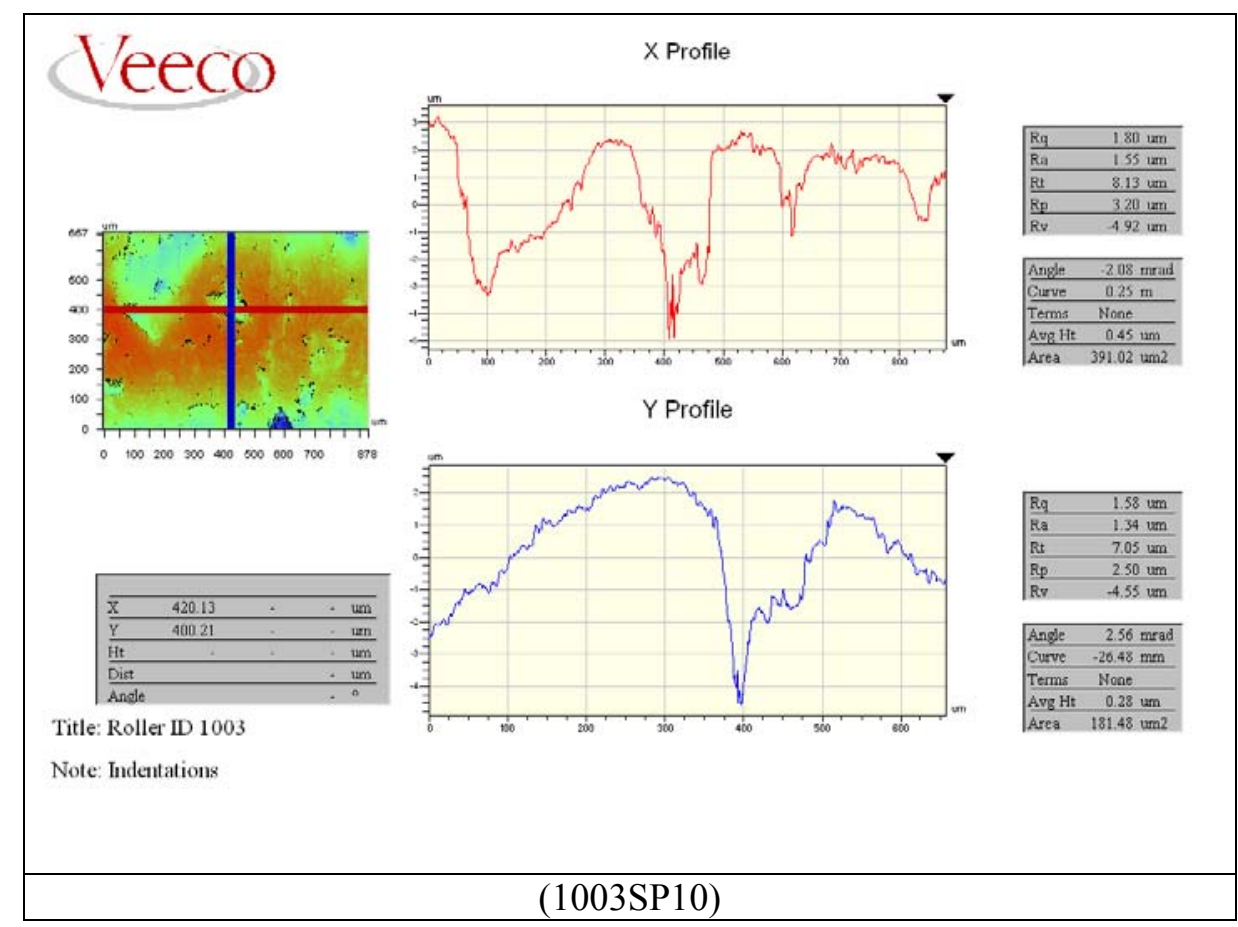

Figure caption / notes:

(1003SP10) 2D measurements of the cylindrical roller whose 3D image of the same area in Figure (1003SP09).

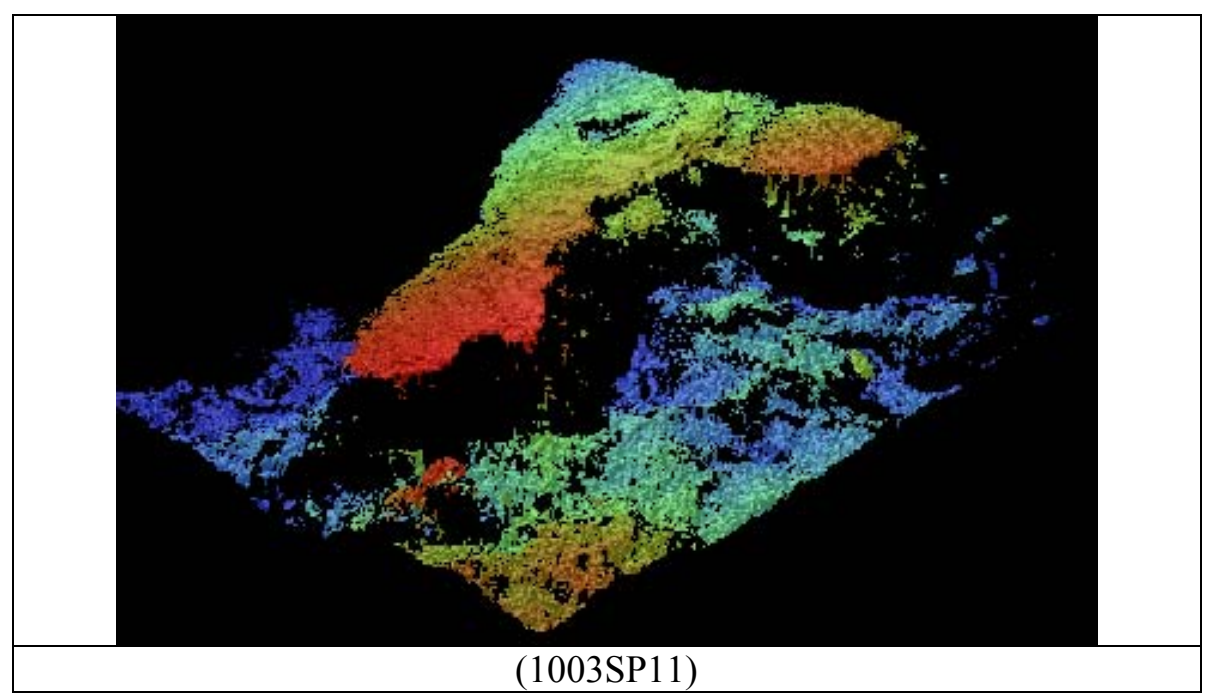

Figure caption / notes:

(1003SP11) 3D reconstruction of an embedded metallic particle on the surface of a separator. In terms of altitude, red color is highest, yellow is lower, then green and blue. 


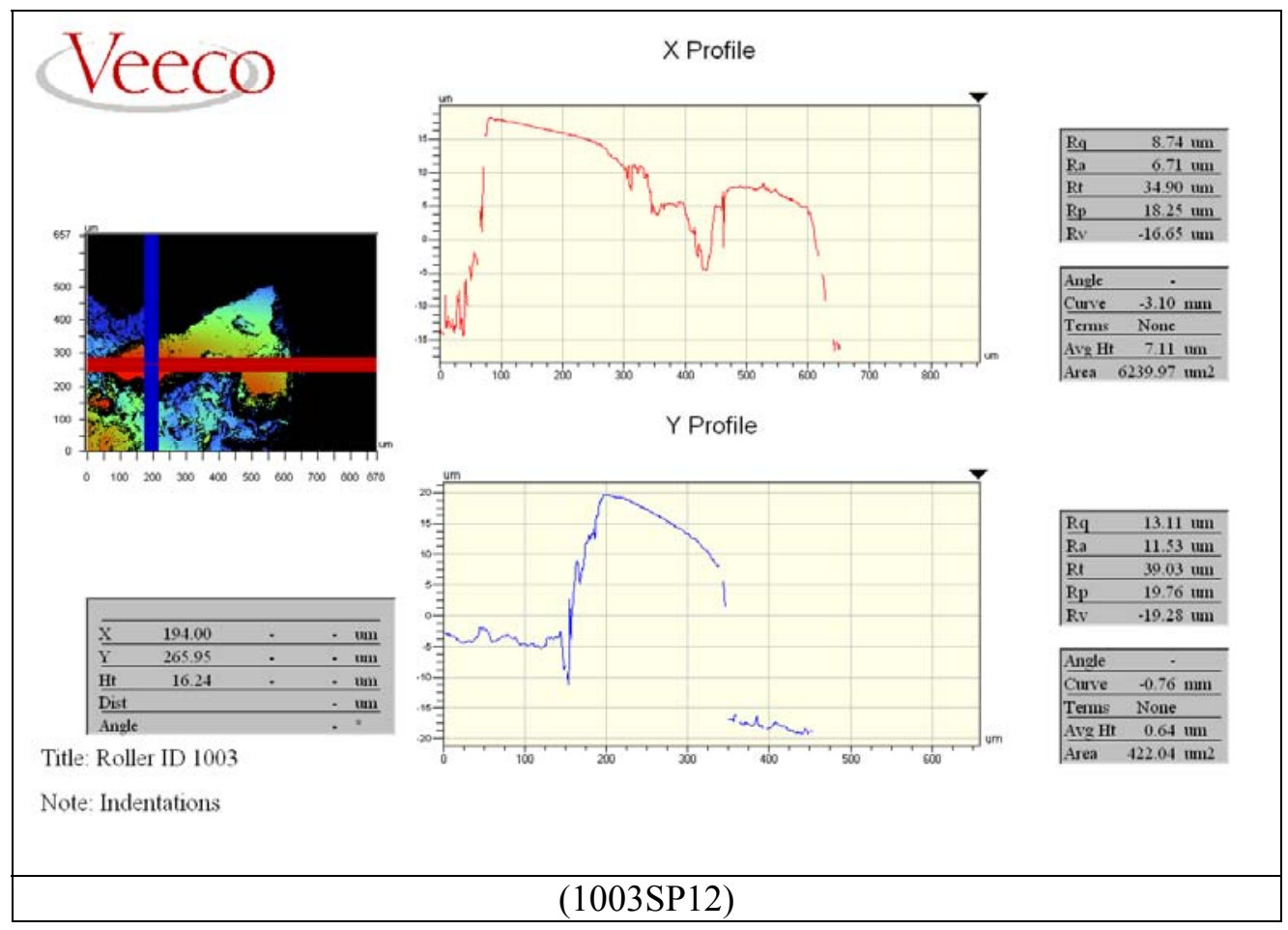

Figure caption / notes:

(1003SP12) 2D measurements of the embedded particle that is shown in Figure (1003SP11). The top of the embedded particle rises about $31 \mu \mathrm{m}$ higher than the surface of the bronze separator. This can been seem from the profiles in both the $\mathrm{X}$ (horizontal) (red) and the $\mathrm{Y}$ (blue) directions.

18) Surface chemical analysis (none)

19) Summary of analysis.

Cylindrical rolling elements and their separators were examined. Wear was much less severe on the cylindrical rolling elements than it was on the DR/SRBs described elsewhere in this report. Roller surfaces displayed circumferential scratches associated with abrasion by hard (steel) wear particles that probably became embedded in the bronze separator and abraded the rollers as they passed by. Surface profiles and topographic mapping showed clear evidence for debris denting and embedment.

20) Related analyses: Section 2.4 on inner and outer races. 


\section{SUMMARY}

The objective of this effort was to investigate and characterize the nature of surface damage and wear to wind turbine gearbox bearings returned from service in the field. Two types of used gearbox bearings were supplied for examination by the National Wind Technology Center (NREL), Boulder, Colorado. One was a double-row spherical roller bearing (SRB) and the other a cylindrical roller bearing (CRB). The latter offers somewhat better resistance to fatigue wear, and is currently gaining favor among designers.

Studies consisted of visual examination, optical and electron microscopy, dimensional measurements of wear-induced macro-scale and micro-scale features, measurements of macro- and micro-scale hardness, 3D imaging of surface damage, studies of elemental distributions on fracture surfaces, and examinations of polished cross-sections of surfaces under various etched and non-etched conditions. Two different etchants were used to reveal different features of the microstructure. Information obtained from these studies was presented in a standard reporting format to facilitate comparison of information and enable easy cross-referencing from one analysis to another. In most cases, the specific bearing elements (e.g., the rollers, the inner races, the outer races) were separately analyzed before drawing a general conclusion about the bearing wear processes.

The following points summarize these findings:

- Damage severity. Contact damage was in general more severe on the SRB than on the CRB.

- Types of damage. The extent of damage and the types of wear features differed at different locations even on the same bearing components. This was particularly true for the SRB. Sketches were prepared to illustrate this observation on rollers and on races.

- Axial loading. There was evidence for axial as well as radial loading in the SRB, and that led to more damage on one side of the double rows of rollers than on the other.

- Scalloping and wear steps. Macroscopically, DR/SRB rollers exhibited several different forms of deformation around the equator. Some had a pronounced 'scalloped' appearance with plastic deformation by shear ('smearing') suggestive of an axial overload. The extent of scalloping was documented using a coordinate measuring machine. Most SRB rolling elements exhibited pitting, as from rolling contact fatigue (RCF). Loss of the crowns of the rollers could be caused by a combination of continuing wear modes such as abrasion, micro-pitting, or localized shear deformation that led to delamination. A distinct circumferential 'wear step' was observed on the outer edge of one SRB inner race.

- White-etching layers. Highly cold-worked materials, appearing as white-etching layers were observed near the surfaces on cross-sections of several components. These layers were in general, significantly harder than the materials lying below them. They do not seem to correspond to a heat-treatment-induced contrast change, as in carburizing or nitriding, but rather, layer thickness varied from one place to another. Evidence therefore strongly suggests that they were formed by mechanical contact and not by a surface hardening treatment of some kind. In general, below the white-etching layers, the etched specimens seemed to be composed of tempered martensite with the finely-dispersed carbides typical of bearing steels. Delamination events in various stages of flake production were observed in the near-surface layers. 
- Role of wear debris. Wear debris particles played a significant role in forming surface features on both the SRB and CRB. Debris particles from steel bearing components are highly cold-worked, and can be produced as spalls or delaminated flakes from cold-worked surface layers. Debris particles vary in size. Some are visible by a hand lens or even to the naked eye. Since the hardness of debris particles is equal to or greater than the surfaces that they come into contact with, they can cause abrasion, denting, and sometimes embedment - especially in softer metals like the bronze roller separators. The presence of debris particles, either loose, or embedded, leads to a localized disruption in the function of the inter-element lubricating film. Depending on when the debris indenting occurred, etches of shallow pits can be sharp or rounded from subsequent plastic deformation. Raised lips around pits can penetrate into the oil film and lead to localized solid contact or disruption in smooth flow between surfaces.

- Micro-cracking. Subsurface cracks, associated with sheared or spalled materials tended to connect with the surface. They occurred at various depths and inclinations within the whiteetching zone. Deeper micro-cracks were finely branched, sometimes running along plastic flow lines and sometimes following a forked, dendritic path. Since high-performance, bearing steels like those examined here have much lower inclusion contents (i.e., are 'cleaner') than typical structural steels, there was no clear evidence that subsurface cracks were nucleated by tramp inclusions in the steel. With such low inclusion content, the probability of observing such things is small.

Concluding Remarks and Recommendations. This investigation demonstrates how a variety of metallurgical tools can be usefully applied to characterize the causes for wear and surface damage in rolling element bearings retrieved from wind turbine gearboxes. From a materials engineering point of view, a lack of specific information about the operating histories of these parts made it impossible directly to correlate the extent and type of contact damage with its root causes. Therefore, any subsequent study of this kind should be supplemented with more complete turbine operating information. Provision was made to include such information in the reporting format used here.

Relative to the forms of damage observed in rolling element bearings, there was nothing particularly unusual or unique about the kinds of surface features observed on the current gearbox components; however, the relative occurrence and severity of these kinds of surface damage is unknown within the U.S. wind turbine fleet. Additional studies of this type would therefore better define the nature and extent of bearing damage in wind turbine gearboxes of various designs, and could add value to any nationwide wind turbine gearbox reliability databases that may be under development. Supplementing field examinations with detailed metallurgical studies of selected components would also help to identify any needs for new materials, surface treatments, or lubricants. It would also facilitate the selection of laboratory tests to be employed when testing the ability of alternative materials and lubricants to withstand the common modes of gearbox bearing failure.

Finally, it is recommended that standardized terminology and nomenclature be established to promote consistency when reporting wind turbine bearing failure modes and wear features. Such a terminology standard would facilitate reporting root causes of bearing gearbox wear and surface damage, and would enable designers and manufacturers to better communicate, understand, document, and compile data on the most prevalent durability issues in wind turbine fleets. 